\title{
VASCULAR EPIPHYTE ASSEMBLAGE STRUCTURE AND DISTRIBUTION PATTERNS IN THE SOUTH-TEMPERATE ZONE
}

BY

\begin{abstract}
AMANDA TAYLOR
A thesis submitted to the Victoria University of Wellington

In fulfilment of the requirements for the degree of

Doctor of Philosophy
\end{abstract}

Victoria University of Wellington

(2016) 
This thesis was conducted under the supervision of:

Dr. Kevin Burns (Primary Supervisor)

Victoria University of Wellington.

Wellington, New Zealand 


\section{Acknowledgements}

First and foremost I would like to thank my supervisor $\mathrm{KC}$ who guided me through these last three years...one analogy at a time! KC taught me many essential survival skills for academia, and was a pleasure to work with. I really appreciated $\mathrm{KC}^{\prime}$ 's open door policy, and that he always made time for his students. I also appreciated his quick responses to emails and draft manuscripts, which is not something many PhD students have the luxury of. I would also like to thank the Burns lab, especially Kirsty, Rachael, and Patrick for wine, debriefs, and rants. Furthermore, I thank all the SBS technicians and staff members who helped me either stay alive in the field (cheers Adrian), made sure my epiphytes got watered and didn't die (thanks Lesley), or helped with the van/equipment (cheers Alan and Sue). The faces of level 5, particularly Mary, Sandra, and Lesley for keeping everyone in check! I am also grateful to Lizzie Towel - what an asset to the university! All the 'shut up and write' sessions, the thesis boot camp, and other workshops greatly improved my writing and will serve me well in my future endeavours. I am especially grateful to the Wellington Branch of the New Zealand Federation of Graduate Women who funded this research. Without NZFGW I would not be where I am today. I would also like to thank the Wellington Botanical Society, Victoria University of Wellington, and the New Zealand Royal Society (Wellington branch) for fieldwork and conference funding. Thanks to Luke Cooney, Anna Carter, Ian Hutton, and Bart Cox for field, equipment, and methodologies aid. Finally, I would like to thank my family for being very patient and getting me through the rough times. Thanks especially to my mum Sandra, sister Torzie, and my partner Andy, who I don't know what I would do without. Thanks for all your words of encouragement and for believing in me. 


\section{General abstract}

Vascular epiphytes, which are specialised to spend their entire life cycle within trees, are significant contributors to local ecosystem services. However, our current understanding of epiphyte distributions, co-occurrences, and general ecology lags far behind that of terrestrial plants. Furthermore, the majority of epiphyte research is undertaken in tropical forests, with comparatively few studies extending into temperate climates. As such, whether epiphytic plant assemblage structure varies geographically, or is influenced by area and isolation effects needs further scrutiny. In addition, how epiphytes are distributed in relation to host tree ontogeny and microclimates specific to south-temperate forests is poorly understood. Here, I attempt to bridge this gap by researching epiphyte distributions and assemblage structure in New Zealand, southern Chile, and Australia.

In the first biogeographic study of epiphyte-host interactions, I determined if epiphyte-host network structure (i.e. nestedness, species co-occurrences, species specialisation) varied among New Zealand and Chilean temperate forests (Chapter 2). At the forest stand level, network structure was consistent with stochastic structuring, which suggests that dispersal and disturbances are important drivers of epiphyte distributions at a biogeographic scale. However, deterministic structure was observed in New Zealand networks with regards to nestedness (i.e. when specialists interact with generalists), which suggests that positive species interactions influence epiphyte distributions at a within-tree scale.

Second, I determined whether the composition of plant communities residing in epiphytic birds' nest ferns (Asplenium goudeyi) on Lord Howe Island, Australia, are influenced by fern size, isolation from a major propagule source and resident plant community richness (Chapter 3 ). Results suggest that plant communities are structured by dispersal. For one, there was a significant isolation effect on resident plant community richness. Additionally, wind-dispersed taxa were well represented in isolated ferns, while animal-dispersed taxa and taxa with no specific dispersal strategies were absent. This is the first study to test the combined effects of area, isolation and resident plant richness on epiphytic plant assemblage structure. 
Third, using Darwin's geological theory of island ontogeny as a theoretical construct, I explored changes in epiphyte species richness throughout tree ontogeny (Chapter 4). Theoretical frameworks have helped bridge the gap between our understanding of vascular epiphytes and terrestrial plants, however, none have been implemented to guide investigations on epiphyte assemblage development. Based on the general features of island ontogeny, I found three stages of epiphyte assemblage development: (i) an initial stage where host trees are devoid of epiphytes, (ii) a second stage where trees acquire epiphytes into maturity, and (iii) a hypothetical stage where epiphyte assemblages follow a period of species decline following host tree mortality. In addition to these results, I found interspecific variation in the ontogenetic stage at which host trees become favourable for epiphyte establishment and the rate at which epiphyte assemblages develop.

Lastly, I explored the systematic distribution of epiphytes and mistletoes in relation to microclimate gradients around the trunks of trees (Chapter 5 ). In addition, I tested the physiological responses of epiphytes and mistletoes to reductions in their most limiting resources to determine if the responses were consistent with their distribution patterns. The radial distributions of epiphytes and mistletoes were highly directional, and paralleled gradients of humidity, light and water. Additionally, the photochemical efficiency of epiphytes and $\mathrm{CO}_{2}$ assimilation in mistletoe leaves decreased in plants growing in environments with lower water and light availability, respectively. However, mistletoe leaves still assimilated $\mathrm{CO}_{2}$ in lower light conditions, which suggests a high plasticity of mistletoes to growing in a canopy environment. Despite over 120 years of recognising the importance of vertical microclimates on epiphyte distributions, this is the first systematic study of epiphytic plant distributions in relation to microclimate gradients around the trunks of trees.

This thesis has increased our understanding of epiphytic plant assemblage structure, and how it is influenced by host tree species, isolation, area and resident plant species richness. In addition, this thesis has increased our understanding of the effect of host tree ontogeny and microclimate on epiphyte distribution patterns. Together, these studies may be built upon more broadly to further elucidate drivers of epiphyte assembly and distribution patterns. 


\section{List of papers}

I. Taylor, A., Saldaña, A., Zotz, G., Kirby, C. and Díaz, I. (2016). Composition patterns and network structure of epiphyte-host interactions in Chilean and New Zealand temperate forests. New Zealand Journal of Botany, doi: $10.1080 / 0028825 X .2016 .1147471$.

II. Taylor, A. and Burns, K. (2015). Plant composition patterns inside an endemic birds' nest fern (Asplenium goudeyi) on Lord Howe Island: effects of fern size, fern isolation and plant dispersal abilities. Journal of Tropical Ecology, 31: 413421.

III. Taylor, A. and Burns, K. (2015). Epiphyte community development throughout tree ontogeny: an island ontogeny framework. Journal of Vegetation Science, 26: 902-910.

IV. Taylor, A. and Burns, K. (2016). Radial distributions of air plants: a comparison between epiphytes and mistletoes. Ecology (in press).

\section{Author contribution to papers}

I. AT collected data (Wellington, Stewart Island), ran all analyses, wrote and edited the manuscript. AS provided data from Chile and site descriptions. CK provided data (Waikato) and Figure 2.7. AS, GZ, CK, ID, and KB provided comments on the manuscript. AT and KB conceived the study. KB provided valuable comments on data analyses.

II. AT collected data, ran all analyses, wrote and edited the manuscript. AT and KB conceived the study. KB provided valuable comments on data analyses.

III. AT collected data, ran all analyses, wrote and edited the manuscript. AT and KB conceived the study. KB provided valuable comments on data analyses.

IV. AT collected data, designed and performed all experiments, ran all analyses, wrote and edited the manuscript. AT and KB conceived the study. KB provided valuable comments on data analyses. 


\section{Table of Contents}

Acknowledgements

General abstract II

List of papers IV

Author contribution to papers IV

Chapter 1 - General Introduction____ 1

Vascular epiphytes in the south-temperate zone ___ 2

Ecological assembly theory and its application to epiphyte assemblages ___ 3

Drivers of within-tree epiphyte distributions___ 5

Thesis overview ____________________ 6

Chapter 2 - Composition patterns and network structure of epiphyte-host interactions in Chilean and New Zealand temperate forests ___ 8

$\begin{array}{lr}\text { Abstract } & \\ \text { Introduction } & \\ \text { Material and methods } & 10 \\ \quad \text { Study sites and sampling } & 14 \\ \quad \text { Statistical analyses } & 14 \\ \text { Results } & \\ \text { Discussion } & \mathbf{2 1} \\ & \mathbf{2 6}\end{array}$

Chapter 3 - Plant composition patterns inside an endemic birds' nest fern (Asplenium goudeyi) on Lord Howe Island: effects of fern size, fern isolation and plant dispersal abilities

$\begin{array}{lr}\text { Abstract } & \mathbf{3 0} \\ \text { Introduction } & \\ \text { Methods } & \\ \quad \text { Study site and sampling } & \\ \quad \text { Statistical analyses } & 34 \\ \text { Results } & \\ \text { Discussion } & \\ \end{array}$

Chapter 4 - Epiphyte assemblage development throughout tree ontogeny: an island ontogeny framework

$\begin{array}{lr}\text { Abstract __ } & 46 \\ \text { Introduction } & 47 \\ \text { Methods } & 51 \\ \quad \text { Study site and species } & 51 \\ \quad \text { Sampling } & 51\end{array}$ 
Results

Discussion 59

Chapter 5 - Radial distributions of air plants: a comparison between epiphytes and mistletoes 62

Abstract 63

Introduction 64

Methods 66

Study site and species 66

Sampling

Microclimate measurements 66

Plant stress measurements

Statistical analyses 68 69

$\begin{array}{lr}\text { Results } & \\ \text { Discussion } & 70 \\ & 74 \\ & 77\end{array}$

Chapter 6-General discussion 77

The role of chance in structuring epiphyte assemblages 79

Epiphyte distributions in relation to microclimate and tree ontogeny 81

Conclusions and Future directions 83 Appendices 86

Appendix 1 87

References 92 
Chapter

1

Chapter 1-General Introduction 


\section{Vascular epiphytes in the south-temperate zone}

Vascular epiphytes, which are specialised to live non-parasitically on substrate provided by other plants, form an integral component of south-temperate forests. Despite this, most of our knowledge on the ecology of epiphytes has stemmed from research conducted in tropical forests, with only a handful of studies extending into temperate climates (Dawson 1988, Burns and Dawson 2005, Zotz 2005). Given the sheer diversity of epiphytes in tropical forests, which can exceed $25 \%$ (Jorgensen 1999) and even $50 \%$ (Kelly et al. 2004) of all vascular plants, this is unsurprising. However, warmer temperate regions like New Zealand, southern Australia, and southern Chile, also harbour rich epiphyte assemblages. In the Haast ecological district of New Zealand, for example, 28 vascular epiphyte species were recorded on a single host tree (Dickinson et al. 1993). On Chiloé Island, southern Chile, $50 \%$ of all epiphytic filmy ferns and $33 \%$ of all angiosperm species typically found in a temperate Chilean forest were recorded on three individual host trees (Díaz et al. 2010).

In north-temperate forests, high incidences of frost (Benzing 1990) and decreased water availability (Schimper 1888) are postulated to restrict the diversification of epiphyte species (review in Zotz 2005). For comparison, while 22 epiphyte species were recorded along a $1.0 \mathrm{~km}$ trail in Wellington, New Zealand $\left(41^{\circ} \mathrm{S}\right)$, only nine were recorded along a trail of the same length in British Columbia, Canada $\left(48^{\circ} \mathrm{N}\right.$; Burns (2008)). Likewise, while 15 epiphyte species were recorded in the Puyehue National Park, Chile $\left(41^{\circ} \mathrm{S}\right)$, only two were recorded in the Caverns State Park, USA $\left(30^{\circ}\right.$ $\mathrm{N}$; Gentry and Dodson (1987)). As well as climatic influences, the latitudinal asymmetry in epiphyte diversity may be attributed to historical factors. In particular, many southtemperate plant taxa have undergone adaptive radiations due to repeated glaciations and insularity (Moreira-Muñoz 2011).

Perhaps as a result, south-temperate forests are comparable in terms of their epiphyte compositions. Perching lilies (Asteliaceae), for example, are distributed throughout New Zealand, Fiji, Samoa, and Vanuatu. Similarly, the sole genus of the family Griseliniaceae, Griselinia, commonly grows as a shrub epiphyte in New Zealand, southern Chile, and Argentina (Gentry and Dodson 1987). Furthermore, 77\% of south- 
temperate epiphyte species are either ferns or fern allies, while only $9 \%$ are orchids. In comparison, $24 \%$ of epiphyte species in tropical forests are ferns (and fern allies), while $48 \%$ are orchids (Zotz 2005). Regardless of taxonomic grouping, epiphytes play a major role in nutrient cycling (Nadkarni 1985), biodiversity (Ibisch 1996), and habitat for arboreal fauna (Davidson and Epstein 1989). By including south-temperate forests in epiphyte research, our general knowledge of epiphyte ecology will be more complete.

\section{Ecological assembly theory and its application to epiphyte assemblages}

Assembly theory addresses a focal question in ecology: how are complex communities assembled from the wider species pool? Specifically, what is the relative role of chance in structuring ecological communities? Popular opinion has shifted between suggestions of deterministic community structure (Clements 1916) to the belief that communities are structured by chance events (Gleason 1917). In the former, it is argued that niche differentiation and resource partitioning causes segregation among taxa, leading to predictable species compositions (Keddy 1992, Chesson 2000, Gause 2003, Tuomisto et al. 2003, Dornelas et al. 2006, Silvertown et al. 2006). Specifically, nicheassembled communities should not vary in composition between sites of similar environmental conditions (Tuomisto et al. 2003; Dornelas et al 2006). However, the latter suggests that dispersal and disturbances, along with a species' ability to withstand local environmental conditions, randomises species co-occurrences (Connor and Simberloff 1979, Hubbell et al. 1999). This is because high colonisation rates coupled with low species perseverance are expected to randomise community composition, producing unpredictable patterns of species co-occurrences (Zalewski and Ulrich 2006). The extent to which dispersal or competitive interactions may influence species cooccurrences is still largely unknown, and varies among taxonomic groups or species. For example, forest tree communities exhibit structuring analogous to dispersal-assembly (Ehrlen and Eriksson 2000; Jacquemyn et al. 2001), while ant assemblages are shown to be structured by competitive interactions (Hölldobler and Wilson 1990). 
Diamond's (1975) introduction of the term 'assembly rules' sparked further debate when he described the assemblages of frugivorous birds in the archipelago of New Guinea. In his seminal paper, Diamond (1975) postulated that competition for resources generates negative species co-occurrence patterns. Specifically, these patterns portray the combinations of species in a community where rules are thought to exist if particular subsets of species, which could be drawn at random from the local species pool, do not coexist at some local level (Drake 1990). Connor and Simberloff (1979) challenged this idea, stating that assembly rules are a trivial interpretation of species distribution patterns. Although this debate is nearly a century old, the extent to which communities are structured by species interactions or chance events is still a major theme in community ecology.

Research aiming to determine the structure of epiphyte assemblages has found evidence for both deterministic and stochastic structuring. Burns (2007), for example, showed that epiphyte assemblages were structured non-randomly in a New Zealand forest, which he attributed to the sequential colonisation of epiphyte species on developing host trees. Conversely, a similar analysis in Panama found evidence for both deterministic and stochastic assemblage structure (Burns and Zotz 2010). These recent efforts to quantify the properties of epiphyte-host networks have helped elucidate general patterns in epiphyte assemblage structure (see Burns and Zotz 2010), however, whether epiphyte assemblage structure varies between different biogeographic regions and forest types remains poorly resolved. Network analyses may be useful to compare epiphyte assemblages across south-temperate forests because robust biological inferences can be made about species specialisation (Sáyago et al. 2013), ecosystem stability (Dunne et al. 2002, Vázquez and Simberloff 2003), and species interactions (Blick and Burns 2009). 


\section{Drivers of within-tree epiphyte distributions}

Within the vertical column of forest canopies, epiphytes are distributed in relation to the vertical gradients of light and water, which vary with the height of a tree (Wagner et al. 2013). Observations detailing this pronounced distribution span over 120 years, and were first described in Schimper's (1888) monograph of the epiphytic floras of the Americas. In tropical forests, the vertical partitioning of light and water is postulated to occur at finer scales, thus maintaining high epiphyte species diversity (Gentry and Dodson 1987).

Epiphytes are almost exclusively dependent on local microclimate humidity to meet their water requirements (Wolf 1994, Benzing 1998, Zotz and Hietz 2001, Zotz et al. 2001a, Parra et al. 2009). However, as a response to a discontinuous water supply, selection pressures have enabled epiphytes to exploit different parts of the canopy. Tank-forming epiphytes, for example, store water in modified leaf bases, which allows them to persist in the outer reaches of their host trees (Reyes-García et al. 2008). Similarly, epiphytes that exhibit CAM photosynthesis, which is well represented among the Orchidaceae, may withstand high irradiance levels (Griffiths and Smith 1983). At the other extreme, filmy ferns (Hymenophyllaceae) lack a differentiated epidermis and stomata, and are comparatively inefficient at conserving water (Krömer et al. 2007). As such, filmy ferns are often restricted to the lower trunks or branches of their host trees (Proctor 2012). Despite more than a century of recognising epiphyte distributions as they occur vertically within the canopy; few studies have explored epiphyte distributions in relation to other resource gradients, some of which are equally subject to variation in microclimate.

In addition, as trees grow, they undergo both morphological and physiological changes that can influence the development of epiphyte assemblages, including the provision of new substrate for epiphytes to colonise (Benzing 1990). Horizontal branches in particular support epiphyte assemblages because they allow canopy soil, a critical water source, to accumulate (ter Steege and Cornelissen 1989, Enloe et al. 2006). During early tree ontogeny, the simple architecture lacks structures presumed to facilitate the development of epiphyte assemblages (Benzing 1990). However, as trees 
age and expand, epiphytes become established and undergo assemblage development. As such, positive linear relationships between tree size and epiphyte species diversity are regularly documented (Hietz-Seifert et al. 1996, Zotz and Vollrath 2003, Burns and Dawson 2005, Flores-Palacios and Garcia-Franco 2006, Hirata et al. 2008), following one of the most general patterns in ecology. Although the relationship between tree size and epiphyte species diversity is well-established, whether or not epiphyte assemblages develop uniformly regardless of host species needs further scrutiny. For example, is there interspecific variation in the ontogenetic stage at which host trees begin to acquire epiphyte species? Do epiphyte assemblages develop faster on particular hosts? By considering these questions, our knowledge of within-tree distributions of epiphytes will be more complete.

\section{Thesis overview}

This dissertation presents an original research that aims to determine whether epiphytic plant assemblage structure varies geographically, or is influenced by area and isolation. In addition, this dissertation aims to determine the influence of host tree ontogeny and microclimate on epiphyte distribution patterns. Data chapters are arranged as manuscripts that are either published or are in review. As such, there will be some repetition in the general introduction and discussion sections.

Chapter 2 presents a quantitative analysis on the network structure of epiphyte assemblages on 1978 host trees among nine south-temperate forests in New Zealand and southern Chile. I tested for non-random patterns in the degree of nestedness (when species-poor assemblages are subsets of the suite of species that occur in species-rich assemblages), negative species co-occurrences (average number of species pairs that do not co-exist), the number of links (number of species interactions), and network specialisation (frequency of specialist species in the epiphyte-host network). Additionally, I suggest reasons as to why epiphyte-host interactions may vary across the different biogeographic regions, which raises questions for future comparative studies on epiphyte-host interactions. 
In Chapter 3 I explore the importance of chance in structuring plant communities inhabiting 119 epiphytic birds' nest ferns on Lord Howe Island, Australia. First, I tested the hypothesis that plant community richness is influenced by fern size and fern isolation from a major propagule source. Second, I tested whether plant composition patterns were a reflection of plant dispersal strategies. Additionally, I constructed species-specific incidence functions to gain insight into the effect of resident plant species richness on individual species distributions among ferns. Related, I tested whether plant communities showed evidence for negative species co-occurrences.

Chapter 4 builds upon Darwin's geological theory of island ontogeny to explore changes in epiphyte species richness throughout the life span of 371 host trees. I predicted three stages of epiphyte assemblage development: (1) an initial stage where host trees are devoid of epiphytes because they lack sufficient structural support, (2) a second stage where trees acquire epiphytes as adults and continue to do so into maturity, and (3) a final stage where epiphyte assemblages progress through a period of species decline following tree mortality. I tested model predictions by first assessing the relationship between epiphyte species richness and host tree diameter. Second, I tested whether relationships between epiphyte species richness and host tree diameter varied between host species. Finally, I suggest mechanisms as to why epiphyte assemblage development may vary between host species.

Chapter 5 explores the spatial pattern of mistletoes $(n=137)$ and epiphytes $(n=$ 510) in relation to microclimate gradients around the trunks of trees. First, I tested the null hypothesis that mistletoes and epiphytes are distributed uniformly around the trunks of their host trees. Second, I tested whether mistletoes and epiphytes were distributed in relation to the availability of their most limiting resources. Lastly, I tested the physiological responses of mistletoes and epiphytes to changes in their most limiting resources and determined if the responses were consistent with their distribution patterns. 
2

Chapter 2 - Composition patterns and network structure of epiphyte-host interactions in Chilean and New Zealand temperate forests 


\section{Abstract}

Ecological networks are becoming increasingly used as a framework to study epiphytehost interactions. However, efforts to quantify the properties of epiphyte-host networks have produced inconsistent results. Epiphyte-host interactions in New Zealand and Chilean temperate forests were quantified to test for non-random patterns in nestedness, negative co-occurrences, number of links, and network specialisation. Results showed that three out of five New Zealand networks were significantly more nested than null model expectations, compared with just one out of four Chilean networks. Epiphytes co-occurred more often than null model expectations in one New Zealand network and one in Chile. In all cases, the number of links maintained by each epiphyte and host species was consistent with null model expectations. Lastly, two New Zealand networks and one in southern Chile were significantly less specialised than null model expectations, with all remaining networks returning low specialisation scores. As such, aside from the tendency for greater nestedness in New Zealand networks, most epiphyte species were distributed among their host trees at random. I attribute the result of nestedness in New Zealand to the abundance of large nest epiphytes (Astelia spp. in particular), which may facilitate the sequential colonisation of epiphyte species on developing host trees. The lack of negative co-occurrences suggests that negative species interactions are not an important determinant of species assemblage structure. Low network specialisation scores suggest that epiphytes are selecting for specific host traits, rather than specific host species for colonisation. 


\section{Introduction}

Theoretical and empirical studies of species interaction networks have substantially improved our understanding of the general processes structuring species assemblages (Bascompte et al. 2003, Ulrich and Gotelli 2007, Vázquez et al. 2009, Blüthgen 2010). Antagonistic interactions between parasites and hosts, for example, are significantly influenced by host phylogeny (Bellay et al. 2011). Similarly, spatio-temporal species distributions may influence the mutually beneficial interactions between plants and pollinators (review in Vázquez et al. 2009). However, recent efforts to quantify the properties of commensalistic epiphyte-host interactions have produced inconsistent results, and the occurrence of general patterns in epiphyte-host networks remains poorly resolved.

Species interaction networks can be characterised by two properties; the number of links maintained by each higher and lower trophic level (i.e. number of species interactions), and the compositions of interacting species (Figure 2.1, Boccaletti et al. 2006). One common measure used to describe species composition patterns is the degree of nestedness. Nested species assemblages occur when specialist (i.e. rare) species interact with generalist (i.e. common) species, thus producing a pattern of asymmetric specialisation (Darlington 1957). Nestedness is a pattern often associated with mutualistic networks (Bascompte et al. 2003), however, it is also postulated to commonly occur in epiphyte-host networks (Piazzon et al. 2011). Burns (2007), for example, observed one of the highest levels of nestedness ever recorded for any type of species interaction in an epiphyte-host network in New Zealand. Similarly, Sáyago et al. (2013) observed a high degree of nestedness in an epiphyte-host network on the central western coast of Mexico. However, a distinct lack of nestedness was later observed in a similar analysis in Panama (Burns and Zotz 2010), and in British Columbia, Canada (Burns 2008), which suggests that nestedness may not be a general pattern in epiphyte-host networks.

Mutually exclusive to nestedness is the measure of negative species cooccurrence patterns, or 'checkerboard' distributions, which arise when particular species pairs never co-exist (Diamond 1975). Competition for resources and niche 
differentiation are thought to exclude weaker competitors, thus causing segregation among taxa (Silvertown 2004). Negative co-occurrence patterns in epiphyte-host networks may arise from preferential interactions by epiphyte species with different host species (Burns and Zotz 2010). However, similar to nestedness, negative species co-occurrences may not be a general characteristic of epiphyte-host networks. For example, positive species co-occurrences are also observed (e.g. Blick and Burns 2009), and are postulated to result from the sequential colonisation of epiphyte species (Burns 2007).

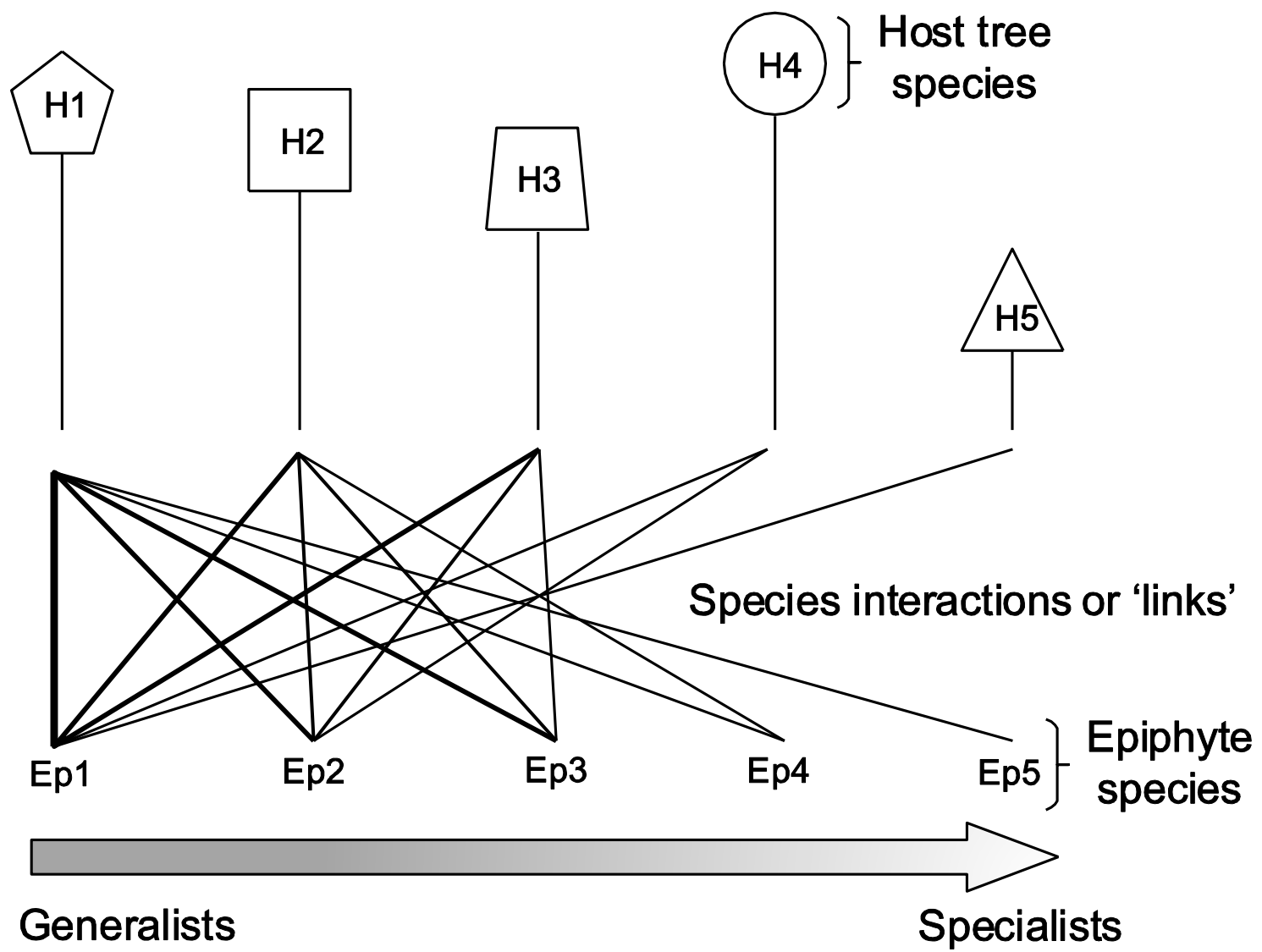

Figure 2.1 Schematic representation of three common measures of network structure used to describe epiphyte-host interactions: number of links, nestedness, and network specialisation (negative species cooccurrences not shown). Lines drawn between each epiphyte (Epn) and host species ( $\mathrm{H} n)$ depict an interaction or 'link'. The frequency at which each species pair interacts is illustrated by line thickness. Thicker lines are indicative of greater interaction frequencies. If all species in a network frequently interact with one another, the degree of network specialisation will be considered low. Species that interact with a number of other species are considered 'generalists', and species that form few interactions are considered 'specialists'. Nestedness occurs when generalist species interact with specialist species, which is illustrated in the schematic. Negative species co-occurrences, which are not illustrated here, are derived by taking the average number of species pairs that never coexist. 
Arguably the most general pattern in epiphyte-host networks is the lack of strict host specificity (e.g. Sáyago et al. 2013). Although strict host specificity is rare, the observation that some epiphyte species occur non-randomly on particular host species is not uncommon (review in Wagner et al. 2015). The extent to which an epiphyte species is a generalist or specialist is typically quantified as the number of 'links' (i.e. species interactions) maintained by each epiphyte and host tree species (Burns 2007). At the network level, overall 'network specialisation' may be quantified by incorporating the frequency of species interactions (Blüthgen et al. 2007). Unlike computing the number of 'links', which is sensitive to sampling effort and network size (Martinez et al. 1999), 'network specialisation' does not underestimate a species' true level of specialisation (Blüthgen et al. 2008).

Deviations from general patterns in epiphyte-host interaction networks may be produced by two factors. First, in some cases analyses are restricted to select taxonomic groups or species. For example, Sáyago et al. (2013) only considered 18 epiphytic bromeliad species, despite the co-occurrence of ten epiphytic orchids and one epiphytic cactus at their study site in Mexico. Similarly, Burns (2008) restricted analyses to epiphyte assemblages on one host tree species in British Columbia, Canada. Second, different metrics are used, some of which may overestimate the degree of nestedness in an interaction network (Almeida-Neto and Ulrich 2011). For one, Burns (2007) characterised nestedness using the nestedness temperature calculator (NTC), which is arguably the most common technique used to quantify nestedness in species interaction networks (Atmar and Patterson 1993). However, the NTC is prone to type-I statistical errors and is sensitive to matrix size, owing to the way in which the matrix is reshuffled (Almeida-Neto and Ulrich 2011). Although Burns (2007) corrected for these errors, a comprehensive study by Almeida-Neto et al. (2008) suggests an even more conservative metric should be used when characterising nestedness.

Nested Overlap and Decreasing Fill (NODF) is one such metric. It calculates deviations from perfect nestedness for each column and row separately. Unlike the calculation of matrix temperature, NODF is both robust to sampling effort and network size, thus making it appropriate for comparisons of nestedness between sites (AlmeidaNeto et al. 2008). Nevertheless, this metric is used in just half the published epiphytehost network literature, with all others using variations of matrix temperature. Here, I 
use the conservative NODF metric to compare the degree of nestedness in epiphytehost networks from New Zealand and southern Chile. In addition, I quantify the degree of negative species co-occurrences, number of links, and network specialisation in an attempt to elucidate general patterns in epiphyte-host network structure. I do not restrict sampling to specific taxonomic groups or species; rather, interactions among all sighted epiphyte and host tree species are included in the analyses. 


\section{Material and methods}

\section{Study sites and sampling}

The analyses relied upon inventories of epiphyte distributional data collected from five New Zealand forests and four from southern Chile (Figure 2.2).

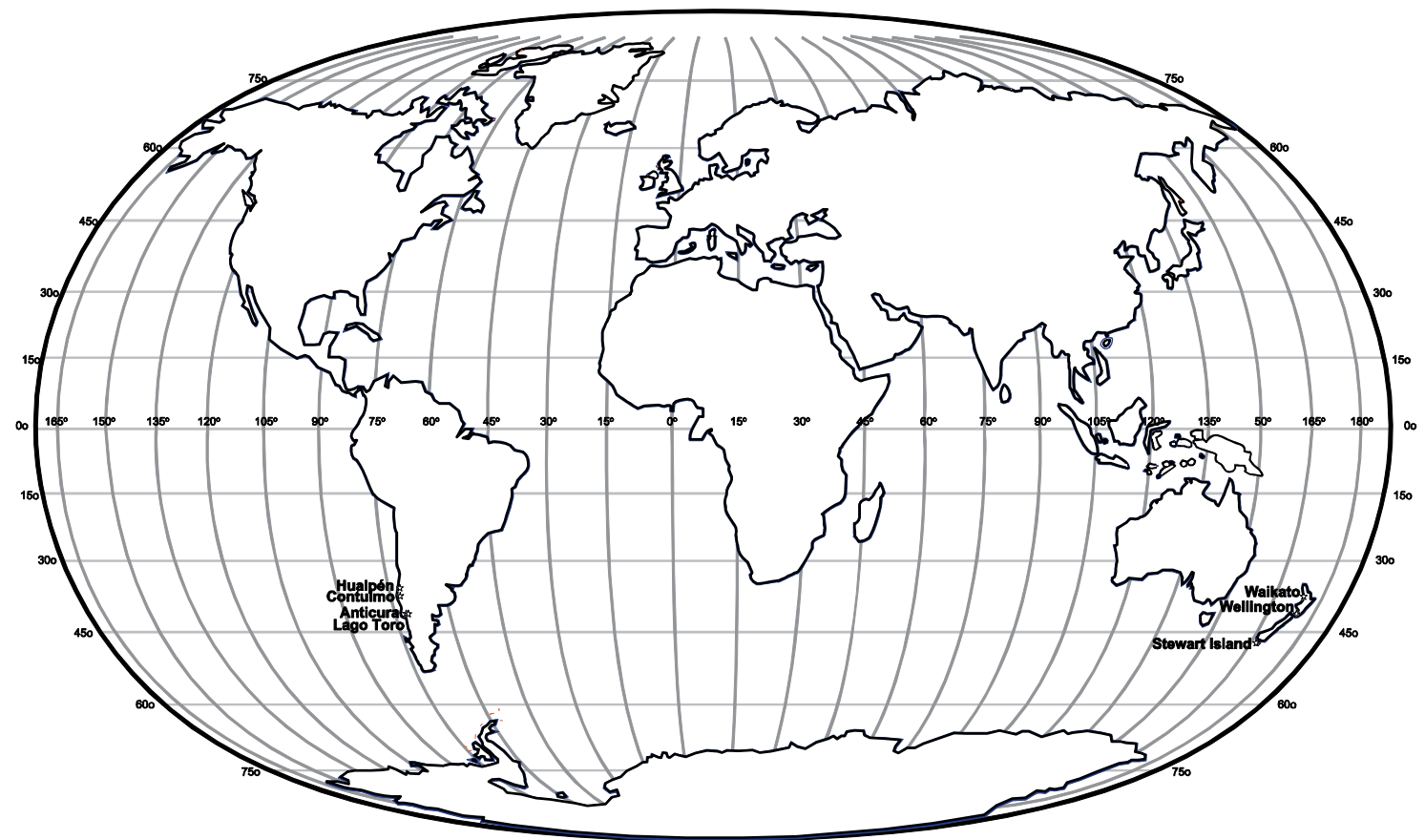

Figure 2.2 Map illustrating the location of each inventory of epiphyte-host distribution data collected from Chile and New Zealand.

In all cases, epiphyte assemblages were sampled from the ground using binoculars, and only sections of mature forest were sampled. Sampling protocol for the Wellington and Stewart Island sites follow Taylor and Burns (2015), while the Waikato sites were sampled following Bryan (2011). In Chile, host trees were sampled on either side of trails, similar to Taylor and Burns (2015). In all cases, only trees with epiphytes were sampled. Details on the number of trees sampled, tree heights, tree diameters, and climate of each site are provided in Table 2.1. To minimise difference in sampling effort, I pooled data collected from two pairs of adjacent sites on the upper North Island of New Zealand. The first pair, Hakarimata Scenic Reserve $\left(37^{\circ} 39^{\prime} S, 175^{\circ} 07^{\prime} E\right)$ and Pukemokemoke Reserve $\left(37^{\circ} 35^{\prime} \mathrm{S}, 175^{\circ} 22^{\prime} \mathrm{E}\right)$ is located in the Waikato region of New 
Zealand's North Island. These two sites (termed North Waikato) were pooled together based on similarities in host tree assemblages and climate, although they differ in size. The canopy of the 1850 ha Hakarimata Scenic Reserve primarily consists of broadleaved evergreens, particularly Beilschmiedia tawa (Lauraceae), Dysoxylum spectabile (Meliaceae), Elaeocarpus dentatus var. dentatus (Elaeocarpaceae), and Litsea calicaris (Lauraceae). Canopy emergents such as Knightia excelsa (Proteaceae), Laurelia novaezelandiae (Atherospermataceae), and Metrosideros robusta (Myrtaceae) are also common. Podocarps, mainly Dacrydium cupressinum, Prumnopitys ferruginea, Podocarpus laetus (Podocarpaceae), Phyllocladus trichomanoides (Phyllocladaceae) and Agathis australis (Araucariaceae) occur in pockets. Pukemokemoke Reserve, although smaller with 38 ha, is one of the most ecologically diverse forest remnants in the Waikato region. Podocarpus totara var. totara, and Prumnopitys taxifolia (Podocarpaceae) are common canopy species at Pukemokemoke Reserve, in addition to those found at Hakarimata Reserve.

The second pair of pooled sites, Maungatautari Ecological Island $\left(38^{\circ} 02^{\prime} \mathrm{S}\right.$, $\left.175^{\circ} 34^{\prime} \mathrm{E}\right)$ and Pirongia Forest Park $\left(37^{\circ} 58^{\prime} \mathrm{S}, 175^{\circ} 01^{\prime} \mathrm{E}\right)$ is also located in the Waikato region of New Zealand's North Island (termed South Waikato). Maungatautari Ecological Island features 3363 ha of broadleaf/podocarp forest with a surrounding predator-proof fence. Common canopy tree species include Beilschmiedia tawa, Dacrydium cupressinum, Prumnopitys ferruginea and Metrosideros robusta (Myrtaceae). Pirongia Forest Park is the most extensive patch of forest remaining in the Waikato region, and consists of the same forest type and climate as Maungatautari Ecological Island. However, unlike Maungatautari, a predator-proof fence does not protect Pirongia Forest Park, although controls for introduced pests are in place.

The third New Zealand site, Otari Wilton's Bush reserve $\left(41^{\circ} 14^{\prime} \mathrm{S}, 174^{\circ} 45^{\prime} \mathrm{E}\right)$, is the largest area of remaining native forest on the Wellington Peninsula, located in the lower North Island of New Zealand (termed North Wellington). The reserve encompasses 96 ha of mature and regenerating coastal broadleaf/podocarp forest. The higher strata of the forest are dominated by five broadleaved evergreen tree species, Beilschmiedia tawa, Dysoxylum spectabile, Corynocarpus laevigatus (Corynocarpaceae), Elaeocarpus dentatus var. dentatus and Melicytus ramiflorus. Knightia excelsa and Laurelia novae-zelandiae frequently emerge above the canopy, 
along with scattered remnants of Dacrydium cupressinum and Prumnopitys ferruginea (for a full site description see Taylor and Burns 2015).

East Harbour Regional Park ( $\left.41^{\circ} 19^{\prime} \mathrm{S}, 174^{\circ} 45^{\prime} \mathrm{E}\right)$, another Wellington site (termed South Wellington), covers approximately 2,000 ha split into four forest zones. Sampling occurred in the 'northern zone', which consists of mixed beech/broadleaf/podocarp forest. Two southern beeches, Fuscospora solandri and Fuscospora truncata commonly grow on the hill slopes while broadleaf/podocarp forest prevails in the valleys. Here, the canopy consists of mature Dacrydium cupressinum, Prumnopitys ferruginea, Prumnopitys taxifolia, Weinmannia racemosa (Cunoniaceae), Melicytus ramiflorus, Elaeocarpus dentatus var. dentatus, and Elaeocarpus hookerianus. Dacrycarpus dacrydioides (Podocarpaceae) and Laurelia novae-zelandiae are common emergent trees. Metrosideros robusta is scattered throughout the forest. One conspicuous feature of East Harbour Regional Park is the large number of podocarps at either the seedling or mature stages of growth, with comparatively few at intermediate stages of growth.

The southernmost forest sampled in this study, Rakiura National Park, Stewart Island $\left(47^{\circ} 00^{\prime} \mathrm{S}, 167^{\circ} 50^{\prime} \mathrm{E}\right)$, is also the southernmost broadleaf/podocarp forest in New Zealand. After the North and South Islands, Stewart Island is the third largest island in the New Zealand archipelago. Rakiura National Park covers $85 \%$ of the island, and is the most undisturbed New Zealand forest sampled in this study. Dominant canopy species include Dacrydium cupressinum, Metrosideros umbellata, Dacrycarpus dacrydioides, Podocarpus laetus, Prumnopitys ferruginea and Weinmannia racemosa. New Zealand plant species nomenclature follows Allan (1961), Moore and Edgar (1980) and Connor and Edgar (1987). Nomenclature for Prumnopitys follows de Laubenfels (1978), Fuscospora follows Heenan and Smissen (2013), Podocarpus laetus follows Molloy (2015), and Astelia hastata follows Birch (2015).

The northernmost Chilean site, Hualpén Botanical Reserve, is located on the Hualpén Peninsula in close proximity to the Biobio River mouth, Concepción ( $36^{\circ} 47^{\prime} \mathrm{S}$, $\left.73^{\circ} 09^{\prime} \mathrm{W}\right)$. The 73 ha reserve is one of the largest remnants of Coastal Mediterranean sclerophyll forest, which is comprised exclusively of angiosperms. The canopy is dominated by four evergreen tree species Lithrea caustica (Anacardiaceae), Cryptocarya alba (Lauraceae), Peumus boldus (Monimiaceae) and Aextoxicon 
punctatum (Aextoxicaceae). Also occurring in the canopy to a lesser extent are Citronella mucronata (Cardiopteridaceae) and Eucryphia cordifolia (Eucryphiaceae). Regenerating individuals of Gevuina avellana (Proteaceae), Myrceugenia planipes (Myrtaceae), and Luma apiculata (Myrtaceae) occur in the understory (Luebert and Pliscoff 2006).

Contulmo Reserve $\left(38^{\circ} 00^{\prime} \mathrm{S}, 73^{\circ} 10^{\prime} \mathrm{W}\right)$ is a Valdivian rainforest located in the seaward foothills of the Cordillera Nahuelbuta (coastal range). This reserve is of considerable interest as the flora represents an outlier of the Valdivian rainforest, which is typical of more southerly latitudes (Baeza et al. 1999). The canopy of the 82 ha reserve is dominated by three evergreen tree species, Persea lingue (Lauraceae), Laurelia sempervirens (Lauraceae), and Eucryphia cordifolia (Eucryphiaceae), and one deciduous tree species Lophozonia obliqua (Nothofagaceae). Podocarpus salignus (Podocarpaceae) occurs to a lesser extent, while individuals of Nothofagus dombeyi (Nothofagaceae) frequently emerge above the canopy.

Anticura $\left(40^{\circ} 39^{\prime \prime} 57^{\prime} \mathrm{S}, 73^{\circ} 10^{\prime} \mathrm{W}\right)$ is an old-growth temperate rainforest comprised primarily of broadleaved evergreens within the Puyehue National Park, Entrelagos. Dominant canopy species and understory regrowth include Eucryphia cordifolia (Cunoniaceae), Nothofagus dombeyi (Nothofagaceae), Laureliopsis philippiana (Atherospermataceae), and Aextoxicon punctatum (Aextoxicaceae; Luebert and Pliscoff 2006). Also common in the understory are regenerating individuals of Amomyrtus luma (Myrtaceae), Azara lanceolata (Salicaceae), Caldcluvia paniculata (Cunoniaceae), Gevuina avellana (Proteaceae), Myrceugenia planipes (Myrtaceae), and Rhaphithamnus spinosus (Verbenaceae; Saldaña and Lusk 2003).

The southernmost Chilean site, Lago Toro $\left(40^{\circ} 46^{\prime} \mathrm{S}, 72^{\circ} 16^{\prime} \mathrm{W}\right)$, is a Valdivian rainforest located within the Puyehue National Park, Entrelagos. Two co-occurring angiosperms, Nothofagus nitida and Laureliopsis phillippiana (Monimiaceae) are common in the canopy, as well as two podocarps Saxegothaea conspicua (Podocarpaceae) and Podocarpus nubigenus (Podocarpaceae). Drimys winteri (Winteraceae), Weinmannia trichosperma (Cunoniaceae), and Embothrium coccineum (Proteaceae) occur to a lesser extent (Muñoz-Schick 1980). Chilean plant species nomenclature follows Zuloaga et al. (2008). Nomenclature for Lophozonia follows Heenan and Smissen (2013). 
Table 2.1 Details on the number of individual host trees sampled $(n)$, maximum host tree heights ( $\mathrm{m}$ ), and host tree diameter ( $\mathrm{cm}$ dbh) from each site. Tree diameter is divided up into four size categories where the corresponding cells show the percentage (\%) of trees in a particular diameter class. Annual average rainfall (mm), and average annual temperature $\left({ }^{\circ} \mathrm{C}\right)$ of sampling sites in New Zealand and southern Chile are also shown. Climate data are averages of 20 years (CliFlo: NIWA's National Climate Database 2015), and 38 years (Luebert and Pliscoff 2006), respectively.

\begin{tabular}{|c|c|c|c|c|c|c|c|c|}
\hline Site & $n$ & $\begin{array}{c}\text { Tree } \\
\text { heights }(\mathrm{m})\end{array}$ & $\begin{array}{c}\%<25 \\
\mathrm{~cm} \mathrm{dbh}\end{array}$ & $\begin{array}{l}\% \text { 25-50 } \\
\mathrm{cm} \text { dbh }\end{array}$ & $\begin{array}{l}\% 50-75 \\
\mathrm{~cm} \mathrm{dbh}\end{array}$ & $\begin{array}{c}\%>75 \\
\mathrm{~cm} \mathrm{dbh}\end{array}$ & $\begin{array}{l}\text { Rain } \\
(\mathrm{mm})\end{array}$ & $\begin{array}{c}\text { Temp } \\
\left({ }^{\circ} \mathrm{C}\right)\end{array}$ \\
\hline North Waikato & 100 & $15-35$ & 14 & 65 & 15 & 6 & 1285 & 13.8 \\
\hline South Waikato & 100 & $20-35$ & 13 & 54 & 18 & 15 & 1811 & 13.8 \\
\hline North Wellington & 371 & $15-35$ & 9 & 44 & 30 & 17 & 1249 & 12.8 \\
\hline South Wellington & 269 & $15-50$ & 41 & 39 & 12 & 7 & 1415 & 14.0 \\
\hline Stewart Island & 203 & $9-50$ & 33 & 49 & 10 & 7 & 1700 & 9.3 \\
\hline Hualpén & 227 & $20-25$ & 33 & 47 & 17 & 4 & 1107 & 12.7 \\
\hline Contulmo & 262 & $25-30$ & 28 & 41 & 25 & 5 & 1961 & 12.7 \\
\hline Anticura & 244 & $35-40$ & 30 & 31 & 24 & 15 & 2800 & 9.8 \\
\hline Lago Toro & 202 & $20-25$ & 31 & 34 & 25 & 10 & 2200 & 9.2 \\
\hline
\end{tabular}




\section{Statistical analyses}

Rarefaction was used to determine if complete inventories of epiphyte species and their host trees were obtained from each forest, and that observed network properties were not an artefact of sampling effort (Gotelli and Colwell 2001, Zartman 2003). Rarefaction computes the expected number of species interactions from a subset of species randomly drawn from the wider species pool (Simberloff 1978). A hyperbolic curve was fitted to the rarefaction analyses with subsamples of individual epiphyte occurrences, which were randomly drawn 1,000 times from the total species pool.

I tested for non-random patterns in nestedness and negative species cooccurrences using two metrics, Nested Overlap and Decreasing Fill (NODF) and the checkerboard score (c-score), respectively. All NODF scores were weighted for easy comparison between sites. Perfectly nested assemblages were given a score of 100 , while communities that assembled at random were given a score of zero. The c-score is simply the average number of species pairs that never coexist in a matrix (Stone and Roberts 1990). A c-score that is significantly larger than randomised expectations is indicative of segregation among taxa (i.e. species co-occur less often than expected by chance). Conversely, a c-score that is significantly less than randomised expectations suggests aggregation among taxa (i.e. species co-occur more often than expected by chance). Similar to the NODF metric, I normalised the c-score so that a value of zero indicated that all species pairs coexist and one indicated that all species pairs never coexist. The observed NODF and c-score values were then compared to 5,000 simulated replicates using fixed marginal sums and a swap algorithm.

I quantified species specialisation by comparing the observed number of links (i.e. number of species interactions) maintained by each epiphyte and host species to the expected number of links. The expected number of links was calculated using a simple procedure following Burns (2007). First, epiphytes were randomly assigned to individual host trees to form a null interaction matrix with marginal totals identical to the observed values. This was replicated 5,000 times for each site separately. The average number of links maintained by each epiphyte and host species in the null interaction matrix was considered the expected number of links. Overall network specialisation was determined using the specialisation index $\left(\mathrm{H}_{2}{ }^{\prime}\right)$. The $\mathrm{H}_{2}{ }^{\prime}$ index is a 
derivative of the Shannon entropy, and considers the frequency of species interactions. Networks composed of only specialist species were given an $\mathrm{H}_{2}^{\prime}$ value of one, while networks composed of only generalist species were given an $\mathrm{H}_{2}^{\prime}$ value of zero. The observed $\mathrm{H}_{2}^{\prime}$ index was compared to 5,000 simulated replicates using fixed marginal sums and a swap algorithm (Gotelli 2000). Lastly, I compared the degree of species and network specialisation, negative species co-occurrences, and nestedness between New Zealand and southern Chile using two-tailed $t$-tests. All statistical analyses were conducted in R version 3.1.2 (R Development Core Team, Vienna, Austria) with the addon libraries bipartite version 2.04 (Dormann et al. 2009) and vegan version 2.0-10 (Dixon and Palmer 2003). 


\section{Results}

A total of 4721 epiphyte occurrences were recorded on 1978 host individuals (see Appendix 1 for all epiphyte and host species names, including species authorities). All hyperbolic curves reached an asymptote and provided a good fit to the rarefaction analyses for each site (mean $R^{2}=0.98$ ). Three out of five New Zealand networks, and one from southern Chile were significantly more nested than expected by chance (Figure 2.3, Table 2.2).

A) North Waikato

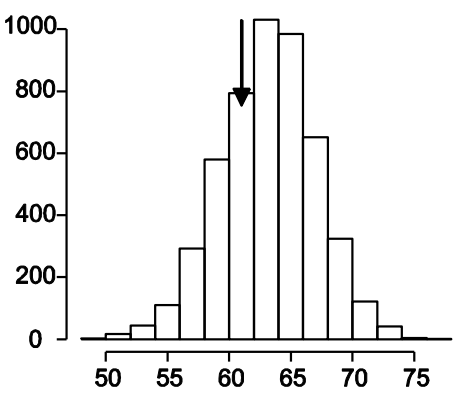

D) South Wellington

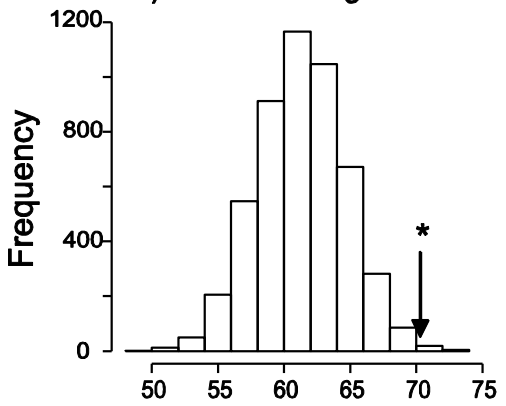

G) Contulmo

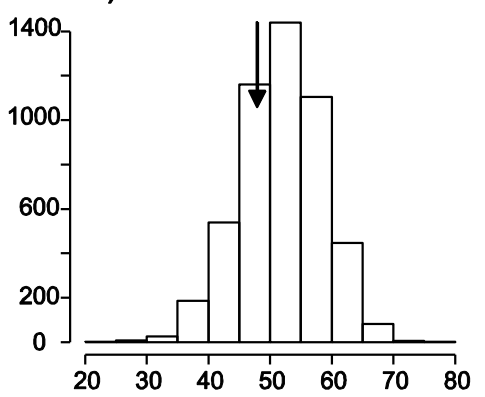

B) South Waikato

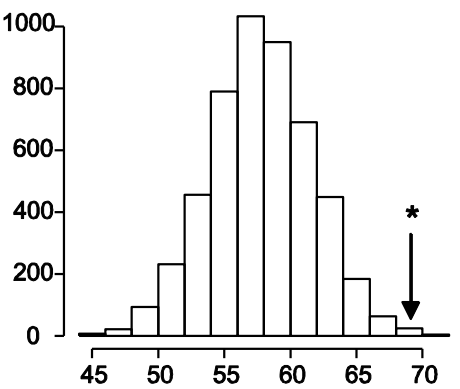

E) Stewart Island

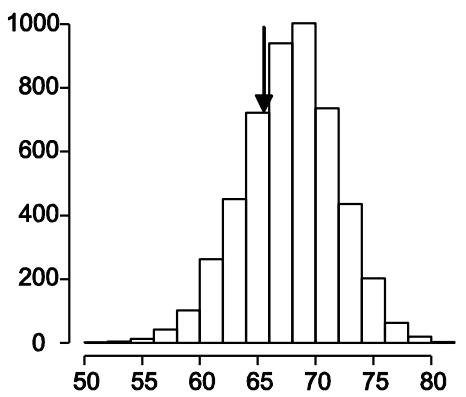

H) Anticura

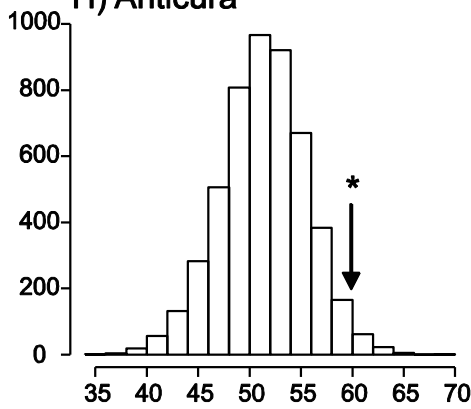

Weighted NODF null models
C) North Wellington

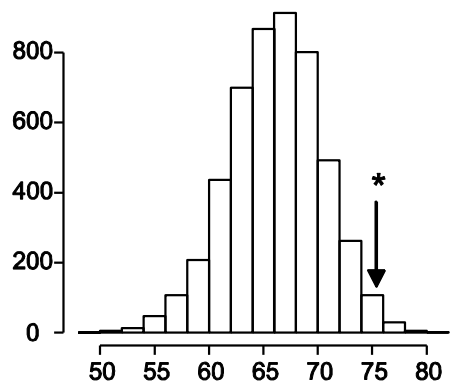

F) Hualpén

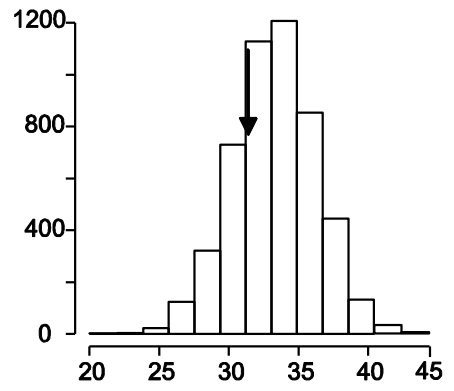

I) Lago Toro

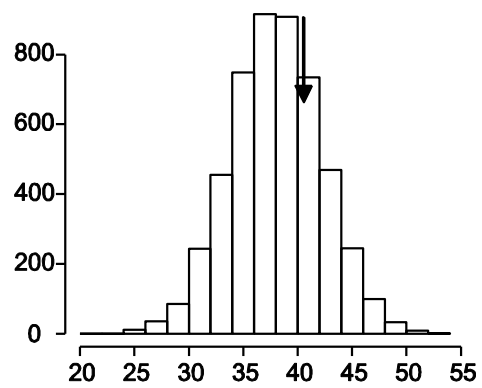

Figure 2.3 Nestedness (weighted NODF) scores of nine south-temperate forests in New Zealand and Chile. Score were generated by taking the average weighted NODF from 5,000 randomised simulations using fixed marginal sums and a swap algorithm. Arrows indicate the observed NODF score. Observed values that differ significantly from null model expectations $(P<0.05)$ are depicted with an asterisk. 
Table 2.2 Results of the network analyses; nestedness (NODF), species co-occurrences (c-score), network specialisation ( $\left.\mathrm{H}_{2}{ }^{\prime}\right)$, and the number of links (No. links) conducted for nine epiphyte-host networks in New Zealand and southern Chile. Observed values that differ significantly from randomised expectations $(P<0.05)$ are in bold. Plus and minus signs indicate if observed values were significantly more or less than randomised expectations.

\begin{tabular}{|c|c|c|c|c|c|c|c|c|}
\hline \multirow{2}{*}{ Site } & \multicolumn{2}{|c|}{ NODF } & \multicolumn{2}{|c|}{ c-score } & \multicolumn{2}{|c|}{$H_{2}^{\prime}$} & \multicolumn{2}{|c|}{ No. links } \\
\hline & statistic & z-score & statistic & z-score & statistic & z-score & epiphytes & hosts \\
\hline North Waikato & 62.84 & -0.66 & 0.14 & 0.15 & 0.12 & 0.53 & 8.69 & 5.14 \\
\hline South Waikato & $68.10^{+}$ & 0.17 & 0.22 & -0.82 & $0.10^{-}$ & -1.77 & 6.20 & 5.05 \\
\hline North Wellington & $76.88^{+}$ & -3.45 & 0.08 & -0.74 & 0.09 & 0.51 & 5.40 & 5.40 \\
\hline South Wellington & $71.39^{+}$ & 2.50 & $0.07^{-}$ & 0.90 & 0.11 & 1.15 & 9.64 & 5.40 \\
\hline Stewart Island & 65.41 & 3.28 & 0.18 & -0.41 & $0.11^{-}$ & 3.18 & 5.00 & 8.00 \\
\hline Hualpén & 32.17 & 0.70 & 0.20 & 0.19 & 0.35 & 1.18 & 5.07 & 5.07 \\
\hline Contulmo & 48.56 & -0.58 & 0.23 & -0.06 & 0.17 & -1.15 & 4.56 & 4.56 \\
\hline Anticura & $60.15^{+}$ & -0.54 & $0.11^{-}$ & 0.84 & $0.11-$ & -3.34 & 6.07 & 8.27 \\
\hline Lago Toro & 41.59 & -0.02 & 0.22 & -0.42 & 0.25 & -1.34 & 5.27 & 5.27 \\
\hline
\end{tabular}


In addition, epiphyte assemblages were significantly more nested in New Zealand compared with Chile $(t$-test $=3.65, P=0.02)$. Epiphyte species co-occurred more often than expected by chance at one New Zealand site (South Wellington: c-score $=0.07, \mathrm{ZS}$ $=0.90, P=<0.001$ ) and one site in Chile (Anticura: $\mathrm{c}$-score $=0.11, \mathrm{ZS}=0.84, P=<0.001$ ). However, the degree of species co-occurrence did not differ between the two regions $(t$-test $=-1.17, P=0.30$, Figure 2.4$)$.

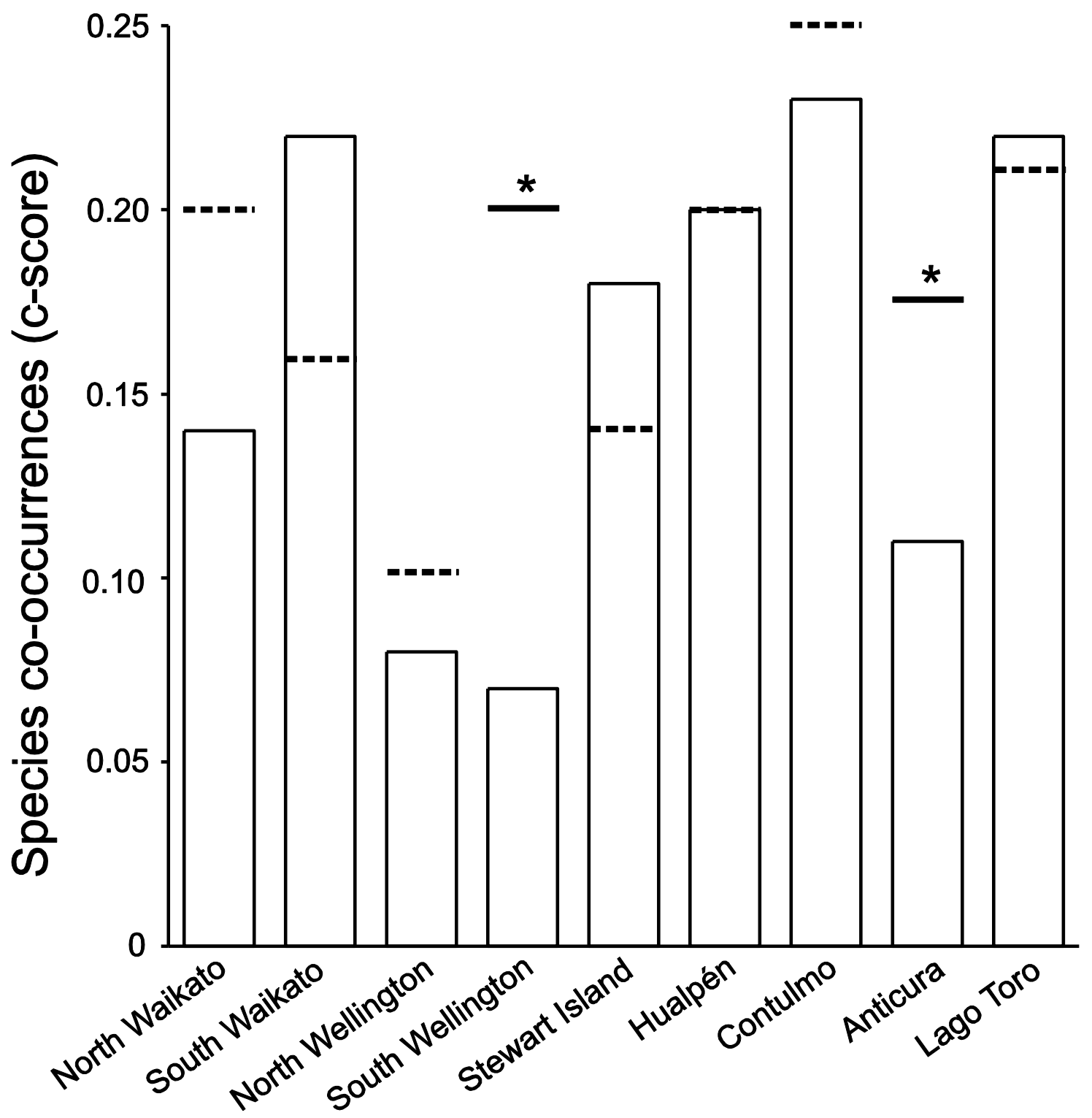

Figure 2.4 Results from the species co-occurrence analyses testing for the number of checkerboard units (c-score) between all species pairs in nine epiphyte-host interaction matrices from New Zealand and southern Chile. The observed c-score was compared with the expected c-score, which was derived from 5,000 randomised simulations using fixed marginal totals and a swap algorithm. The height of each bin represents the observed c-score and the dashed lines represents the expected c-score. Observed values that differ significantly from randomised expectations $(P<0.05)$ are indicated by a solid bold line and an asterisk. 
In all cases, the observed number of links between each host tree and epiphyte species was statistically indistinguishable from randomised expectations (Figure 2.5). However, the frequency-based $\mathrm{H}_{2}{ }^{\prime}$ index showed significantly less network specialisation at two sites in New Zealand (South Waikato: $H_{2}{ }^{\prime}=0.10, \mathrm{ZS}=-1.77, P=<0.001$; Stewart Island: $H_{2}{ }^{\prime}=0.11, \mathrm{ZS}=3.18, P=0.002$ ) and one site in Chile (Anticura: $H_{2}{ }^{\prime}=0.11, \mathrm{ZS}=-3.34, P$ $=<0.001)$, but no significant difference in specialisation between the two regions ( $t$-test $=-2.20, P=0.11$, Figure 2.6).
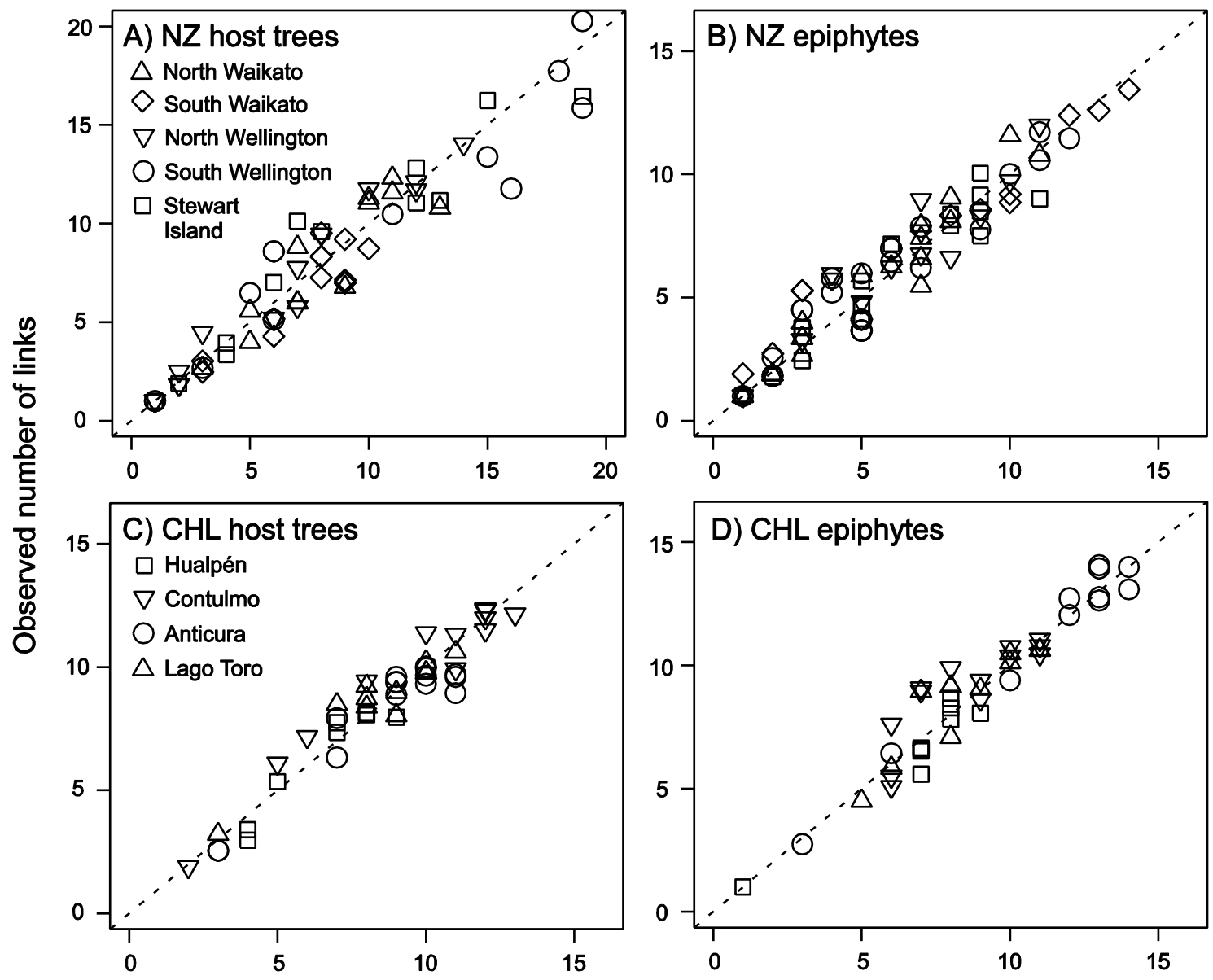

Expected number of links

Figure 2.5 Relationship between the observed number of links (species degree) and expected number of links for New Zealand host trees (a), New Zealand epiphyte species (b), Chilean host trees (c), and Chilean epiphyte species (d). Expected values were generated by taking the average number of links from 5,000 randomised simulations. The centred dotted line is the isocline. Points below the isocline indicate segregation among taxa and points above the isocline indicate aggregation among taxa. 


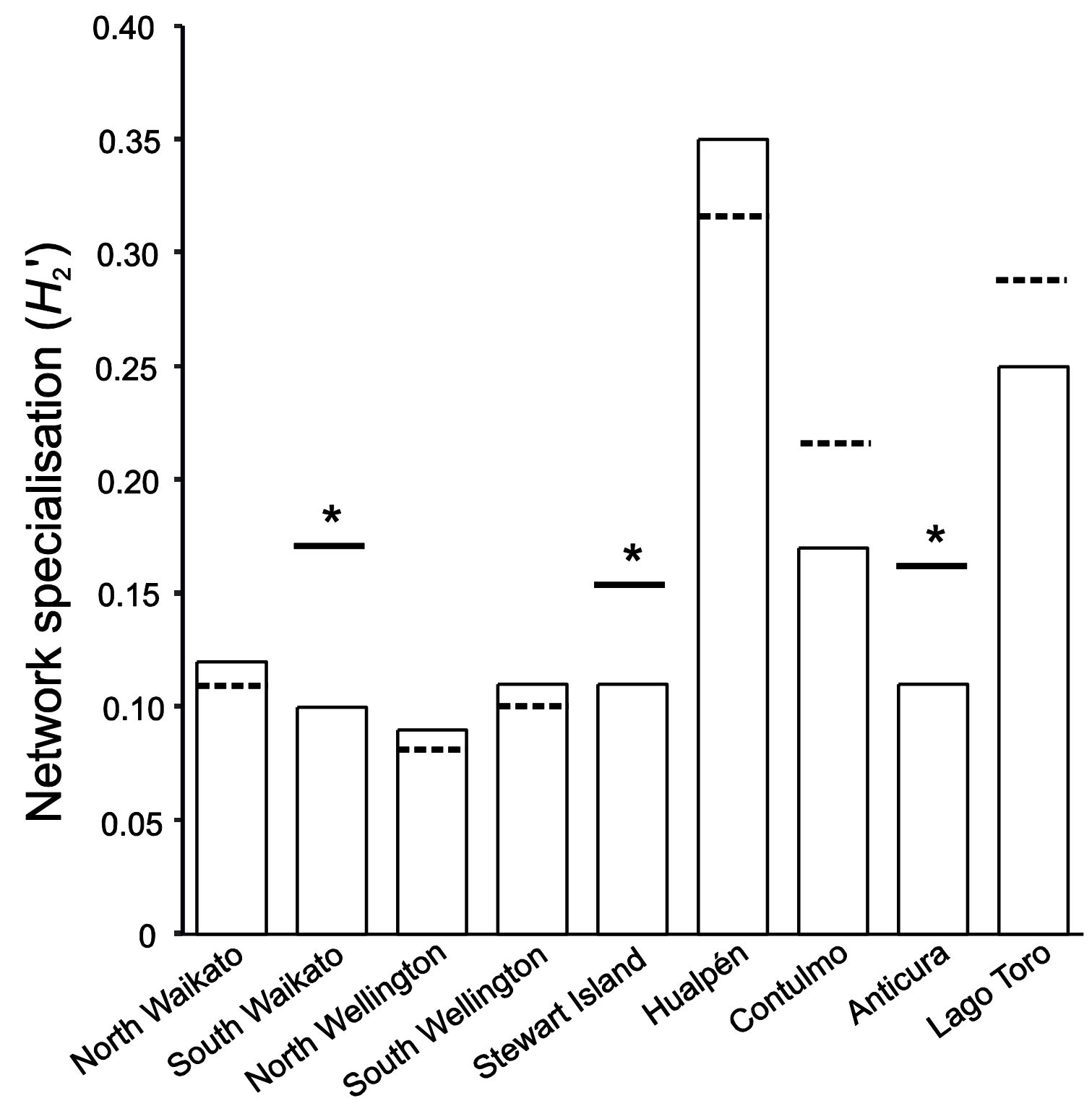

Figure 2.6 Results from the network specialisation analyses $\left(\mathrm{H}_{2}{ }^{\prime}\right)$ of nine south-temperate forests in New Zealand and Chile. The observed $\mathrm{H}_{2}$ ' score was compared with the expected $\mathrm{H}_{2}$ ' score, which was derived from 5,000 randomised simulations using fixed marginal totals and a swap algorithm. The height of each bin represents the observed $\mathrm{H}_{2}{ }^{\prime}$ score and the dashed line represents the expected $\mathrm{H}_{2}{ }^{\prime}$ score. Observed values that differ significantly from randomised expectations $(P<0.05)$ are indicated by a solid bold line and an asterisk. 


\section{Discussion}

The purpose of this paper was to elucidate general patterns in epiphyte assemblage structure, by comparing epiphyte-host network properties across south-temperate forests in New Zealand and southern Chile. Deterministic structure was observed in five out of nine epiphyte-host networks, however, when considering each individual network against the four metrics tested $(9 \times 4), 27$ out of 36 results were consistent with null model expectations. As such, the majority of epiphyte-host networks showed no deterministic structure when taking into account individual measures of network properties. Despite this, I found a general tendency for nestedness in New Zealand networks, which were significantly more nested relative to southern Chile. Nestedness in epiphyte-host networks is hypothesised to occur as a result of the sequential colonisation of epiphyte species on developing host trees (Burns 2007). Two large 'nest' epiphytes (Figure 2.7), Astelia hastata and Astelia solandri (Asteliaceae), facilitate this process by accumulating organic debris and water, which break down into a moisturerich humus (Dawson and Sneddon 1969). A number of epiphytes with higher resource requirements are almost exclusively associated with these large nests, particularly woody shrubs and hemiepiphytes. In support of Burn's (2007) interpretation, nest epiphytes were uncommon at the sites where nestedness did not deviate from null model expectations. For example, only one Astelia individual was recorded on Stewart Island, New Zealand. Additionally, the nest-like Fascicularia bicolor (Bromeliaceae) was only sparsely recorded in southern Chile.

However, factors other than the abundance of nest epiphytes may produce a nested result. For one, Burns (2007) suggested that specialist epiphyte species are only found on the largest host trees, thus producing nested assemblages. Alternatively, nestedness may occur when epiphyte assemblages on small-diameter trees form perfect subsets of epiphyte assemblages on large-diameter trees (Zhao et al. 2015). In this study, there was no marked difference in host tree diameter distributions, however, sites with a higher percentage of larger diameter trees were on average significantly nested. For example, $17 \%$ of trees sampled in North Wellington, and $15 \%$ of trees sampled in South Waikato and Anticura were $>75 \mathrm{~cm}$ diameter, and were all significantly nested. In comparison, only $4 \%-10 \%$ of trees at every other site were in 
the same diameter range. Another factor that may influence nestedness is network size (i.e. number of interacting species). Nielsen and Bascompte (2007) demonstrated that network size, rather than sampling effort (i.e. number of sampling units), is more important in determining a nested structure in species interaction networks. In support of this, New Zealand networks were on average larger than those from Chile. Similarly, the largest network in Chile, Anticura, also showed a significant nested pattern.

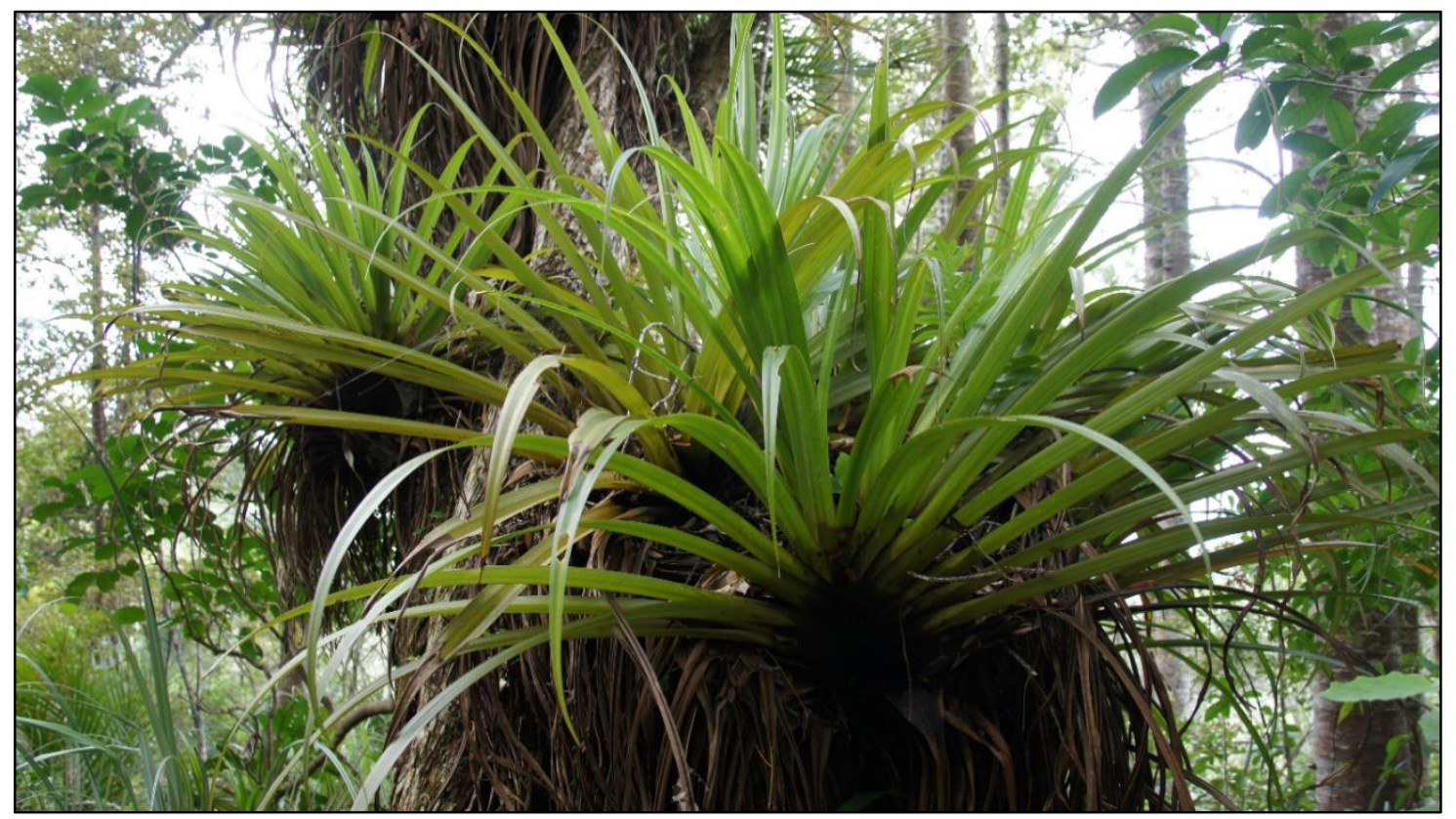

Figure 2.7 A common nest epiphyte endemic to New Zealand, Astelia hastata (Asteliaceae), perched on an Elaeocarpus dentatus var. dentatus (Elaeocarpaceae) host. Photo credit: Catherine Kirby.

Species co-occurrences were consistent with null model expectations in seven of the nine epiphyte-host networks, which suggests that negative species interactions (e.g. competition) are not important in structuring epiphyte assemblages (Figure 2.4). Randomised species co-occurrences are hypothesised to occur when species persistence is low relative to colonisation (Zalewski and Ulrich 2006). However, epiphyte colonisation is inherently slow, and depends on the availability of suitable microhabitats (Dickinson et al. 1993), bark characteristics (Mehltreter et al. 2005) and tree diameter (Hirata et al. 2008). Likewise, epiphyte persistence varies with patch connectivity (Johansson et al. 2012) and disturbance (Winkler et al. 2007). As such, I propose that slow rates of colonisation and variation in species persistence may 
randomise epiphyte assemblages. It is important to note, however, that in two epiphyte-host networks species co-occurred significantly more than randomised expectations, which agrees with some previous results on the aggregated distributions of epiphytes on their host trees (Blick and Burns 2009).

The degree of species specialisation, quantified by the number of links maintained by each epiphyte and host species, was consistent with null model expectations (Figure 2.5). However, the specialisation $\left(\mathrm{H}_{2}{ }^{\prime}\right)$ index, which accounts for species interaction frequencies, found three epiphyte-host networks to be less specialised than expected by chance, with all remaining networks returning low specialisation $\left(\mathrm{H}_{2}{ }^{\prime}\right)$ scores (Figure 2.6). Generalised species interactions are commonly observed in plant-pollinator networks (Olesen et al. 2002). In commensalistic epiphytehost networks, low specialisation scores may result from epiphytes selecting for specific host traits, rather than specific host species (Wagner et al. 2015). Moreover, as trees grow, host traits and microclimate conditions change in ways that can influence epiphyte species occupancy (Benzing 1990). A young tree in the understory, for example, may lack suitable growing sites, however, a larger individual of the same species may offer a number of habitats that may facilitate the establishment of epiphytes (Zotz and Vollrath 2003).

These results illustrate some general patterns in epiphyte-host interaction networks, which may be built upon in comparisons between other sites. I stress the importance of consistency in terms of what metrics and null models to use in network analyses. Here, the most conservative metric to measure nestedness, NODF (AlmeidaNeto et al. 2008), still suggests nestedness in New Zealand networks. Although this may be attributed to network size (Nielsen and Bascompte 2007), tree diameter distributions (Zhao et al. 2015), or branching architecture, I hypothesise that the abundance of nest epiphytes (Astelia spp. in particular) is the main determinant of nestedness in this study. However, further fine-grained analyses are needed to tease apart specific factors that produce a nested structure in epiphyte-host networks. For example, are assemblages on podocarps more nested than broadleaved evergreens? Similarly, what specific host traits affect epiphyte distributions most? By comparing the results of this study more broadly with future datasets, we may be able to elucidate the mechanisms structuring commensalistic epiphyte-host interactions. 
Chapter

3

Chapter 3 - Plant composition patterns inside an endemic birds' nest fern (Asplenium goudeyi) on Lord Howe Island: effects of fern size, fern isolation and plant dispersal abilities 


\section{Abstract}

The importance of deterministic and stochastic processes in structuring ecological communities is an enduring debate. Although this debate is nearly a century old, the extent to which communities are structured by species interactions or chance events is a central issue in ecology. Here, I examined plant assemblages inhabiting 119 epiphytic birds' nest ferns (Asplenium goudeyi) on Lord Howe Island, and determined the effect of fern size, isolation, and plant dispersal strategies on plant species compositions. Additionally, I constructed species-specific incidence functions to gain insight into the effect of resident plant species richness on individual plant species distributions among ferns. Fern size and fern isolation significantly predicted plant community richness. Additionally, plant composition patterns did not deviate from randomised expectations. Individual species occurrences increased with increasing community richness, and no species exclusions were observed. Wind-dispersed taxa, which accounted for $29 \%$ of all species, were well represented in isolated ferns. Comparatively, animal-dispersed taxa were confined to ferns nearest a major propagule source, which suggests that dispersal plays a key role in structuring plant communities inhabiting epiphytic birds' nest ferns. This study emphasises the importance of epiphytes with a nest-like growth form as habitat for plants in a harsh environment. 


\section{Introduction}

Numerous fundamental ideologies in ecology and evolution have arisen from investigating species distributions on islands. Perhaps the most controversial, is the role of chance in structuring ecological communities. One school of thought maintains that communities are structured in a predictable way, and that niche differentiation or species exclusions play an important role in community assembly dynamics (Clements 1916, Hutchinson 1959, Keddy 1992, Tilman 1994, Chesson 2000, Gause 2003, Tuomisto et al. 2003, Dornelas et al. 2006, Silvertown et al. 2006). However, an opposing argument suggests that communities are structured by chance events, which randomise species compositions (Gleason 1917, Connor and Simberloff 1979, Hubbell et al. 1999). While this debate came about nearly a century ago, the extent to which species compositions are structured by chance is still a major theme in community ecology (Diamond 1975, Zobel 1997, Grace 1999, Ricklefs and Lovette 1999, Grime 2006).

In addition to islands, species composition patterns have been analysed for forest fragments (Ehrlén and Eriksson 2000, Jacquemyn et al. 2001), urban parks (Fernández-Juricic 2000), and fresh water ecosystems (Mouillot 2007). However, indepth studies on the structure of epiphyte assemblages are uncommon (Johansson 1974, Jüriado et al. 2009, Buckley 2011). Additionally, no study has analysed the structure of plant assemblages living within epiphytic plants, which may act as foundation species in some environments. One such environment is on the vertical faces of the southern mountains of Lord Howe Island (hereafter LHI), a volcanic remnant in the South Pacific. Here, many individuals of the endemic birds' nest fern Asplenium goudeyi D.L. Jones (Aspleniaceae; Figure 3.1) persist, and are utilised by plants that may otherwise not survive the harsh cliff environment.

Birds' nest ferns are typically epiphytic, and capture plant material within the upright extensions of their fern fronds. This plant material is broken down into a nutrient-rich soil, which provides a medium for propagules to germinate in (Zhang et al. 2010). Plant communities living within birds' nest ferns may be influenced by fern size, age, and fern isolation from a major propagule source. For one, plant taxa may establish more frequently in larger ferns as they are able to intercept comparatively more 
dispersers (Hinsley et al. 1995, Ricklefs and Lovette 1999). Additionally, species establishment success may be higher in larger ferns because they are presumably older, contain more microhabitats, and have been exposed to dispersers for a longer period of time (Williams 1964, Paulay 1994). Furthermore, species immigration rates should theoretically be highest in ferns closest to a major propagule source, which in this case is the forest at the base of the cliffs (MacArthur and Wilson 1967). Another major source of variation in plant community composition may arise from interspecific differences in species dispersal modes (Hurtt and Pacala 1995, Hubbell 2001, Ozinga et al. 2004). Wind-dispersed taxa, for example, are capable of long-distance dispersal, and are considered to be good colonisers relative to taxa with other dispersal strategies (Howe and Smallwood 1982). Additionally, animal-dispersed taxa are reliant on frugivores to disperse their seeds, which may influence establishment success.

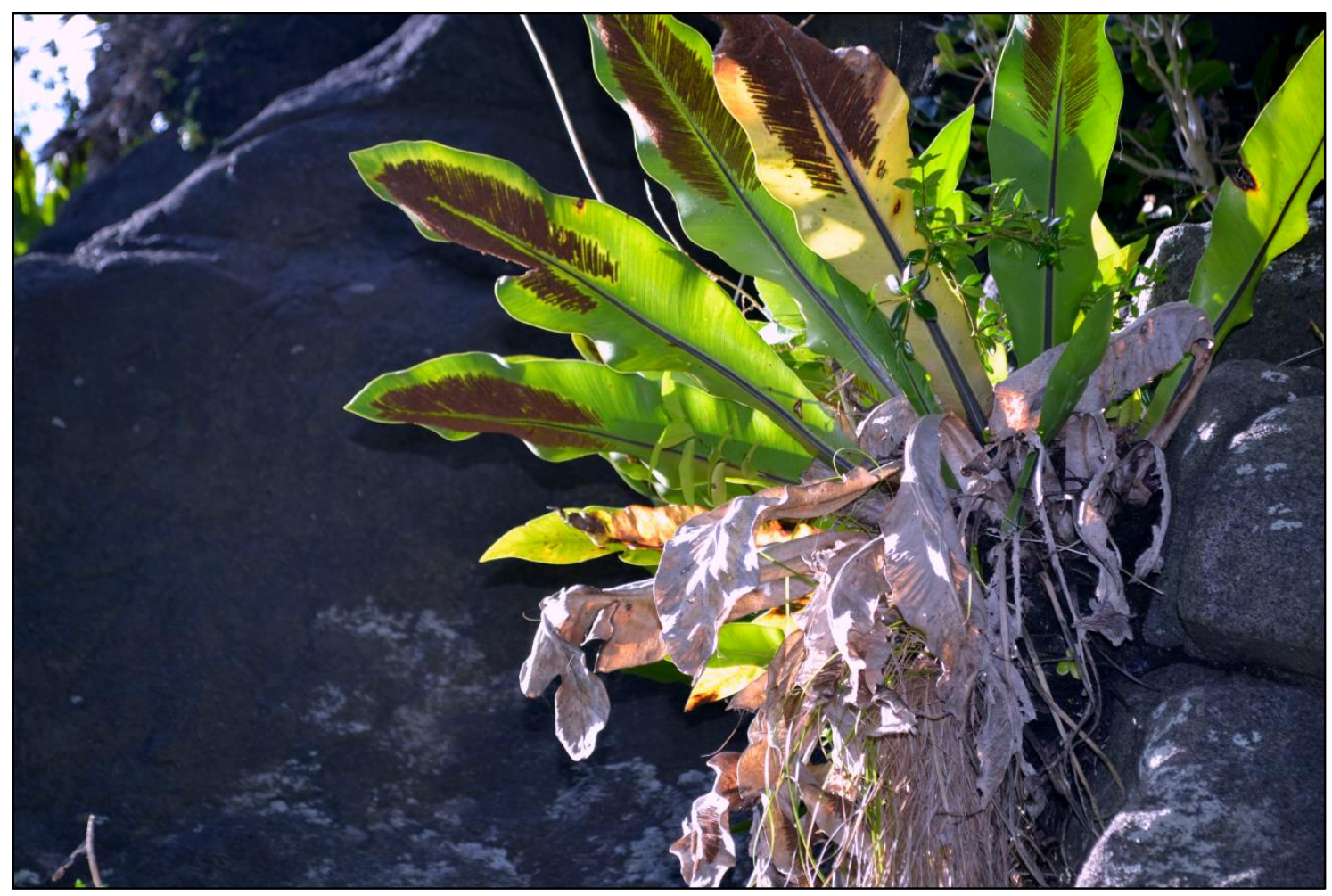

Figure 3.1 A small plant community inhabiting an Asplenium goudeyi birds' nest fern perched on Mount Lidgbird, Lord Howe Island, Australia. 
In this study, I examined plant communities inhabiting epiphytic birds' nest ferns on LHI, and determined whether they exhibit any predictable species composition patterns. First, I tested the hypothesis that plant community richness will be influenced by fern size and fern isolation from forest vegetation. Second, I tested whether plant species compositions were a reflection of plant dispersal modes by regressing fern occupancy by species split into dispersal modes against isolation from forest vegetation. Lastly, I constructed species-specific incidence functions to determine the effect of plant species interactions on individual species occupancy of ferns. 


\section{Methods}

\section{Study site and sampling}

The study was conducted on LHI, a subtropical island in the south-west Pacific ( $31^{\circ} 54^{\prime} \mathrm{S}$, $159^{\circ} 08^{\prime} \mathrm{E}$; Figure 3.2).

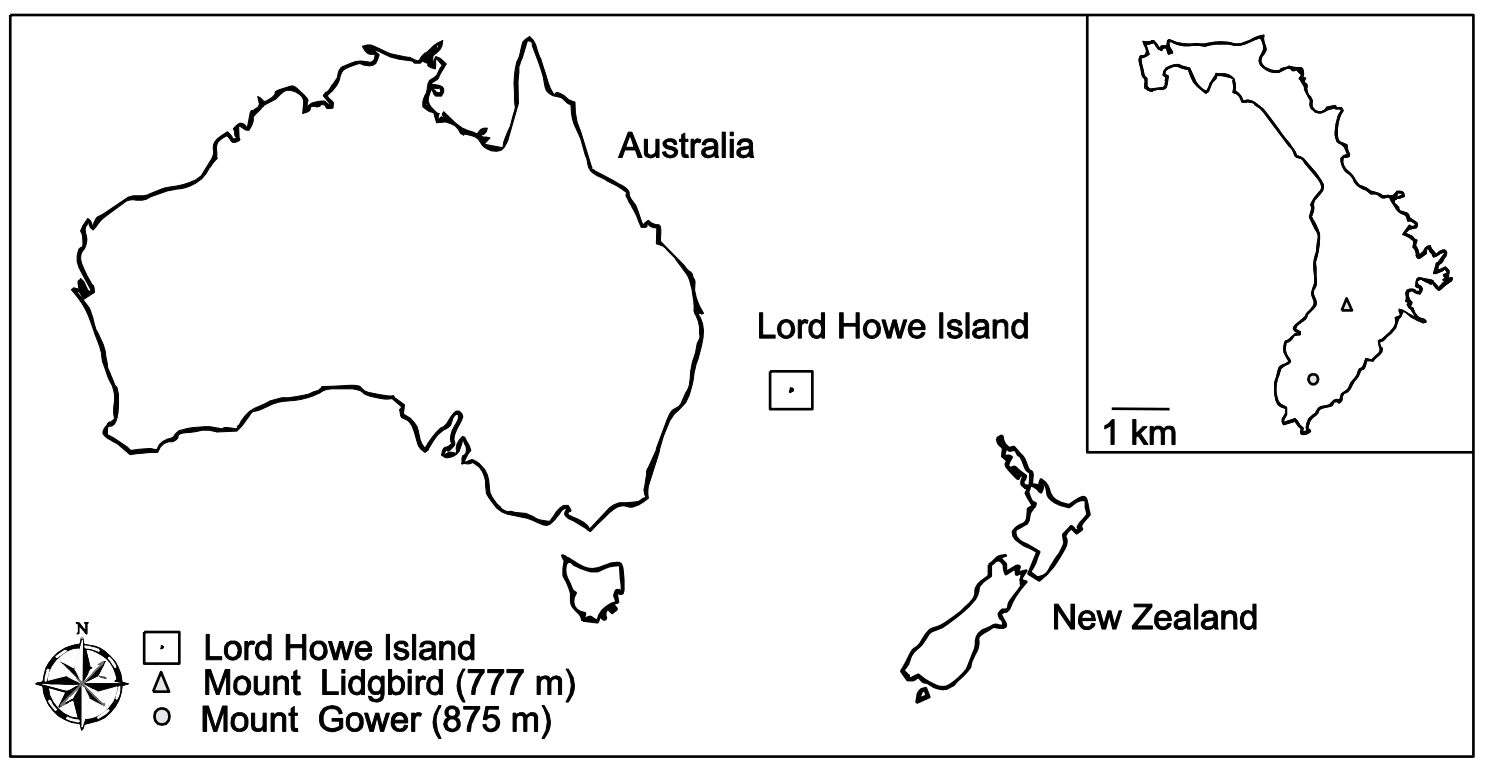

Figure 3.2 Map of Lord Howe Island and its location in relation to Australia and New Zealand. The mountains on which Asplenium goudeyi reside on, Mount Lidgbird and Mount Gower, are also shown. Scale is for Lord Howe Island only.

Maximum daily temperatures average from $18^{\circ} \mathrm{C}$ in the cooler months (MaySeptember) to $25^{\circ} \mathrm{C}$ in the warmer months (November-April). Within the study area, precipitation averages $1500 \mathrm{~mm}$ per annum (Australian Government Bureau of Meteorology 2015). Topography consists of two steep mountains in the south, which are composed of alkaline olivine basalt and hawaiites. The northern end of the island is primarily composed of calcerenite and coral sands (Pickard 1984). Field work was carried out over July 2014 on the western facing slopes of Mount Lidgbird (Figure 3.3). Here, I sampled plant communities living inside 119 birds' nest ferns within seven randomly marked 20-m-long transects. Short transects were used for safety purposes. At each fern, I recorded the presence/absence of plant taxa, fern size, and fern isolation from the forest vegetation. Fern size was quantified by multiplying the widest distance 
between the cliff and an adjacent fern frond, with the widest distance between two adjacent fern fronds parallel to the cliff. Essentially, this measurement is the catchment area at which ferns may capture falling debris and dispersers. Fern isolation was a vertical measurement, taken from the base of each fern to the adjacent forest vegetation.

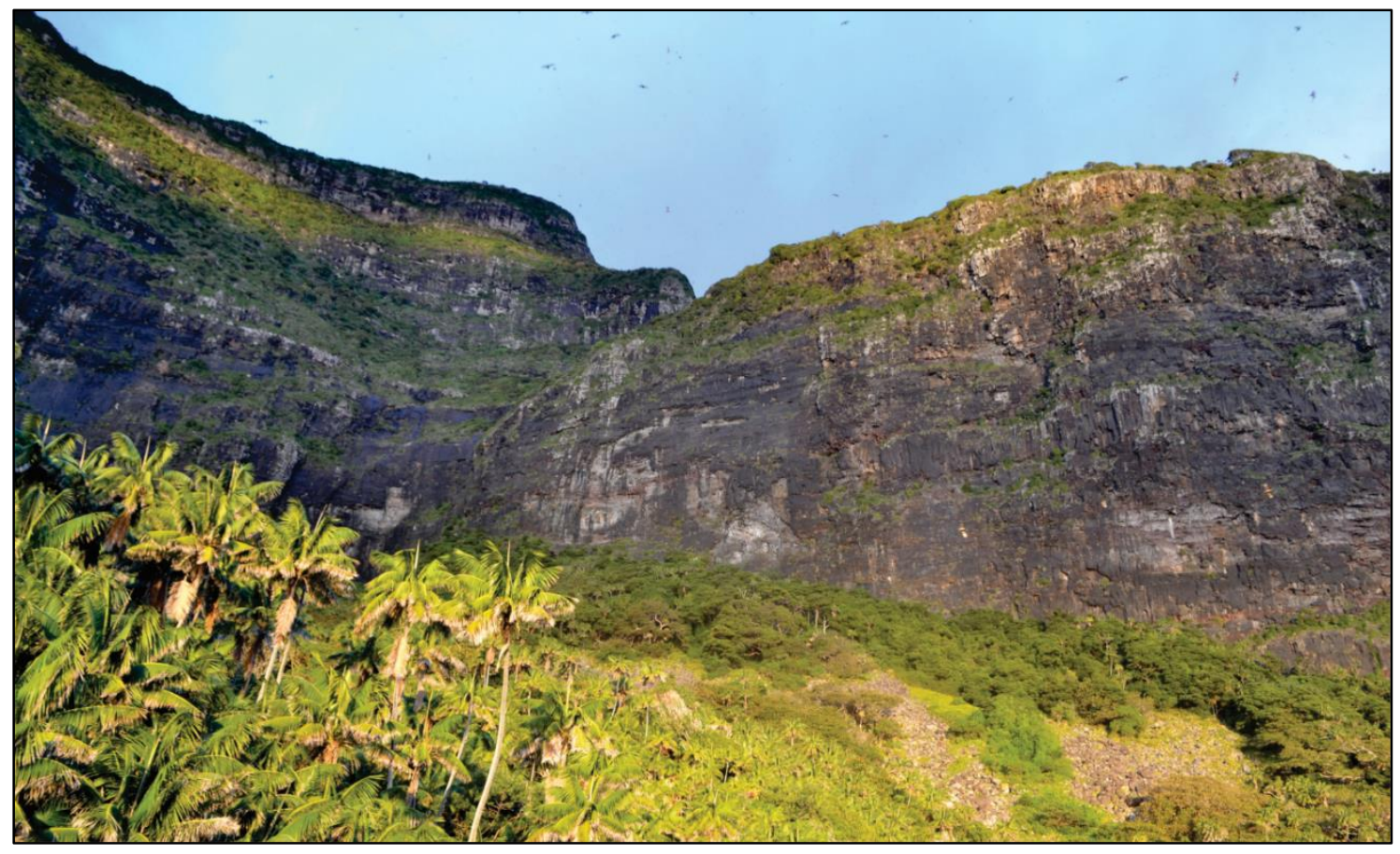

Figure 3.3 View of Asplenium goudeyi ferns perched on the western-facing slopes of Mount Lidgbird on Lord Howe Island. A large boulder bank and kentia palms (Howea forsteriana) are visible in the foreground.

I used a strict sampling criteria to ensure that plant taxa living within birds' nest ferns did not disperse via vegetative spread. For one, ferns that were not clearly separated from neighbouring ferns by at least $1 \mathrm{~m}$ were omitted. Likewise, ferns growing less than $1 \mathrm{~m}$ from a major vegetation source, such as forest vegetation or vegetation growing directly on the cliff face, were also omitted. Vegetation growing below the cliffs was reasonably homogeneous, thus I assumed that each plant community received colonisers from the same species pool. Birds' nest ferns, which typically spend their entire life cycle within trees, were not abundant on trees growing close to the cliffs. As such, I believe that plants colonising the cliff-dwelling ferns did not disperse from the 
forest-dwelling ferns. Vegetation at the base of the cliffs ranged in height from $\sim 0.5 \mathrm{~m}$ (small or juvenile shrubs) to $\sim 4 \mathrm{~m}$ (stunted forest trees). One exception was the kentia palm (Howea forsteriana), which on occasion exceeded the height of all other trees. Shrubs and small trees were able to grow directly at the cliff base, while larger trees grew progressively further back. Plants that could not be identified in the field were collected and identified at the LHI museum herbarium.

\section{Statistical analyses}

Generalised linear models assessed the relationship between fern size, fern isolation from the forest vegetation, and plant community richness. I analysed patterns of community composition using the c-score metric (Stone and Roberts 1990). The c-score is simply the number of 'checkerboard units' between all species pairs in a matrix. A cscore that is significantly larger than randomised expectations is indicative of segregation among taxa (i.e. species co-occur less often than expected by chance). Conversely, a c-score that is significantly less than randomised expectations indicates aggregation among taxa (i.e. species co-occur more often than expected by chance). The observed c-score was compared to 5000 replicates using fixed row and column totals and a swap algorithm (Gotelli 2000). I assessed if patterns in plant composition were related to plant dispersal modes by regressing species divided into three dispersal modes against distance from the forest vegetation. Grasses, ferns and plants with pappus or wings were considered wind-dispersed; fleshy-fruited taxa were considered animal-dispersed; and plants with no specific adaptations for wind or animal dispersal were considered a separate category (Table 3.1). Finally, species-specific incidence functions were constructed for species that occurred 10 or more times using logistic regression. Incidence functions relate the probability of a species occurring in a plant assemblage, with the overall species richness of combined plant assemblages (Diamond 1975). All statistical analyses were conducted in R version 3.1.2 ( $R$ Development Core Team, Vienna, Austria) with the add-on libraries bipartite version 2.04 (Dormann et al. 2009), popbio version 2.4 (Stubben and Milligan 2007) and vegan version 2.0-10 (Dixon and Palmer 2003). 
Table 3.1 Species and family names of plants living inside the epiphytic fern Asplenium goudeyi. The number of times each species occurred in a plant community and their mode of dispersal is also shown.

\begin{tabular}{lcccc}
\hline Species & Family & $n$ & Dispersal mode & Exotic/Native \\
\hline \hline Ageratina adenophora (Spreng.) King \& H.Rob. & Asteraceae & 3 & Wind & Exotic \\
Alyxia ruscifolia R.Br. & Apocynaceae & 30 & Animal & Native \\
Callisia fragrans (Lindl.) Woodson & Commelinaceae & 40 & No adaptations & Exotic \\
Coprosma putida C.Moore \& F.Muell. & Rubiaceae & 7 & Animal & Native \\
Coprosma spp. & Rubiaceae & 1 & Animal & Native \\
Cryptocarya triplinervis R.Br. & Lauraceae & 1 & Animal & Native \\
Dodonaea viscosa subsp. burmanniana (DC.) J.G.West & Sapindaceae & 2 & No adaptations & Native \\
Drypetes deplanchei (Brongn. \& Gris) Merr. & Putranjivaceae & 7 & Animal & Native \\
Ehrharta erecta Lam. & Poaceae & 28 & Wind & Exotic \\
Lagunaria patersonia (Andrews) G.Don & Malvaceae & 4 & No adaptations & Native \\
Lilium formosanum Wallace & Liliaceae & 10 & No adaptations & Exotic \\
Melaleuca howeana Cheel & Myrtaceae & 4 & No adaptations & Native \\
Microsorum howense Tindale \& P.S.Green & Polypodiaceae & 26 & Wind & Native \\
Muehlenbeckia complexa (A.Cunn) Meisn. & Polygonaceae & 4 & Animal & Native \\
Nephrolepis cordifolia (L.) K. Presl & Lomariopsidaceae & 10 & Wind & Native \\
Paspalum spp. & Poaceae & 12 & Wind & Exotic \\
Peperomia urvilleana A.Rich. & Piperaceae & 94 & Animal & Native \\
Poa annua L. & Poaceae & 21 & Wind & Exotic \\
Solanum nigrum L. & Solanaceae & 5 & Animal & Exotic \\
Sophora howinsula (W.R.B.Oliv.) P.S.Green & Fabaceae & 2 & No adaptations & Native \\
Trifolium spp. & Fabaceae & 2 & No adaptations & Exotic \\
\hline \hline
\end{tabular}




\section{Results}

Generalised linear models showed a significant effect of fern size and fern isolation from the forest vegetation on plant community richness $\left(G L M: F_{1}=20.57 ; P<0.001\right.$ and $F_{1}=$ $6.13 ; P=0.03$ respectively; Figure 3.4$)$.
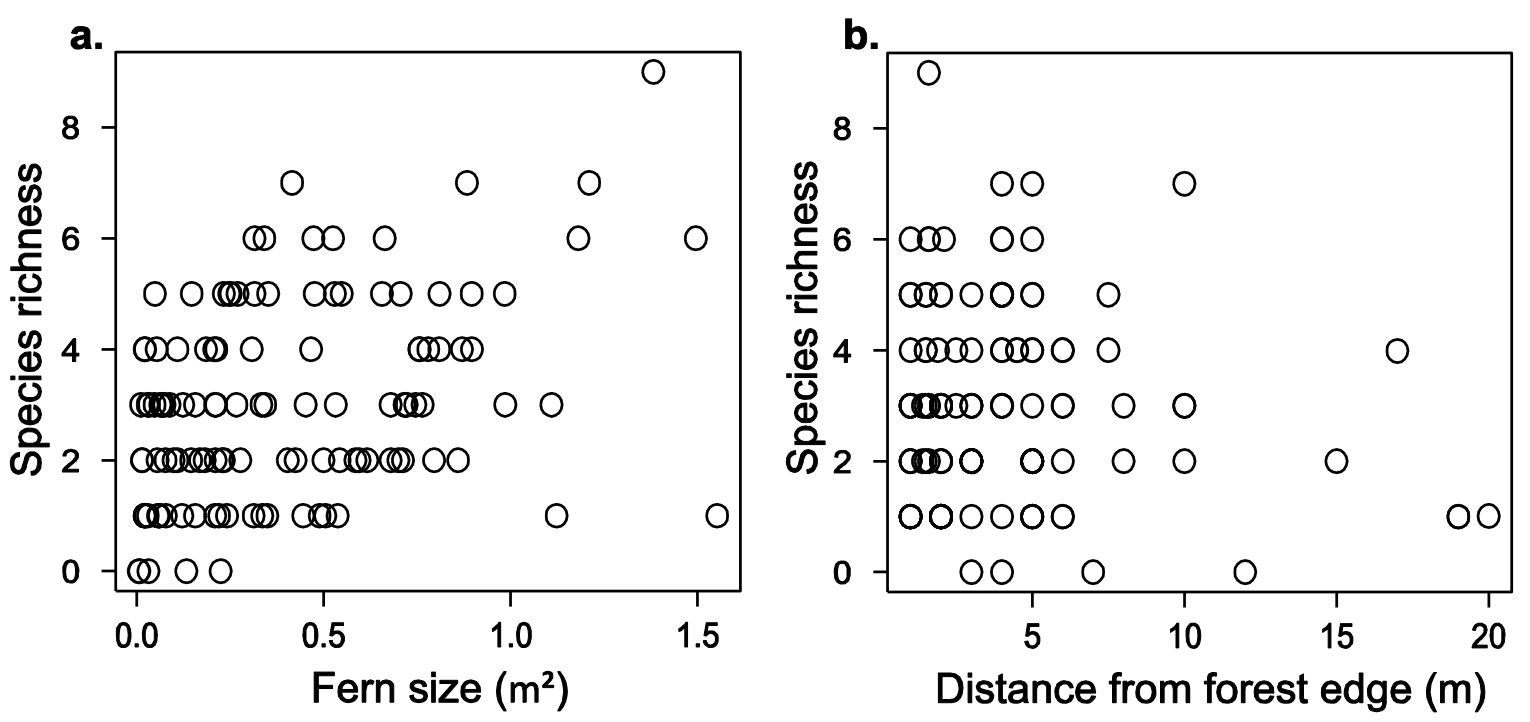

Figure 3.4 The effect of fern size (a) and fern isolation (b) on species richness of plant communities living inside the epiphytic fern Asplenium goudeyi on Lord Howe Island.

Patterns of community composition were not significantly different from randomised expectations as depicted by the c-score metric (CS $=2.73 ; \mathrm{ZS}=1.27 ; P=0.11$ ). Additionally, non-significant deviations from randomised expectations were found between dispersal modes; animal-dispersed taxa $(\mathrm{CS}=0.28 ; \mathrm{ZS}=-0.34 ; P=0.42$ ), winddispersed taxa $(C S=1.03 ; \mathrm{ZS}=0.90 ; P=0.18)$, and taxa with no specific dispersal adaptations ( $C S=0.51 ; Z S=-0.53 ; P=0.29$ ). The percentage of animal-dispersed taxa and taxa with no specific dispersal adaptations significantly decreased with increasing isolation from the forest vegetation (GLM: $F_{1}=27.7 ; P<0.001$ and $F_{1}=7.37 ; P=0.01$ respectively). Conversely, the percentage of wind-dispersed taxa in plant communities significantly increased with increasing isolation from the forest vegetation (GLM: $F_{1}=$ 53.8; $P<0.001 ;$ Figure 3.5). 

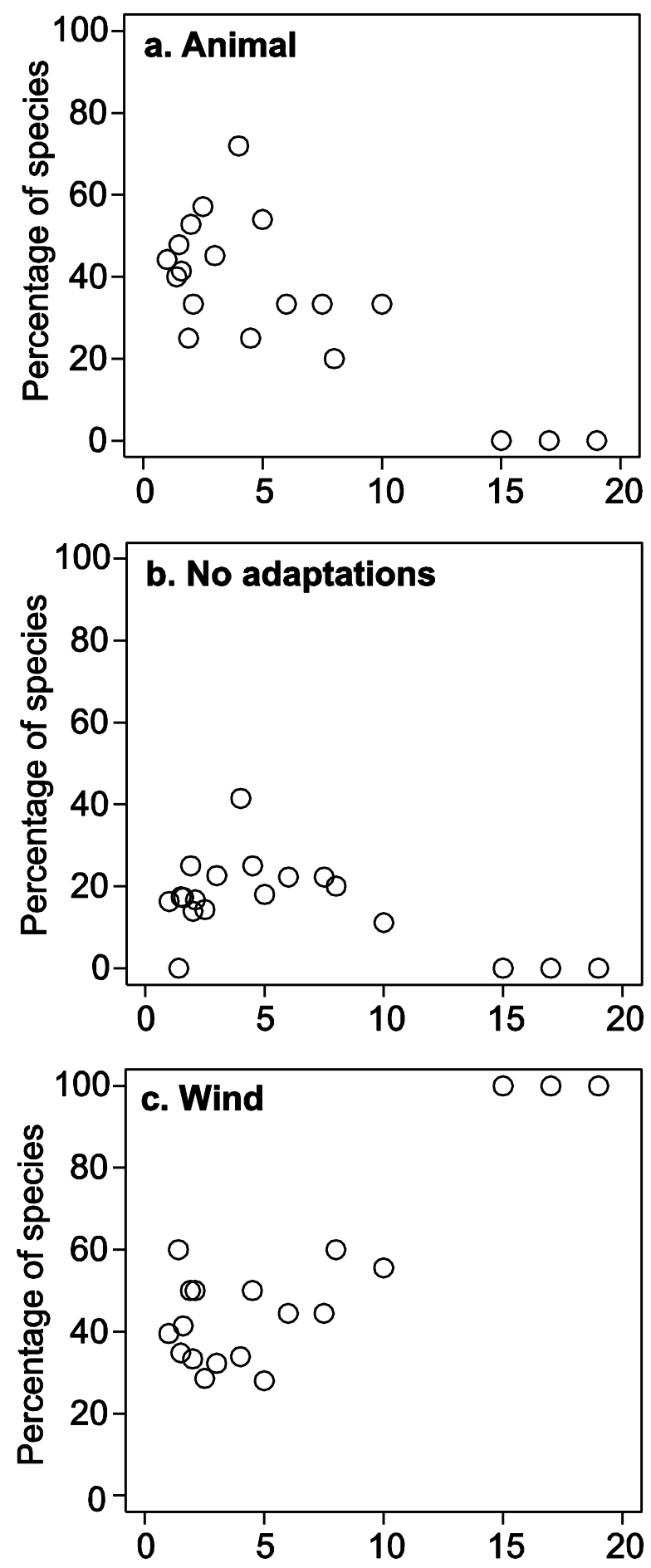

Figure 3.5 Percentage of species from three dispersal modes; animal-dispersed (a), no specific dispersal adaptations (b), and wind-dispersed (c), plotted against Asplenium goudeyi isolation from forest vegetation on Lord Howe Island. 
In all cases, the probability of an individual occupying plant communities significantly increased with fern community richness (Table 3.2). Incidence functions, which were constructed using logistic regression, found no evidence for species exclusions (Figure 3.6).

Table 3.2 Results of the logistic regression model used to create incidence functions of species that occurred in 10 or more plant assemblages. The coefficient represents the log odds of a species occurring in a plant assemblage for every increase in species richness. Standard error (SE), confidence intervals (CI) at the $95 \%$, and significance $(P)$ are also shown.

\begin{tabular}{lccc}
\hline Species & Coefficient \pm SE & $95 \% \mathrm{Cl}$ & $P$ \\
\hline \hline Alyxia ruscifolia & $0.70 \pm 0.15$ & $0.42,1.02$ & $<0.001$ \\
Callisia fragrans & $0.67 \pm 0.14$ & $0.41,0.97$ & $<0.001$ \\
Ehrharta erecta & $0.62 \pm 0.15$ & $0.35,0.93$ & $<0.001$ \\
Lilium formosanum & $0.77 \pm 0.21$ & $0.40,1.25$ & $<0.001$ \\
Microsorum howense & $0.55 \pm 0.13$ & $0.31,0.82$ & $<0.001$ \\
Nephrolepis cordifolia & $0.87 \pm 0.57$ & $0.72,0.96$ & 0.001 \\
Paspalum spp. & $0.88 \pm 0.21$ & $0.51,1.34$ & $<0.001$ \\
Peperomia urvilleana & $0.49 \pm 0.17$ & $0.19,0.84$ & 0.002 \\
Poa annua & $0.43 \pm 0.14$ & $0.17,0.71$ & 0.001 \\
\hline \hline
\end{tabular}



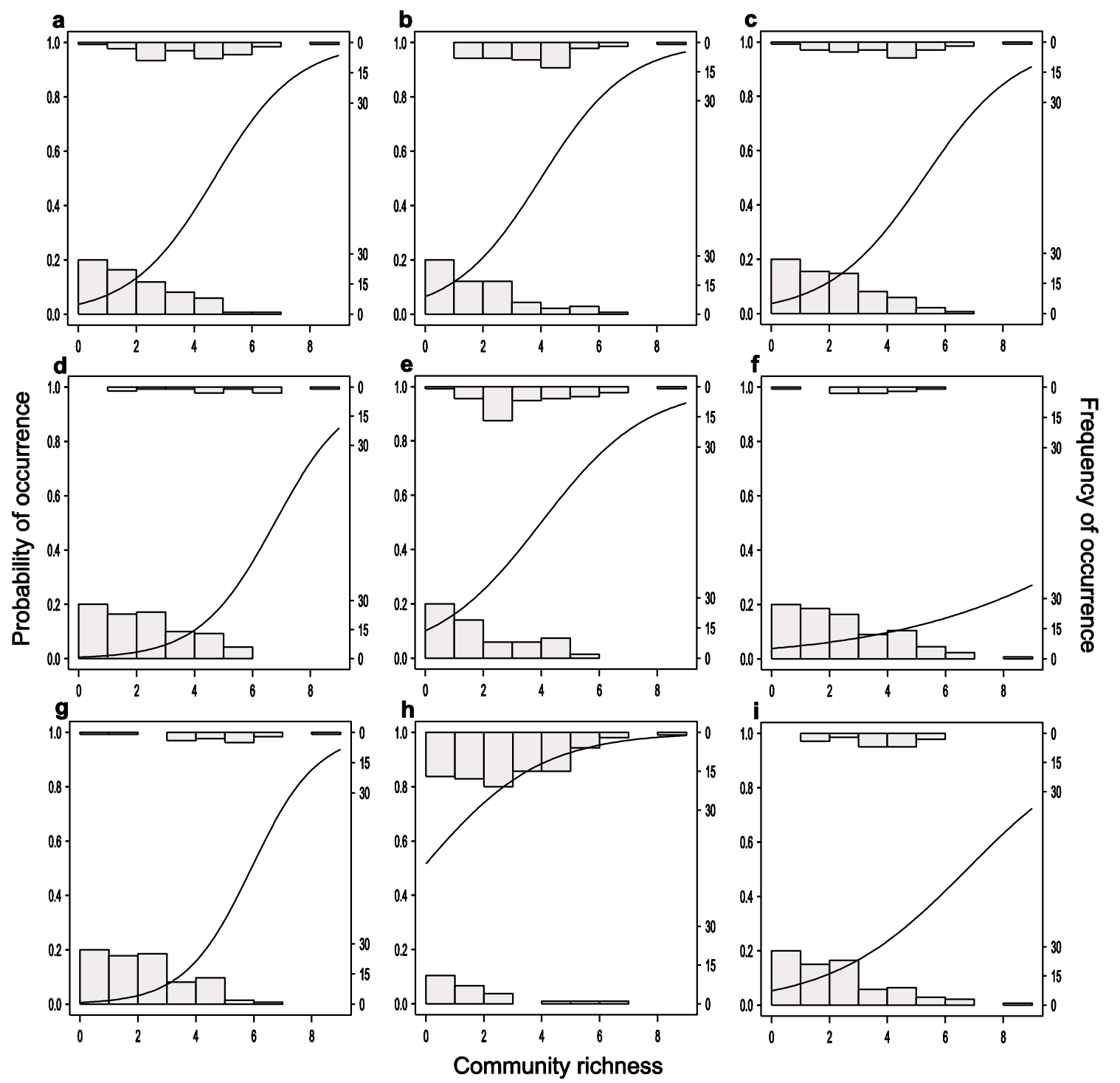

Figure 3.6 Incidence functions of species that occurred 10 or more times in Asplenium goudeyi ferns on Lord Howe Island. Incidence functions relate the probability of a species occurring in a plant community, with plant community richness. The black sigmoidal line represents the probability that a species will be present or absent at a particular measurement of plant community richness. The frequency at which each species was either present or absent at each measurement of species richness is depicted as a frequency histogram. The above frequency histogram is the number of times each species was present in a community, and the below histogram is the number of times each species was absent. Species used in this analyses were Alyxia ruscifolia (a), Callisia fragrans (b), Ehrharta erecta (c), Lilium formosanum (d), Microsorum howense (e), Nephrolepis cordifolia (f), Paspalum spp. (g), Peperomia urvilleana (h), and Poa annua (i). 


\section{Discussion}

These results suggest that plant communities living within Asplenium goudeyi birds' nest ferns are structured by dispersal. For one, wind-dispersed taxa were well represented in isolated ferns. Comparatively, animal-dispersed taxa and taxa with no specific dispersal strategies were lacking. Furthermore, patterns in community composition did not deviate from randomised expectations, which suggests that species interactions are not important in structuring these plant communities. At the species level, individual species occurrences increased with plant community richness. This is consistent with the significant effect of fern size on plant community richness.

The effect of fern size on plant community richness follows one of the most general rules in ecology; the species-area relationship. Like other debris-capturing epiphytes, birds' nest ferns increase their catchment area with age (Reich et al. 2003, Karasawa and Hijii 2006). Larger ferns are able to intercept comparatively more dispersing propagules simply by chance. In addition, a greater amount of organic debris may be intercepted, which eventually decompose into a nutrient-rich humus (Zhang et al. 2010). Similarly, the effect of fern isolation on plant community richness is consistent with another well-documented pattern in ecology (MacArthur and Wilson 1967, Van Dorp and Opdam 1987, Kadmon and Pulliam 1995). Isolation effects may arise from interspecific differences in species colonising or establishment capabilities, propagule limitations, and establishment limitations.

Dispersal limitations, produced by interspecific differences in plant dispersal abilities, may explain variation in fern occupancy by plant species (Ehrlén and Eriksson 2000). Fleshy-fruited taxa generally have larger seeds, and isolation from a major propagule source can limit species dispersal (Sillett and Goslin 1999, Dettki et al. 2000). Moreover, selection pressures on insular taxa have further reduced dispersibility by selecting for larger seed sizes (Kavanagh and Burns 2014). Exotic species, which make up $67 \%$ of all wind-dispersed plants, do not have the same selection pressures acting on reduced dispersibility as insular taxa. Furthermore, wind-dispersed taxa tend to have smaller seeds, which come in greater quantities. As such, wind-dispersed taxa make efficient colonisers (Nathan 2006), and were well represented in isolated ferns. 
Dispersal limitations may be lessened by the presence of neighbouring ferns. Neighbouring ferns may act as agents of dispersal, not only increasing the rate of colonisation, but also reducing species extinctions in plant communities that have experienced disturbances (Ruchty et al. 2001). Species with the ability to spread vegetatively, such as Nephrolepis cordifolia, Microsorum howense and Callisia fragrans, were assumed to be dispersed by wind to Asplenium goudeyi ferns. However, without long term observation of plant communities, I cannot definitively say that dispersal via vegetative spread did not occur. Nevertheless, ferns growing less than $1 \mathrm{~m}$ from neighbouring vegetation were omitted in an attempt to exclude dispersal via vegetative spread. As observed in previous studies, vegetation may grow directly on cliff faces in areas where soil has accumulated (Yuan et al. 2006). Thus, the uncommon occurrences of vegetation growing directly on the cliff face rather than within birds' nest ferns may be an additional source of colonisers. While these occurrences were mainly grasses, incidences of Melaleuca howeana, Ageratina adenophora and Solanum nigrum were also noted.

The regime shift from animal-dispersed plant taxa to wind-dispersed taxa as isolation from the forest vegetation increased may be a result of propagule limitations, here defined as the failure of propagules to reach suitable establishment sites (Tilman 1994). For one, birds' nest ferns may contain insufficient resources to mature plant taxa, particularly trees and shrubs (Stephenson 1981). Moreover, exposure to the elements and lack of food may discourage pollinators and dispersers from leaving the protection of the forest. Propagule limitations maybe lessened for plant communities growing closest to the forest vegetation simply because of proximity to a greater variety of colonisers, pollinators, and dispersers. Additionally, propagule limitations may be lessened for annual plants, particularly smaller-seeded species, which have a colonisation advantage simply because they mature before perennials.

Non-significant patterns of between-fern variation in community composition were observed, which suggests that species interactions play a lesser role in structuring these plant communities. This is consistent with observations of the coexistence of ecologically distinct plant species in cliff habitats throughout the British Isles (Hepburn 1943, Jarvis 1974, Cooper 1997). The lack of negative species co-occurrence patterns may also result from frequent disturbances in the cliff environment, which may 
suppress competitively dominant species. Specifically, rock falls and high winds may dislodge species from plant communities or restrict species from attempted establishment. Additionally, disturbances may create new microsites that facilitate the establishment of less competitively dominant species (Cooper 1997). Although negative species co-occurrences were not observed, individual species occurrences increased with plant community richness. This may occur when resident plants facilitate the establishment of later-colonising species, which is frequently observed in plants growing in harsh environments (McAuliffe 1984, Bertness and Hacker 1994, Valente et al. 2014).

This study highlights the importance of epiphytic birds' nest ferns in providing suitable establishment sites for plants that may otherwise not persist in a cliff environment. Interspecific differences in species dispersal modes explained the regime shift from animal-dispersed plant taxa in non-isolated communities to wind-dispersed taxa in isolated communities. Additionally, the lack of species exclusions suggests that species interactions are less important in structuring these plant communities. Disturbances and facilitation by other plants may prevent competitive species from becoming dominant. I conclude that plant communities inhabiting birds' nest ferns show no predictable patterns of community composition, and are strongly influenced by species dispersal strategies. 
Chapter 4 - Epiphyte assemblage development throughout tree ontogeny: an island ontogeny framework 


\section{Abstract}

Epiphytes are a conspicuous feature of numerous forests, yet they are poorly understood compared with terrestrial plants. Theoretical frameworks have helped bridge this gap; however, important questions relating to epiphyte assemblage development have yet to be answered. For example, at what point in tree ontogeny do epiphytes first establish? Do epiphyte assemblages develop uniformly, or is there variation among host trees? In this study, I build upon Darwin's geological theory of island ontogeny to explore changes in epiphyte species richness throughout the life span of their respective host trees. Based on the general features of island ontogeny, I predict that there are three stages of epiphyte assemblage development: (i) an initial stage where host trees are devoid of epiphytes because they lack sufficient architectural and physiological characteristics suitable for epiphyte establishment, (ii) a second stage where trees acquire epiphytes as adults and continue to do so into maturity, and (iii) a final, hypothetical stage where epiphyte assemblages progress through a period of species decline following host tree mortality. To test my model predictions, I censused epiphyte assemblages on 371 host trees from six New Zealand tree species. I first assessed the relationship between epiphyte species richness and host tree diameter. I then tested whether relationships between epiphyte species richness and host tree diameter varied between host species. Results were consistent with model predictions. I found variation in the ontogenetic stage at which host trees become favourable for epiphyte establishment. Moreover, the rate at which epiphyte species richness increased with host tree diameter varied among host species. My findings indicate that an island ontogeny framework is useful for guiding investigations on epiphyte assemblage development. 


\section{Introduction}

Approximately $10 \%$ of the world's vascular flora live non-parasitically on other plants, typically trees (Benzing 1990). These epiphytic plants contribute significantly to local species diversity, and can represent up to 35\% (Gentry and Dodson 1987) and even 50\% (Kelly et al. 2004) of all vascular flora. Despite being a conspicuous feature of numerous forests, patterns of epiphyte species richness are still poorly understood compared with terrestrial plants. Theoretical frameworks have helped bridge this gap; however, none have been implemented to guide investigations on epiphyte assemblage development throughout tree ontogeny.

As trees grow, their morphological and physiological characteristics change in ways that can influence epiphyte assemblage development (Benzing 1990). These may include changes in tree architecture (Bennett 1987), bark characteristics (LópezVillalobos et al. 2008), canopy soil chemistry (Gustafsson and Eriksson 1995), microclimate conditions (Sporn et al. 2010) and host tree size (Flores-Palacios and Garcia-Franco 2006). During early tree ontogeny, the simple branching architecture precludes the development of epiphyte assemblages (Benzing 1990). However, as trees age and expand, epiphytes become established and undergo primary succession. Consequently, positive linear relationships between tree size and epiphyte species richness are regularly documented (Hietz-Seifert et al. 1996, Burns and Dawson 2005, Flores-Palacios and Garcia-Franco 2006, Hirata et al. 2008), and are analogous to the species-area relationships commonly observed between oceanic islands of varying size.

MacArthur and Wilson's (1967) theory of island biogeography (TolB) has supported epiphyte investigations on colonisation and extinction dynamics (Yeaton and Gladstone 1982, Snäll et al. 2003, Löbel et al. 2006, Laube and Zotz 2007, Burns 2008), dispersal limitations (Buckley 2011), habitat complexity (McMullin et al. 2010) and the effect of tree size (Flores-Palacios and Garcia-Franco 2006). However, the underlying assumptions of the TolB make it less applicable to exploring changes in epiphyte species richness throughout the life span of a host tree. Trees, like oceanic islands, vary in size throughout ontogeny. Therefore, species richness is not a linear or curvilinear function of area, as predicted by the TolB. Most importantly, the TolB makes the implicit 
assumption that the area and isolation of habitat patches remains constant throughout the life span of the species they support.

Darwin's geological theory of oceanic island ontogeny, where islands are born, and islands die, may be a more appropriate guide to investigate epiphyte assemblage development. Although Darwin is best known for his theory of evolution via natural selection, he also made significant contributions to geology. Undoubtedly, the most significant contribution is the observation that different types of islands represent a particular developmental stage - ranging from very young islands, to submerged coral reefs. This geological theory of island ontogeny predicts that as islands age, inhabitable area decreases through the processes of subsidence and erosion (Darwin 1859; Figure 4.1). During this time, an island becomes colonised by dispersing species that radiate and fill all available niche space (Whittaker et al. 2008). As island area decreases, species are lost. The island life cycle is complete when an island submerges back into the ocean, leaving only a coralline ring (Darwin 1859). Thus, very young islands have no species. As islands age, species richness steadily increases. Mature islands are species-rich. Dead islands are devoid of species because they are fully submerged. This is not unlike what one would expect to occur with epiphyte species richness throughout host tree ontogeny. However, contrary to islands, inhabitable area increases with the continual expansion of the trunk and branches (Benzing 1990). Additionally, interspecific differences in host tree characteristics may cause variation in epiphyte assemblage development.

Despite many similarities in the dynamic and transient nature of trees and islands, there are some obvious differences to consider. While island ontogeny operates on an evolutionary time scale, trees are much shorter lived. Therefore, the adaptive radiations common on isolated islands do not occur with epiphytes on their host trees. An isolated archipelago may be thousands of miles away from the nearest population source. Consequently, the establishment of a new species may take several thousand years. For example, a new species would only establish in the Hawaiian archipelago once every $35000 \mathrm{yr}$, prior to the arrival of humans (Loope and Giambelluca 1998). An epiphyte, however, may establish on a host tree within 2-20 yr (Zotz and Vollrath 2003, Werner and Gradstein 2008). Additionally, the nearest population source may be just meters away. Despite these differences, trees and islands are both discrete 
ecological units, and both share characteristics that may explain their species-area relationships.

For example, habitat heterogeneity strongly influences species occurrence patterns on islands, and often correlates with island size (Williams 1964). The complex topography of young to middle-aged oceanic islands allows diversification of species, thus increasing species richness (Paulay 1994). As islands age and subside, area decreases synchronously with habitat heterogeneity and species richness. Conversely, as trees age, habitat heterogeneity increases with the addition of new microclimates and niche space (Kernan and Fowler 1995). Microclimatic conditions are recognised as significant drivers of within-tree epiphyte distributions (Sporn et al. 2010). During tree ontogeny, microclimatic conditions change and may favour different epiphyte species through successional processes. Therefore, habitat heterogeneity of host trees, at least at a within-tree scale, may cause variation in epiphyte species richness.

In this study, I make predictions on how epiphyte assemblages might change during the growth, maturation and eventual death of host trees using the general principles of island ontogeny. Specifically, I predict that there are three stages of epiphyte assemblage development: (i) an initial stage where host trees are devoid of epiphytes because they lack sufficient architectural and physiological characteristics suitable for epiphyte establishment, (ii) a second stage where trees acquire epiphytes as adults and continue to do so into maturity, and (iii) a final stage where epiphyte assemblages progress through a period of species decline following host tree mortality (Figure 4.1). I tested my model predictions on populations of six host tree species that are endemic to New Zealand. I first assessed the relationship between epiphyte species richness and host tree diameter. I then tested whether the relationship between epiphyte species richness and host tree diameter differs between host species. Lastly, I attempt to determine why epiphyte assemblage development may vary between host species. The scaling laws of tree allometry correlate tree diameter with other characteristics, including tree height and age (Thomas 1996, Van Pelt and Nadkarni 2004, Nascimbene et al. 2009). The relationship between tree diameter and tree height is asymptotic; while tree height reaches its maximum, tree diameter may still be increasing (Niklas 1993). Tree diameter is also correlated with other tree characteristics such as bark structure, habitat complexity and tree architecture (Benzing 
1981, Balfour and Bond 1993, Campbell and Newbery 1993, Lyons et al. 2000, Malizia 2003, Male and Roberts 2005). As such, I used tree diameter as an independent variable, with the assumption that larger diameters are indicative of older trees.

a) Oceanic island ontogeny

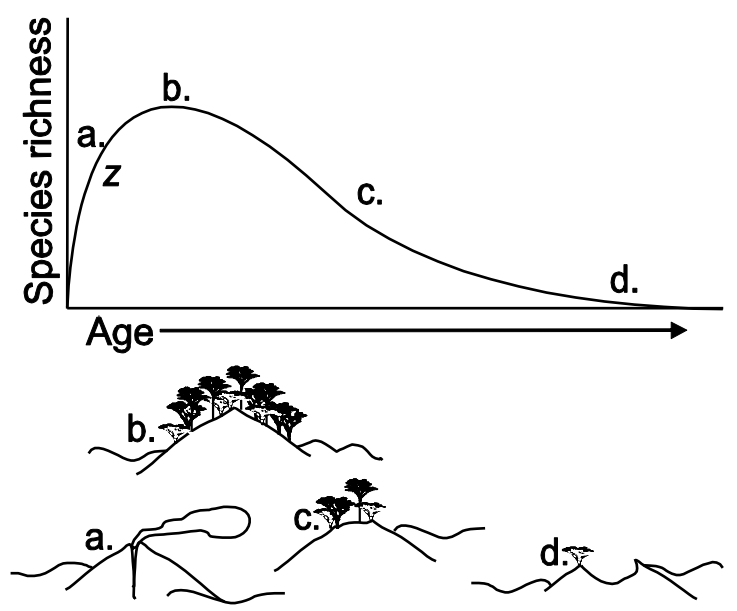

b) Host tree ontogeny

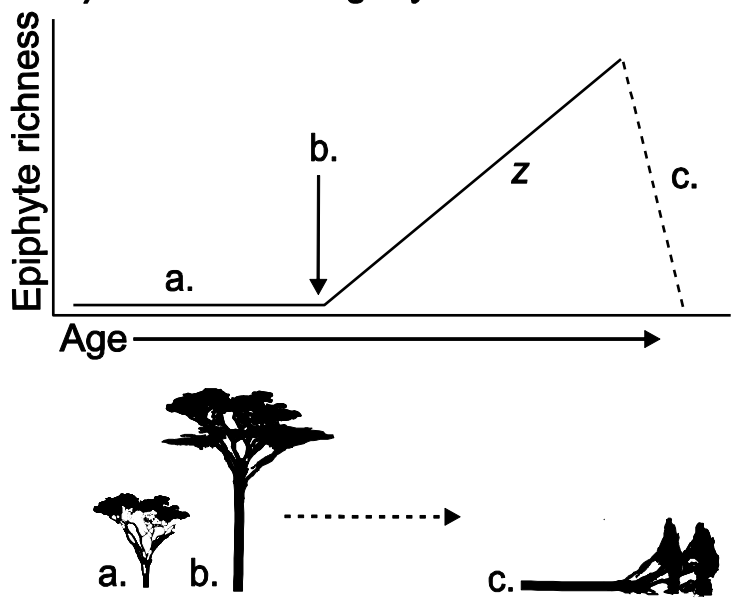

Figure 4.1 Schematic illustrating the island ontogeny framework (a) with respect to epiphyte assemblage development throughout tree ontogeny (b). The theory of island ontogeny predicts that as islands age, inhabitable area decreases through the processes of subsidence and erosion. Young islands initially lack species, however, species eventually become established and undergo adaptive radiations (a). Islands are at their peak species richness at maturity (b). Islands subside and inhabitable area decreases concurrently with species richness (c). The island life cycle is complete when an island submerges back into the ocean leaving only a coralline ring (d). My model (b), predicts that there are three stages of epiphyte assemblage development: (a) an initial stage where host trees are devoid of epiphytes because they lack sufficient morphological and physiological characteristics suitable for epiphyte establishment, (b) a second stage where trees acquire epiphytes as adults and continue to do so into maturity, (c) a final stage where epiphyte assemblages progress through a period of species decline following host tree mortality. The dotted line represents the rate of epiphyte species decline. This line may vary depending on a number of factors (e.g. tree fall vs standing dead tree) and therefore I have kept this prediction hypothetical. The slope $(z)$ represents the rate of species colonisation. 


\section{Methods}

\section{Study site and species}

The study was conducted in Otari-Wilton's Bush Reserve $\left(41^{\circ} 140^{\prime} \mathrm{S}, 174^{\circ} 450^{\prime} \mathrm{E}\right)$, the largest area of remaining native forest on the Wellington Peninsula, located in the lower North Island of New Zealand. The reserve encompasses 96 ha of mature and regenerating coastal podocarp/broadleaf forest at an altitude of $70-280 \mathrm{~m}$ a.s.l. Topography consists of very steep hill slopes with a Greywacke soil parent material. Soil is shallow, and ranges from stony colluvium on ridges and hill slopes to silt loam over colluvium in gullies and hollows. Rainfall normally does not exceed an average of 1240 $\mathrm{mm}$ per annum, and average daily temperatures range from $7^{\circ} \mathrm{C}$ in winter (Jun-Aug) to $20^{\circ} \mathrm{C}$ in summer (Dec-Feb; CliFlo: NIWA'S National Climate Database 2015). Approximately 150 species of flowering plants, conifers and ferns, including epiphytes and lianas, occur in this complex structured forest, similar to that of many tropical forests (Burns and Dawson 2005). The higher strata of the forest are dominated by five tree species, Beilschmiedia tawa (Lauraceae), Dysoxylum spectabile (Meliaceae), Corynocarpus laevigatus (Corynocarpaceae), Elaeocarpus dentatus var. dentatus (Elaeocarpaceae) and Melicytus ramiflorus (Violaceae). Knightia excelsa (Proteaceae) and Laurelia novae-zelandiae (Atherospermataceae) frequently emerge above the canopy, along with scattered remnants of Dacrydium cupressinum and Prumnopitys ferruginea (Podocarpaceae; nomenclature follows Allan (1961), Moore and Edgar (1980) and Connor and Edgar (1987). Nomenclature for Prumnopitys follows de Laubenfels (1978); see Appendix 1 for species authorities). Twenty-two species of vascular epiphytes are found in the area. The most common epiphyte, Pyrrosia eleagnifolia (Polypodiaceae), grows laterally around the trunk and branches of their hosts. Also common in the region are three additional ferns, Asplenium flaccidum, Asplenium oblongifolium and Asplenium polyodon, (Aspleniaceae; fern and allies nomenclature follows Brownsey and Smith-Dodsworth 2000) four orchids Earina autumnalis, Earina mucronata, Dendrobium cunninghamii and Drymoanthus adversus (Orchidaceae), and three shrub epiphytes. Pittosporum cornifolium (Pittosporaceae), Griselinia lucida (Griseliniaceae), and Metrosideros robusta (Myrtaceae) are shrub 
epiphytes that grow in already well-established epiphyte assemblages. The latter two are primary hemi-epiphytes that germinate in the canopy, eventually sending roots down to connect with the forest floor. Metrosideros robusta eventually becomes a freestanding tree once the host has died, similar to species from the genus Ficus. These shrub epiphytes frequently germinate in two nest epiphytes, Astelia solandri and Astelia hastata (Asteliaceae; nomenclature for Astelia hastata follows Birch (2015)). A hanging club moss, Phlegmariurus varius (Lycopodiaceae; nomenclature follows Field and Bostock 2013) also germinates in these large nests. Eight flowering shrubs in the region regularly occur as accidental epiphytes. These are Coprosma lucida, Coprosma grandifolia (Rubiaceae), Leucopogon fasciculatus (Ericaceae), Melicytus ramiflorus (Violaceae), Myrsine australis (Primulaceae), Piper excelsum subsp. excelsum (Piperaceae; nomenclature follows Jaramillo et al. 2008), Pseudopanax arboreus (Araliaceae) and Rumohra adiantiformis (Dryopteridaceae). Filmy ferns (Hymenophyllaceae) are typically found in tropical montane forests of high humidity but also extend into temperate latitudes in areas with high rainfall (Proctor 2012). Otari Wilton's Bush Reserve has a drier climate and, as such, filmy ferns are not a conspicuous feature, although they do occur. When they occur epiphytically, they are often intertwined with liverworts and mosses or in a shrivelled, desiccated state that make them difficult to confidently identify from the ground. Because of this, I decided to omit filmy ferns from this study.

\section{Sampling}

Sampling took place within $10 \mathrm{~m}$ on either side of a $0.6 \mathrm{~km}$ trail in the reserve. By sampling along a trail, I was able to better visually access the canopy than would be possible in off-trail plots. The total area sampled was $1.2 \mathrm{ha}$. I restricted sampling to the six most common host tree species, Beilschmiedia tawa, Dacrydium cupressinum, Elaeocarpus dentatus var. dentatus, Knightia excelsa, Melicytus ramiflorus and Prumnopitys ferruginea. I measured the diameter at breast height ( $\mathrm{dbh}$ at $1.3 \mathrm{~m}$ ) of all target host tree species, including those without epiphytes, in order to obtain a complete size inventory of potential hosts. The study of epiphyte assemblages is fraught with logistical difficulties in accessing the canopy. Consequently, either few trees are 
sampled (Pupulin et al. 1995, Freiberg 1996) or only the lower trunk is sampled (Tewari et al. 1985, Mehltreter et al. 2005). Burns and Dawson (2005) critically evaluated ground-based sampling and correctly identified $91.1 \%$ of all epiphyte and vine species from the ground. I employed similar, strict sampling criteria to ensure accurate inventories of vascular epiphytes from ground-based surveying. First, all trees within the study area were examined for vascular epiphytes by two people using high-powered binoculars. Only host trees that could be accurately viewed from the ground were considered. Six host trees were omitted from the study as visual access into their crowns was unsatisfactory. Host trees were extensively searched by each person at four different locations making sure each branch and area of the trunk was surveyed. Each location around each host tree was repeatedly visited until both persons could traverse around the host tree without locating another epiphyte. An additional, unimpeded view of 30 host trees was obtained from two raised viewing platforms in the reserve and a 60-m canopy walkway. My third prediction of epiphyte assemblage development states that epiphyte species richness should decline following host tree mortality. However, this rate of decline is likely to vary. For example, a tree fall may wipe out an entire epiphyte assemblage (Snäll et al. 2003). Conversely, epiphyte assemblages that remain on an upright deceased or diseased tree, may persist for a lengthy period of time. As such, I did not sample epiphyte assemblages on dead or dying host trees, and kept this prediction hypothetical.

\section{Statistical analyses}

I tested model predictions by first comparing linear with breakpoint regression models. The simple linear regression model, in the log-linear form is:

$$
\log S_{i}=\log C+z \log A_{i}+e_{i}
$$

where $S$ is the number of species, $A$ is island area, $C$ and $z$ are fitted constants and $e$ is the normally-distributed additive error. 
The breakpoint regression model, where there is only one breakpoint, can be written as:

$$
\begin{gathered}
\log S_{i}=\log C+z \log A_{i}+e_{i} \quad \text { for } \log A_{\mathrm{i}} \leq \alpha \\
\log S_{i}=\log C+z_{1} \log A_{i}+z_{2}\left(\log A_{i}-\alpha\right)+e_{i} \quad \text { for } \log A_{\mathrm{i}}>\alpha
\end{gathered}
$$

where $\alpha$ is the breakpoint, and the regression slopes are $z_{1}$ and $z_{1}+z_{2}$. I compared the relative fit of each model using Akaike's information criterion corrected for finite sample sizes $(A I C c)$. This second-order information criterion was used because the $\mathrm{n} / \mathrm{K}$ ratio was small $(<40)$ where $n$ is the sample size and $\mathrm{K}$ is the number of fitted parameters including the intercept (Burnham and Anderson 2002). Following Burnham and Anderson (2002), I calculated DAIC $c$ which represents the differences in $\mathrm{AIC}_{c}$ from the model with the minimum $\mathrm{AIC}_{\mathrm{c}}$ value:

$$
\Delta A I C_{c i}=A I C_{c i}-A I C_{\min }
$$

The models considered to have the most support have a $\mathrm{DAIC}_{\mathrm{c}}$ value of zero. $\mathrm{AIC}_{\mathrm{c}}$ weights (WAICc) were also calculated to provide probabilities of model support that range from 0 (no support) to 1 (whole support). All statistical analyses were conducted in $R \vee 3.0 .3$ ( $R$ Foundation for Statistical Computing, Vienna, AT), with the addon libraries Segmented v 0.3-0.0 (Muggeo 2003) and MuMln v 1.9.13 (Barton 2013). 


\section{Results}

A total of 695 vascular epiphyte occurrences were recorded on 371 host trees. Breakpoint regression with an $\ln (x+1$ to avoid undefined values) transformation best described my model predictions when AICc values were compared between candidate models (Table 4.1).

Table 4.1 Model selection using the second-order Akaike information criterion $\left(\mathrm{AIC}_{\mathrm{c}}\right)$. Delta $(\triangle \mathrm{AICc})$ values were calculated to determine which model best described my model predictions. The models considered to have the most support have a $\Delta \mathrm{AIC}_{\mathrm{c}}$ value of zero. Additionally, $A I C_{c}$ weights $\left(\omega \mathrm{AIC} \mathrm{C}_{\mathrm{c}}\right)$ were also calculated to provide probabilities of model support that range from zero (no support) to one (whole support). The candidate models included a simple linear regression (A), breakpoint regression (B), natural log transformed linear regression (C), and natural log transformed breakpoint regression (D). All models considered to have the most support are highlighted in bold.

\begin{tabular}{|c|c|c|c|c|}
\hline Host tree & Model & $\mathrm{AlC}_{\mathrm{c}}$ & $\triangle \mathrm{AlC}_{\mathrm{c}}$ & $\omega \mathrm{AlC}_{\mathrm{c}}$ \\
\hline \multirow{4}{*}{ Beilschmiedia tawa } & $\mathrm{A}$ & 202.54 & 152.18 & $1.41 \mathrm{E}-34$ \\
\hline & B & 200.45 & 150.08 & 4.01E-34 \\
\hline & C & 53.98 & 3.61 & 0.03 \\
\hline & D & 50.36 & 0.00 & 0.16 \\
\hline \multirow{4}{*}{ Dacrydium cupressinum } & $A$ & 88.45 & 80.58 & 4.97E-19 \\
\hline & B & 61.26 & 53.38 & $3.99 E-13$ \\
\hline & C & 51.14 & 43.27 & $6.28 \mathrm{E}-11$ \\
\hline & D & 7.87 & 0.00 & 0.16 \\
\hline \multirow{4}{*}{ Elaeocarpus dentatus var. dentatus } & $A$ & 379.12 & 269.85 & $3.96 \mathrm{E}-60$ \\
\hline & B & 378.26 & 268.98 & $6.11 E-60$ \\
\hline & C & 119.80 & 10.52 & 8.10E-04 \\
\hline & D & 109.28 & 0.00 & 0.16 \\
\hline \multirow{4}{*}{ Knightia excelsa } & $A$ & 101.82 & 67.79 & $2.98 \mathrm{E}-16$ \\
\hline & B & 86.98 & 52.94 & $4.98 \mathrm{E}-13$ \\
\hline & C & 50.07 & 16.04 & $5.14 \mathrm{E}-05$ \\
\hline & D & -34.03 & 0.00 & 0.16 \\
\hline \multirow{4}{*}{ Melicytus ramiflorus } & $A$ & 255.62 & 175.29 & $1.35 E-39$ \\
\hline & B & 255.00 & 174.68 & $1.83 E-39$ \\
\hline & C & 80.32 & 0.00 & 0.16 \\
\hline & $\mathrm{D}$ & 83.31 & 2.99 & 0.04 \\
\hline \multirow{4}{*}{ Prumnopitys ferruginea } & $A$ & 57.01 & 54.913 & $1.86 \mathrm{E}-13$ \\
\hline & B & 46.36 & 44.26 & $3.84 \mathrm{E}-11$ \\
\hline & C & 13.59 & 11.49 & 5.00E-04 \\
\hline & D & 2.10 & 0.00 & 0.16 \\
\hline
\end{tabular}


This was true in all cases except for Melicytus ramiflorus, which was best described by linear regression. The 'breakpoint' is the mean diameter at which epiphytes established on host trees. However, epiphytes could establish at any stage within the 95\% confidence limits (Table 4.2, Figure 4.2). Before the breakpoint, there was no relationship between epiphyte species richness and host tree diameter $(z=0)$. Host trees acquired epiphytes at diameters ranging from $5.58 \mathrm{~cm}$ (Melicytus ramiflorus) to $43.38 \mathrm{~cm}$ (Dacrydium cupressinum). After the breakpoint, epiphyte species richness consistently scaled positively with host tree diameter. However, the rate at which epiphyte species richness increased with host tree diameter varied between hosts. Beilschmiedia tawa had the lowest regression slope $(z=0.66)$, indicating epiphyte species richness increased with tree diameter more slowly than all other host species. This was followed consecutively by Melicytus ramiflorus $(z=0.71)$, Elaeocarpus dentatus var. dentatus $(z=1.01)$, Prumnopitys ferruginea $(z=1.02)$ and Knightia excelsa $(z=1.47)$. Dacrydium cupressinum had the steepest regression slope of $z=2.05$. The percentage variation in epiphyte species richness explained by host tree diameter was highest for Knightia excelsa $\left(R^{2}\right.$ adj $\left.=0.94\right)$ and lowest for Melicytus ramiflorus $\left(R^{2}\right.$ adj $=$ 0.52; Table 4.2). The diameter ranges of trees measured are included in Table 4.2. 
Table 4.2 Results of the breakpoint regression analyses of epiphyte species richness-host tree diameter data on 371 host trees. The breakpoint is the mean diameter at which epiphytes established on host trees. However, epiphytes could establish at any stage within the $95 \%$ confidence limits. The number of host trees sampled $(n)$, diameter ranges sampled $(\mathrm{cm} \mathrm{dbh})$, coefficient of variation $\left(R^{2}\right)$, and $95 \%$ confidence intervals $(\mathrm{Cl})$ values are also shown.

\begin{tabular}{lccccc}
\hline \multicolumn{1}{c}{ Host tree } & $n$ & Breakpoint $(\mathrm{cm} \mathrm{dbh})$ & Diameter range $(\mathrm{cm})$ & $R^{2}{ }_{a d j}$ & $95 \% \mathrm{Cl}$ \\
\hline \hline Beilschmiedia tawa & 92 & $11.70 \pm 1.28$ & $2.70-106.00$ & 0.53 & $(7.10,19.11)$ \\
Dacrydium cupressinum & 25 & $43.38 \pm 1.11$ & $2.40-177.80$ & 0.93 & $(34.81,53.52)$ \\
Elaeocarpus dentatus var. dentatus & 95 & $13.74 \pm 1.51$ & $2.60-97.80$ & 0.59 & $(6.11,31.19)$ \\
Knightia excelsa & 53 & $17.64 \pm 1.06$ & $1.80-69.20$ & 0.94 & $(15.64,19.89)$ \\
Melicytus ramiflorus & 88 & $5.58 \pm 1.51$ & $1.90-53.40$ & 0.52 & $(2.46,12.68)$ \\
Prumnopitys ferruginea & 28 & $14.59 \pm 1.19$ & $3.00-83.50$ & 0.87 & $(10.18,21.12)$ \\
\hline \hline
\end{tabular}




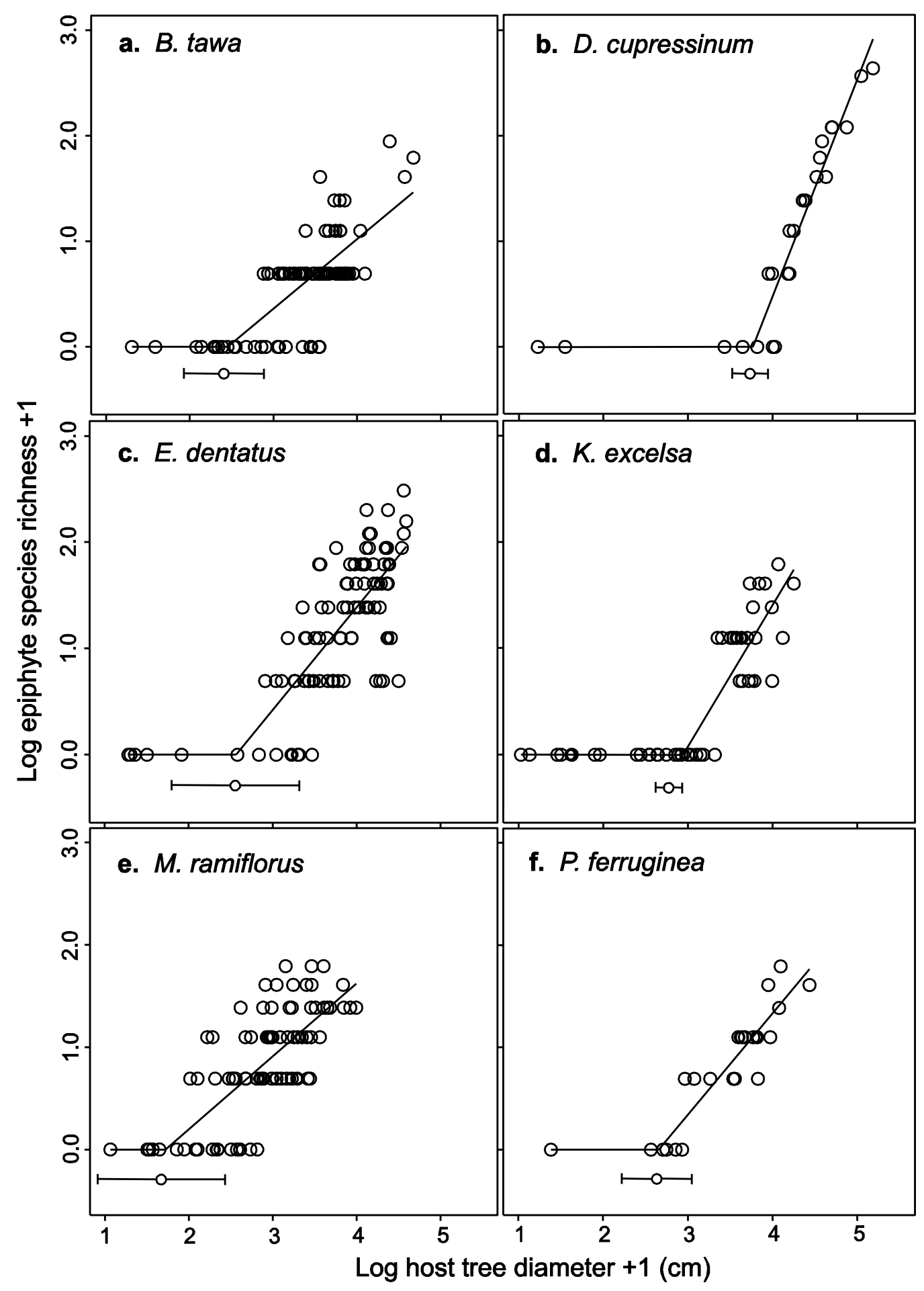

Figure 4.2 Breakpoint regression analysis of epiphyte species richness as a function of host tree diameter (dbh) on Beilschmiedia tawa (a), Dacrydium cupressinum (b), Elaeocarpus dentatus var. dentatus (c), Knightia excelsa (d), Melicytus ramiflorus (e), and Prumnopitys ferruginea (f). The breakpoint is the mean diameter at which epiphytes become established on their respective host tree. Below each breakpoint, the $95 \%$ confidence interval is shown. Epiphytes could establish at any stage within the $95 \%$ confidence limits. Both variables are natural $\log (x+1)$ transformed to avoid undefined values. 


\section{Discussion}

These findings indicate that Darwin's theory of island ontogeny is useful for investigating epiphyte assemblage development throughout tree ontogeny. I found variation in the ontogenetic stage at which host trees become favourable for epiphyte establishment. Moreover, the rate at which epiphyte species richness increased with host tree diameter varied between host species.

Epiphytes rely heavily on robust structures to colonise during tree ontogeny (Benzing 1990). Horizontal branches, in particular, support epiphyte assemblages because they allow canopy soil, a critical water source, to accumulate (ter Steege and Cornelissen 1989, Enloe et al. 2006). Interspecific differences in the development of branches and crotches may explain variation in epiphyte assemblage development between host trees. Dispersing epiphyte propagules, particularly largerseeded species, are less likely to establish on vertical compared with horizontal surfaces (Gaxiola et al. 2008). Three canopy emergent trees, Dacrydium cupressinum, Prumnopitys ferruginea, and Knightia excelsa acquired epiphytes at larger diameters. Perhaps the vertical growth form of these trees inhibits epiphyte establishment until sufficient branches have formed. Moreover, larger diameter trees accumulated epiphyte species faster than smaller hosts, once the first epiphyte had established. This suggests that at some point in ontogeny, branches become ideal, horizontal growing platforms, which may withstand large epiphyte assemblages.

The early development of suitable growing platforms may be why Melicytus ramiflorus, a sub-canopy tree, acquired epiphytes prior to any other host. Despite this, epiphyte assemblages remained depauperate even on larger individuals. MacArthur and Wilson (1967) hypothesised that smaller islands are more vulnerable to stochastic events such as storms and tidal surges that may keep them below equilibrium. Sub-canopy trees do not produce structures capable of withstanding large epiphyte loads. Therefore, stochastic events such as branch falls may be more common in smaller tree species. Even so, smaller trees remain important habitat for epiphytes (Sporn et al. 2010). Small trees may be valuable 'stepping stones' for epiphyte dispersal between host trees. These stepping stones may increase the rate of colonisation, and reduce extinctions on trees that have experienced a disturbance (Ruchty et al. 2001). 
Similarly, many species become established on isolated islands by using nearby islands as agents of dispersal (Gilpin 1980).

The role of dispersal limitation on structuring insular assemblages is well established (e.g. MacArthur 1972, Holyoak et al. 2005, Buckley 2011). Dispersal decreases with increasing isolation from the species pool, resulting in fewer species on isolated islands (MacArthur and Wilson 1967). For epiphytes, however, it is difficult to disentangle dispersal limitations from establishment limitations (Werth et al. 2006). For example, epiphyte distributions are often clumped, which is postulated to be a result of dispersal limitation (Burns and Zotz 2010). However, establishment depends on a range of other factors (e.g. site conditions, competition) that determine species persistence. Establishment success may explain the regime shift from pioneering species such as Pyrrosia eleagnifolia to more competitively advanced species such as Metrosideros robusta as tree diameter increases. This is because changes in bark structure, $\mathrm{pH}$, water-holding capacities, rugosity, and branch architecture increase habitat heterogeneity (Bergey et al. 1995, Zotz et al. 1999, Belinchón et al. 2009, Jueriado et al. 2012). Habitat heterogeneity may cause variability in epiphyte species richness as each species is adapted to different habitats, some of which may not become available until later in tree ontogeny or through facilitation cascades.

At a whole-tree scale, habitat heterogeneity may vary depending on the distribution of individual host trees. For example, trees distributed at low densities have higher light interception (Hietz 2005). Subsequently, epiphytes able to withstand exposed conditions may be more persistent than those heavily restricted by humidity. Conversely, trees distributed at high densities may produce a shaded understorey; therefore, epiphytes adapted to low light environments may be more common than light-demanding species. Perhaps host trees that offer a wider variety of habitats are able to acquire more epiphyte species. Elaeocarpus dentatus var. dentatus, for example, had the second highest epiphyte species richness despite rarely growing above $15 \mathrm{~m}$ in height or $1.0 \mathrm{~m}$ in diameter (Allan 1961). The rough bark and highly branched architecture may produce a heterogeneous environment that supports different epiphyte species.

On oceanic islands, the presence of a freshwater lens is essential for species dependent on freshwater habitats (Sfenthourakis and Triantis 2009). Resource 
pressures are therefore increased on habitat specialists that require freshwater resources to persist. Similarly, epiphyte species adapted to higher water and soil nutrient environments have increased resource pressures (Angelini and Silliman 2014). Facilitation by other epiphytes may allow these specialists to survive in the arid canopy by providing higher resource environments. For example, the two endemic nest epiphytes, Astelia hastata and Astelia solandri, have specific leaf structures that guide water down into a catchment area, similar to that of bromeliads (Dawson and Lucas 2005). Organic debris is intercepted by these leaf structures and eventually forms a rich canopy soil (Wardle et al. 2003). A number of epiphyte species germinate in these large nests, which may in turn increase the rate at which epiphyte species richness increases with host tree diameter.

Finally, the rate at which epiphyte assemblages developed may be a result of the target area effect. Larger tree species are more likely to intercept dispersing epiphyte propagules simply by chance. This is true on larger islands, which offer a larger target area for dispersing species (Ricklefs and Lovette 1999). Interestingly, the diameter at which epiphytes established on host trees varied between tree species. This suggests that factors other than target area are more important for the initial development of epiphyte assemblages, such as establishment success. Studies on epiphyte population dynamics have shown that dispersal and establishment are important in structuring epiphyte assemblages because of the highly stochastic environment in which they live (Strong 1977, Bennett 1987).

In summary, I explored how epiphyte assemblages might change during the growth, maturation and eventual death of host trees using the general principles of Darwin's geological theory of island ontogeny. I found variation in the ontogenetic stage at which host trees become favourable for epiphyte establishment. Moreover, the rate at which epiphyte species richness increased with host tree diameter varied between host species. Whether or not the same comparison could be made in tropical forests is unknown. I suggest mechanisms driving variation in epiphyte assemblage development; however, further quantitative analyses are needed to confirm such mechanisms. 
5

Chapter 5 - Radial distributions of air plants: a comparison between epiphytes and mistletoes 


\section{Abstract}

Vertical gradients of light and humidity within forest canopies are major predictors of air plant distributions. Although this pattern was first recognised over 120 years ago, few studies have considered an additional axis of resource availability, which exists radially around the trunks of trees. Here, I explored the radial position of mistletoes and epiphytes in relation to gradients of light and humidity around the trunks of their host trees. Additionally, I correlated microclimate occupancy with plant physiological responses to shifting resource availability. The radial distributions of mistletoes and epiphytes were highly directional, and related to the availability of light and humidity, respectively. Mistletoes were consistently oriented northwest, parallel to gradients of higher light intensity, temperature, and lower humidity. Comparatively, epiphytes were consistently oriented away from the sun to the southeast. The rate of $\mathrm{CO}_{2}$ assimilation in mistletoes and photochemical efficiency of epiphytes was highest in plants growing under conditions of high light and water availability, respectively. However, the photosynthetic parameters of mistletoe leaves suggest that they are also efficient at assimilating $\mathrm{CO}_{2}$ in lower light conditions. My results bridge a key gap in our understanding of within-tree distributions of epiphytes and mistletoes, and raises further questions on the drivers of air plant distributions. 


\section{Introduction}

Microclimate (i.e. light, water, temperature) is a long-recognised driver of plant distributions. Plant assemblages at forest edges, for example, are reflective of a microclimate with lower relative humidity, greater wind speeds, solar radiation, and soil temperatures (Gehlhausen et al. 2000). Likewise, rapid changes in microclimate from canopy disturbances have direct effects on plant recruitment and growth (Denslow et al. 1990). One of the most conspicuous microclimate gradients occurs within the vertical column of forest canopies, where light and humidity vary with the height of a tree. Distributed in relation to these gradients, are specialised group of plants that utilise trees as substrate to grow on: air plants (Benzing 1990). Schimper (1888) was the first to describe the vertical distribution of air plants in his seminal monograph on the epiphytic floras of the Americas. However, a wealth of literature has since followed, and mechanisms behind the vertical stratification of air plants are well-established (Krömer et al. 2007). Despite more than a century of recognising air plant distributions as they occur vertically within the canopy; few studies have explored spatial patterns of air plants as they occur radially around the trunks of trees, which are equally subject to variation in microclimate. Additionally, studies that do consider the radial positioning of air plants are either observational (e.g. Tremblay and Castro 2009), related to a single explanatory variable (e.g. Botto-Mahan et al. 2000), or more commonly, radial position is measured but never discussed beyond the methods (e.g. Wyse and Burns 2011). By considering microclimate gradients that exist not only vertically within the canopy, but radially around the trunks of trees, our knowledge of within-tree distributions of air plants (hereafter specifically referred to as epiphytes or mistletoes) will be more complete.

Vascular epiphytes, which utilise their host trees solely for structural support, are wholly dependent on microclimate humidity to meet their water requirements (Zotz et al. 2001b). However, as a response to a discontinuous water supply selection pressures have enabled epiphytes to exploit different parts of the canopy. Filmy ferns (Hymenophyllaceae), for example, lack a differentiated epidermis and stomata, and are therefore inefficient at conserving water (Krömer et al. 2007). As such, filmy ferns are 
generally restricted to the lower trunks or branches of their host trees (Proctor 2012). Tank-forming epiphytes, however, store water in modified leaf bases, which allows them to persist in the outer reaches of the canopy (Reyes-García et al. 2008). In comparison, hemiparasitic mistletoes divert water and some mineral nutrients away from the xylem of their host trees, and are more reliant on host tree water potential rather than microclimate humidity to meet their water requirements (Ehleringer et al. 1985). Similar to epiphytes, mistletoes are postulated to partition resources within the canopy environment, although studies testing this hypothesis are rare (Shaw and Weiss 2000). Indeed, it is intuitive that mistletoes are most restricted by the canopy light environment, considering they must produce their own photoassimilates (Hull and Leonard 1964).

Although the effect of host tree aspect on epiphyte and mistletoe distributions has received little attention in the literature, the effect of aspect on terrestrial plant distributions is well established. Forest edges oriented towards the sun, for example, have more pronounced edge effects that travel further into the forest (Gehlhausen et al. 2000). Likewise, slope aspect has significant effects on floristic composition (Kutiel 1992), the radial growth of trees (Fekedulegn et al. 2003), and plant species associations (Badano et al. 2005). Here, I explore the radial distributions of mistletoes and epiphytes in relation to gradients of light and humidity around the trunks of trees. First, I use circular statistics to test the null hypothesis that epiphytes and mistletoes are distributed uniformly around the trunks of their host trees. Second, I test whether epiphytes and mistletoes are distributed in relation to the availability of their most limiting resources; working under the assumption that mistletoes are light limited and epiphytes are water limited. Lastly, I test the physiological responses of mistletoes and epiphytes to changes in their most limiting resources, to determine if the responses are consistent with their distribution patterns. 


\section{Methods}

\section{Study site and species}

The study was conducted in the Nelson Lakes National Park ( $\left.41^{\circ} 48^{\prime} \mathrm{S}, 172^{\circ} 50^{\prime} \mathrm{E}\right)$, situated in the upper region of New Zealand's South Island. The climate is sub-alpine and rarely deviates from $1000 \mathrm{~mm}$ of precipitation annually, and an average daily temperature of $10^{\circ} \mathrm{C}$ (CliFlo: NIWA'S National Climate Database 2015). Three southern beeches of the family Nothofagaceae; Fuscospora fusca, Fuscospora cliffortioides and Lophozonia menziesii dominate the higher strata of the forest. Two species of mistletoe from the family Loranthaceae parasitize the trunks of these southern beeches; Peraxilla colensoi and Peraxilla tetrapetala. Strict host specificity is prominent among Peraxilla mistletoes, which makes them highly dependent on their host ranges (Norton and De Lange 1999). Peraxilla tetrapetala parasitize Fuscospora cliffortioides and to a lesser extent $F$. fusca, however, the preferred host of Peraxilla colensoi is Lophozonia menziesii. Also occurring in the region, are three epiphytic ferns; Asplenium flaccidum (Aspleniaceae), Hymenophyllum multifidum (Hymenophyllaceae) and Notogrammitis billardierei (Polypodiaceae). Unlike Peraxilla mistletoes, strict host specificity in epiphytes is rare, although it does occur (review in Wagner et al. 2015). In Nelson Lakes National Park, however, vascular epiphytes are often restricted to Lophozonia menziesii hosts, presumably because they offer the most suitable bark substrate.

\section{Sampling}

Fieldwork was carried out over a three year period between April 2012 and April 2015. I sampled along $19 \mathrm{~km}$ of trapping lines, which traverse distinct bands of all three southern beech hosts. All trees $>10 \mathrm{~cm}$ dbh (diameter at breast height, $1.3 \mathrm{~m}$ ) were searched for epiphytes and mistletoes within $5 \mathrm{~m}$ of each trapping line. Because the trapping lines follow natural contours within the forest (i.e. trees were not felled to make the trails), edge effects were not considered to influence epiphyte distributions. To determine if epiphytes and mistletoes exhibit a directional bias I quantified their cardinal direction (in degrees) using a mirrored compass. In addition, I measured the 
height at which epiphytes and mistletoes occurred on their host trees. Filmy ferns have rhizomatous structures that allow plants to move laterally around the host trunk. The locality of mat-forming fronds is assumed to be the optimum habitat selected by these plants, similar to the spread of vegetation by mistletoes. As such, the cardinal directions of mistletoes and filmy ferns were obtained by taking the angle at the midpoint between the minimum and maximum spread of vegetation (Figure 5.1). Six Peraxilla colensoi mistletoes were omitted from this study as they wrapped completely around their host trunks.

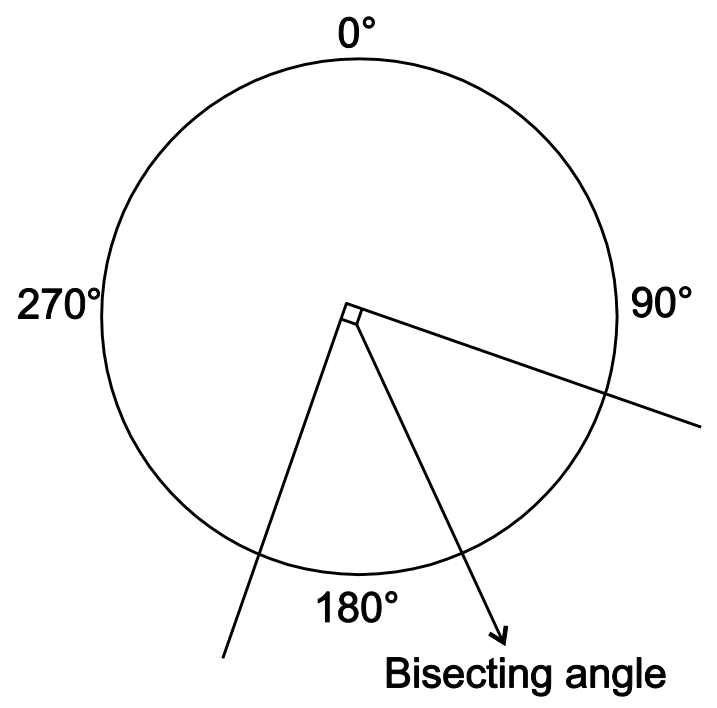

Figure 5.1 Schematic illustrating a 'bisecting angle', which is the angle at the midpoint between the minimum and maximum spread of vegetation.

\section{Microclimate measurements}

I quantified the microclimatic variables hypothesised to most restrict mistletoe and epiphyte distributions: light and water, respectively. In my study region, tree aspects oriented northwest receive more sunlight than those oriented southeast. Thus, all microclimate measurements were taken on the northwest and southeast aspects of host trees. I quantified the amount of photosynthetically active radiation (PAR) that may be intercepted by mistletoe foliage by characterising the light environment on 15 randomly selected Fuscospora cliffortioides trees and 15 Lophozonia menziesii trees within the size range of $30-35 \mathrm{~cm}$ dbh. I did not quantify the light environment on 
Fuscospora fusca because mistletoe infections were uncommon on this host. I characterised the light environment using hemispherical photography. All photographs were taken within the hour before sundown in April 2014 using a digital camera with a $180^{\circ}$ fisheye lens attachment (FC-E8, Nikon 950). The resulting 60 digital images were analysed using Canopy Gap Analyser 2.0 (Frazer et al. 1999). In addition, I measured the relative humidity and temperature on 15 randomly selected Lophozonia menziesii hosts within the size range of $30-35 \mathrm{~cm}$ dbh. Measurements were made every April (20132015), over 10 consecutive days (following Parra et al. 2009), at 10 minute intervals using HOBO temperature/relative humidity data-loggers (Onset, Bourne, Massachusetts, USA).

\section{Plant stress measurements}

I experimentally assessed the physiological responses of mistletoes and epiphytes to reductions in light and water availability (respectively) to determine if the responses were consistent with their distribution patterns. Photosynthetic parameters of mistletoe leaves were obtained using a Li-6400 portable photosynthesis system (Li-Cor, Lincoln, Nebraska, USA). Field measurements were made in April 2014 using two fully expanded leaves; one oriented northwest, and one oriented southeast. Leaf temperature remained constant, relative humidity was maintained at approximately $80 \%$ and ambient $\mathrm{CO}_{2}$ was fixed at $400 \mu \mathrm{l}$. Photosynthetic light response curves were created by increasing levels of photosynthetic photon flux density (PPFD) from $0 \mu \mathrm{mol}$ $\mathrm{m}-2 \mathrm{~s}-1$ to $2000 \mu \mathrm{mol} \mathrm{m}-2 \mathrm{~s}-1$. Measurements were made on five individual plants per species. Prior to each measurement photosynthesis was allowed to stabilise for five minutes. Chlorophyll fluorescence was used to determine the photochemical efficiency of 30 Notogrammitis billardierei epiphytes split into two conditions of experimentallyinduced water stress and one control ( $n=10$ for each condition), over an experimental period of 98 days. Chlorophyll fluorescence measurements were made every seven days using a chlorophyll fluorometer (PAM-2000, Heinz Walz GmbH, Effeltrich, Germany). Prior to taking measurements all epiphytes were dark acclimated for 45 minutes. 


\section{Statistical analyses}

Rayleigh's test of uniformity was used to test the null hypothesis that mistletoes and epiphytes are distributed uniformly around the trunks of their host trees. Bootstrap confidence limits were obtained for the directional means following the parameters of a von Mises distribution (the circular normal distribution). Additionally, a WatsonWilliam's two-sample test of homogeneity was used to compare the directional means of mistletoes and epiphytes. Differences in microclimate measurements between the northwest and southeast aspects of host trees were compared with Mann-Whitney Utests and Student's $t$-tests. The photosynthetic parameters of mistletoe leaves were analysed by fitting a light response curve. Fitting a linear regression with points below the asymptote derived the point at which light-limited $\mathrm{CO}_{2}$ fixation occurred and the rate of $\mathrm{CO}_{2}$ assimilation. Photosynthetic capacity was derived from the asymptote of the curve. Repeated measures analysis of variance (RMANOVA) tested for changes in the photochemical efficiency of Notogrammitis billardierei under two water deficit conditions and one control. I allocated 'water deficit condition' as the between-subject factor and 'time' as the within-subject factor. All statistical analyses were conducted in $R \vee$ 3.1.2 (R Foundation for Statistical Computing, Vienna, Austria), with the add-on libraries CircStats v 0.2-4 (Agostinelli and Agostinelli 2009) and circular v 0.4-7 (Lund et al. 2013). 


\section{Results}

Mistletoe $(n=137)$ and epiphyte $(n=510)$ distributions were highly directional (Rayleigh's test $P<0.001$ in all cases; Table 5.1). Mistletoes exhibited a directional bias for the northwest while epiphytes exhibited a directional bias for the southeast (Figure 5.2). Additionally, the directional means of mistletoes and epiphytes were significantly different (Watson's test, $P<0.001$ ).

Table 5.1 Results of Rayleigh's test of uniformity that determined whether arboreal epiphytes and mistletoes exhibited a directional bias in their distribution around host tree trunks. All directional means were significant to $P=<0.001$, which is indicative of a non-uniform distribution. Confidence limits following the parameters of a von Mises distribution, and average height data are also shown.

\begin{tabular}{ccccc}
\hline Air plants & $n$ & $\begin{array}{c}\text { Directional mean } \\
\text { (degrees) } \pm \text { SE }\end{array}$ & $95 \% \mathrm{Cl}$ & $\begin{array}{c}\text { Mean height } \\
(\mathrm{m}) \pm \mathrm{SE}\end{array}$ \\
\hline \hline Asplenium flaccidum & 65 & $161.72 \pm 1.18$ & $159.25,164.88$ & $2.74 \pm 0.02$ \\
Hymenophyllum multifidum & 182 & $174.49 \pm 1.06$ & $171.62,177.75$ & $1.41 \pm 0.02$ \\
Notogrammitis billardierei & 263 & $146.4 \pm 1.37$ & $144.08,149.20$ & $0.91 \pm 0.01$ \\
Peraxilla colensoi & 67 & $331.02 \pm 2.10$ & $330.03,331.03$ & $3.49 \pm 0.05$ \\
Peraxilla tetrapetala & 70 & $330.47 \pm 2.22$ & $330.60,331.1$ & $3.44 \pm 0.03$ \\
\hline \hline
\end{tabular}

Average \% PAR was significantly higher on the northwest (33.34 \pm 0.48$)$ compared to the southeast $(28.83 \pm 0.49$, Mann-Whitney U-test $P=0.006)$ aspects of host trees. Mean temperatures ranged from $10.20^{\circ} \mathrm{C}$ on the northwest aspect to $9.61^{\circ} \mathrm{C}$ on the southeast aspect and did not significantly differ (Student's t-test $P=0.29$ ). Average \% daily RH was significantly higher on the southeast aspect $(96.06 \pm 0.61)$ compared with the northwest $(90.66 \pm 0.47$, Whitney U-test $P=0.007)$. Light-limited $\mathrm{CO}_{2}$ fixation of mistletoe leaves occurred below a PPFD of $700 \mu \mathrm{mol} m-2 \mathrm{~s}-1$ in all cases except for the southeast oriented leaves of Peraxilla colensoi, which occurred below a PPFD of 600 $\mu \mathrm{mol}$ m-2s-1 (Figure 5.3). 


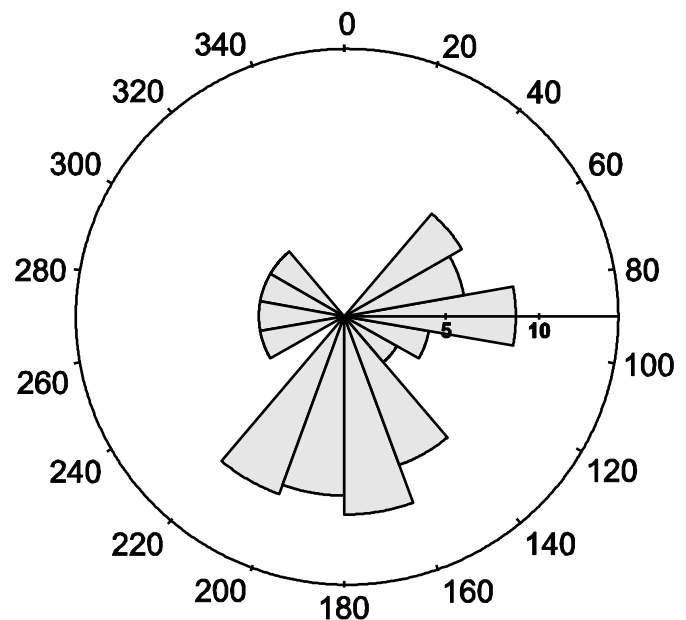

a) Asplenium flaccidum $n=65$

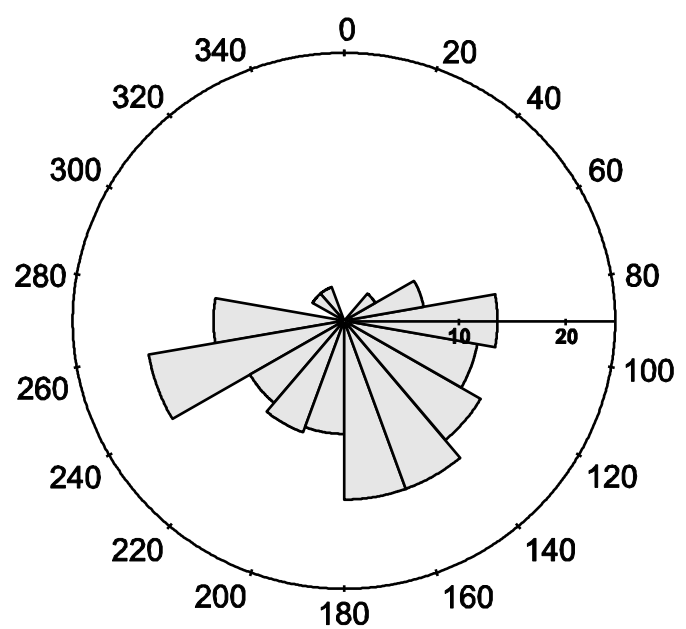

b) Hymenophyllum multifidum $n=182$

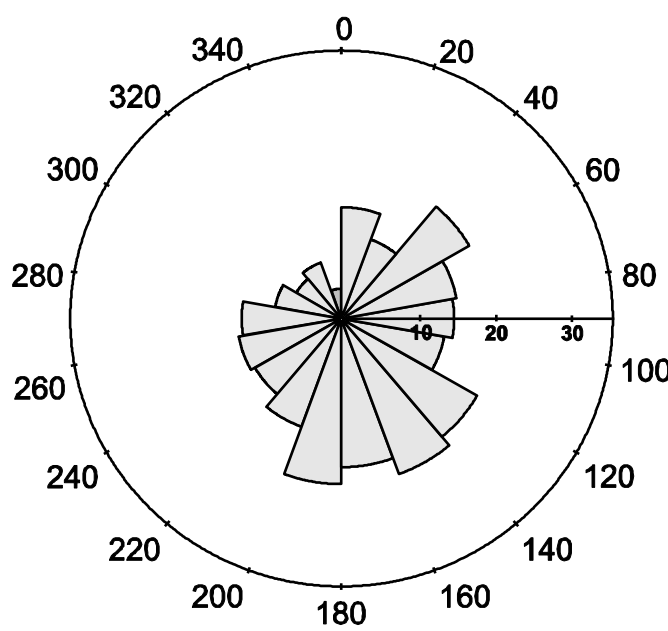

c) Notogrammitis billardierei $n=263$

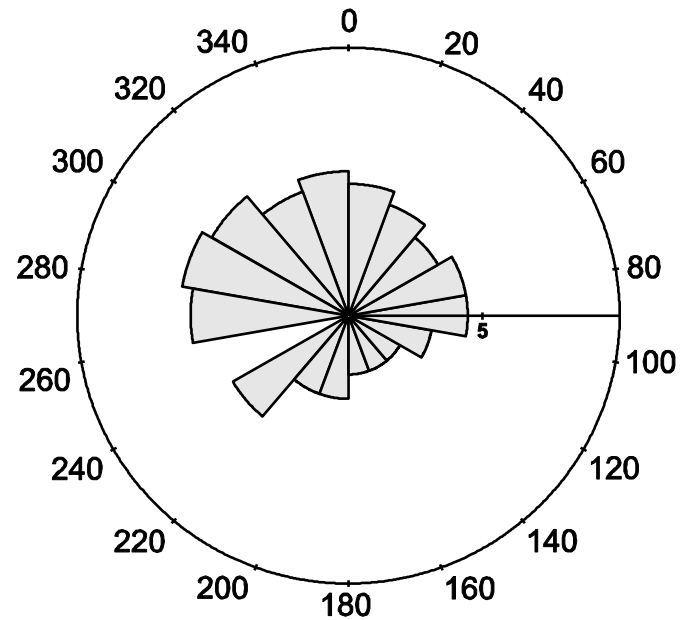

d) Peraxilla colensoi $n=67$

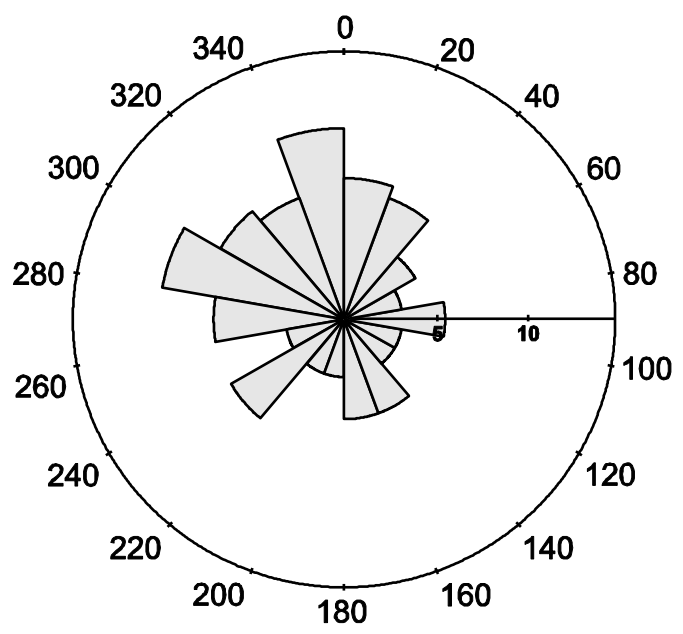

e) Peraxilla tetrapetala $n=70$

Mistletoes

Figure 5.2 Rose diagrams illustrating the cardinal direction (measured in degrees) of epiphytes and mistletoes as they occur radially around their host tree trunks. The length of the 'petals' are proportional to the frequency of species occurrences at each cardinal direction.

\section{Epiphytes}




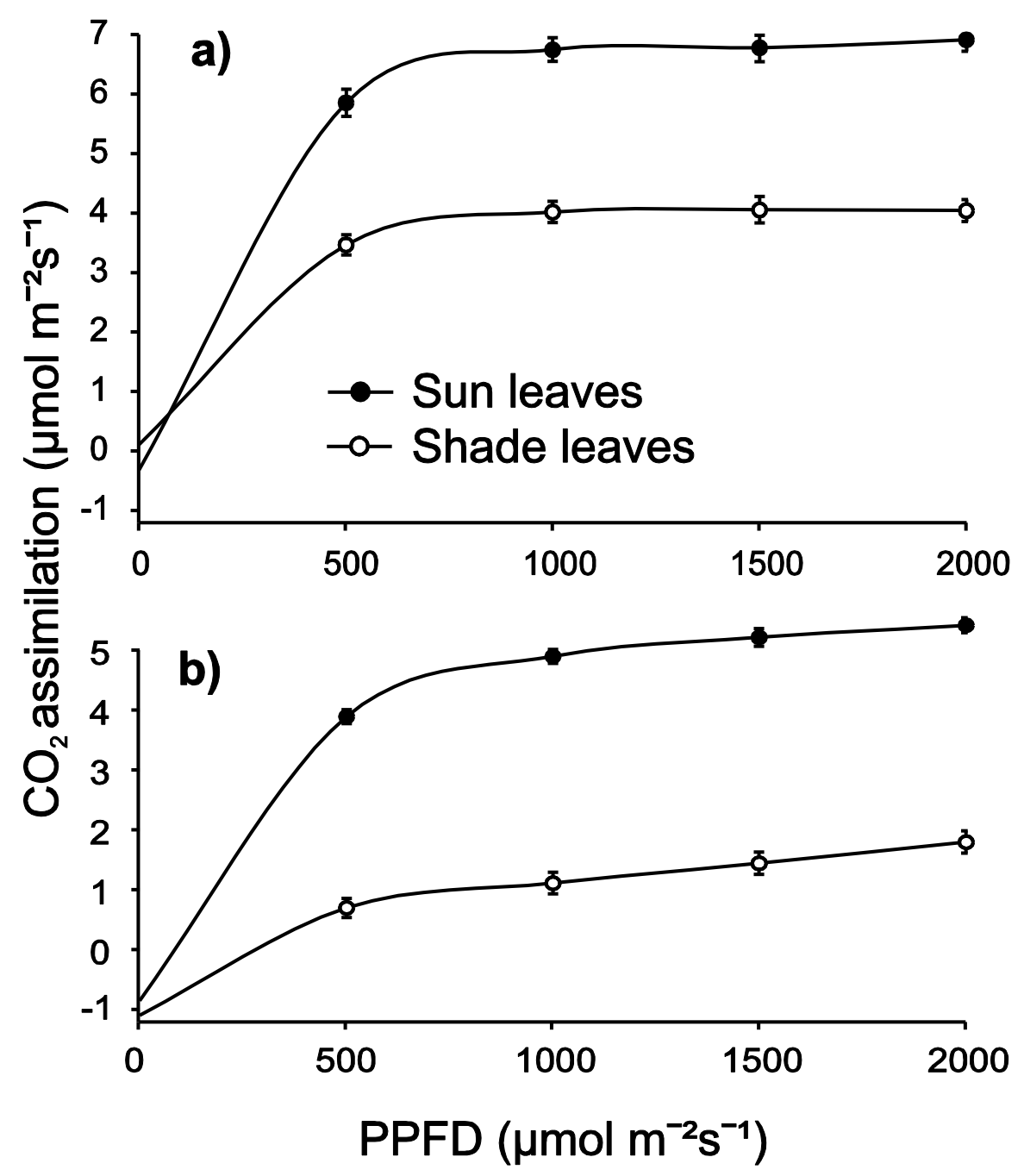

Figure 5.3 Light response curve showing the relationship between $\mathrm{CO}_{2}$ assimilation and photosynthetic photon flux density (PPFD) in Peraxilla tetrapetala (a) and Peraxilla colensoi (b) leaves growing on the northwest aspect (sun leaves) and southeast aspect (shade leaves) of their respective hosts. Values are averages of ten measurements (five on sun leaves and five on shade leaves) taken on five plants of each species.

Peraxilla tetrapetala and Peraxilla colensoi leaves oriented northwest assimilated $\mathrm{CO}_{2}$ more efficiently than those oriented southeast, as depicted by the regression slope below the asymptote of the light response curve (NW slope $=0.013,0.010$ and SE slope $=0.007,0.004$ respectively). Similarly, photosynthetic capacity was highest for Peraxilla tetrapetala and Peraxilla colensoi leaves growing on the northwest aspect compared with leaves growing on the southeast (NW Amax $=6.91 \mu \mathrm{mol} m-2 \mathrm{~s}-1,5.52 \mu \mathrm{mol} \mathrm{m}-2 \mathrm{~s}-$ 1 and SE Amax $=4.04 \mu \mathrm{mol}$ m-2s-1, $1.90 \mu \mathrm{mol}$ m-2s-1 respectively). Repeated measures 
analysis of variance indicated significant effects of water deficit condition (RMANOVA: $F_{2,14}=1440, P=<0.001$ ) and time (RMANOVA: $F_{2,14}=6.287, P=<0.001$ ) on the photochemical efficiency of Notogrammitis billardierei ferns. A significant interaction between the two factors (RMANOVA: $F_{14,28}=33.642, P=<0.001$, Figure 5.4 ) was also observed.

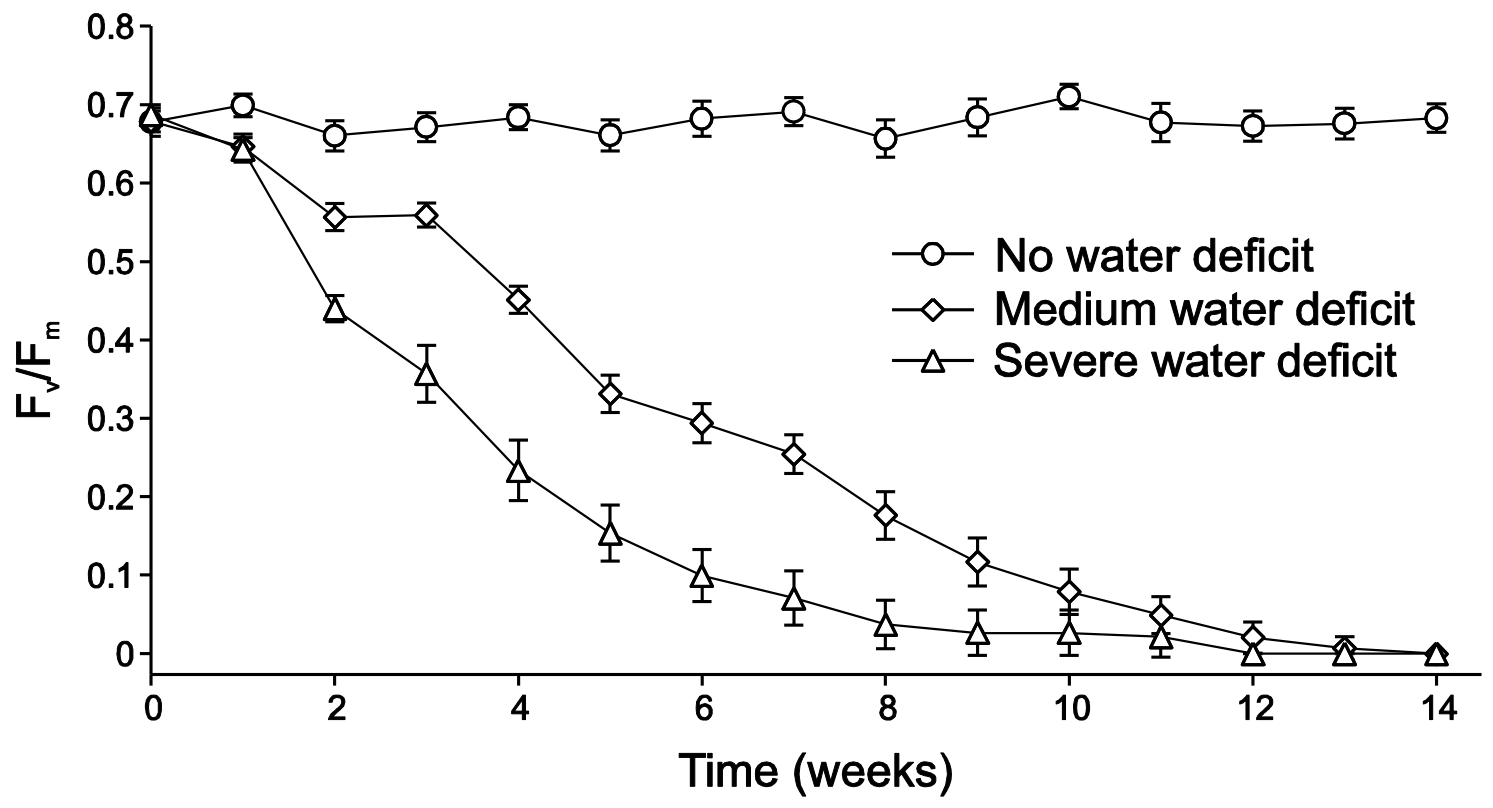

Figure 5.4 Mean values ( \pm SE) of photochemical efficiency of 30 Notogrammitis billardierei ferns exposed to two conditions of water deficit (medium and severe) and one control ( $n=10$ for each condition), over a 14 week experimental period. 


\section{Discussion}

To my knowledge, this is the first study to document the systematic distribution of vascular epiphytes and mistletoes in relation to a pronounced resource gradient that exists around the trunks of trees. Mistletoes were consistently oriented northwest, parallel to gradients with higher PAR, temperature, and lower humidity. Additionally, comparisons of mistletoe photosynthetic parameters showed differences in photosynthetic capabilities both between leaves growing in high and low light environments, and between species. Perhaps the most striking was the result of Peraxilla colensoi leaves oriented southeast, which showed a $66 \%$ decrease in the maximum capacity to exploit light energy for photosynthesis relative to leaves oriented northwest. Comparatively, Peraxilla tetrapetala showed only a $44 \%$ decrease, which suggests a higher plasticity of Peraxilla colensoi mistletoes in response to light availability within the canopy.

While my results agree with previous observations that mistletoe occurrences are correlated with the availability of light (Shaw and Weiss 2000), the effect of light may be indirect. Mistletoes occurring at forest edges, for example, grow faster, produce more fruit, and have longer flowering times relative to mistletoes growing in forest interiors (review in Burgess et al. 2006). However, Montgomery et al. (2003), among others, attributed this positive effect to pollinator behaviour rather than light availability. Similarly, mistletoe distributions may be limited by temperature. In the northern hemisphere, mistletoe range shifts to higher altitudes are attributed to rising temperatures (Dobbertin et al. 2005). Likewise, mistletoes growing in semi-arid regions reportedly germinate on the cooler aspects of their hosts (Botto-Mahan et al. 2000). Thus, it is reasonable to consider that germination success of mistletoes in cooler temperate forests increases on host aspects oriented towards the sun.

Unlike mistletoes, epiphytes were consistently oriented southeast, which correlated with lower PAR, temperature, and higher humidity. Moreover, decreased photochemical efficiency was observed in water stressed plants just 10 days into a 98 day water deficit experiment. Indeed, water availability is an important determinant of epiphyte distributions (Zotz et al. 2001), and interspecific differences in desiccation 
tolerance may influence radial position. Previous studies comparing the effect of slope aspect on poikilohydric bryophytes and lichens at forest edges, for example, found intensified edge effects when oriented towards the sun (Hylander 2005). While poikilohydric plants make up just $0.2 \%$ of the world's vascular flora, the strategy is common among the Hymenophyllaceae, and is present in some Asplenium species (review in Proctor and Tuba 2002). In terms of the light environment, epiphytes that are physiologically adapted to humidity also tend to be adapted to lower light intensities (Graham and Andrade 2004). Parra et al. (2009), for example, observed that filmy ferns did not inhabit microclimates exceeding 30\% light intensity. Thus, rather than selecting for habitats with high humidity, epiphytes may be selecting for lower PAR. Similar to mistletoes, temperature may also influence the radial distribution of epiphytes. For one, increased temperatures may induce water stress in epiphytes by evapotranspiration (Zotz and Hietz 2001). On the contrary, low temperatures may increase incidences of frost, thus limiting epiphyte distributions (Kreft et al. 2004). Bryophytes, which Notogrammitis billardierei were found exclusively growing on, may retain water and regulate temperature (Zotz and Vollrath 2003), and may facilitate the establishment of these ferns.

This study emphasises the importance of microclimates that exist radially around the trunks of trees as potential drivers of epiphyte and mistletoe distributions. It is important to note, however, that my findings are only representative of adult plants and neglects other life stages. Whether or not aspect affects germination and establishment of epiphytes and mistletoes, for example, needs further scrutiny. Likewise, competition for substrate space may limit epiphyte and mistletoe distributions, although evidence for this is rare (Burns and Zotz 2010). In this study, the two mistletoes Peraxilla colensoi and Peraxilla tetrapetala varied in cardinal orientation by $<1^{\circ}$, and height by $0.05 \mathrm{~m}$ yet parasitised different hosts. Comparatively, all three epiphytic ferns and Peraxilla colensoi, which shared the same Lophozonia menziesii hosts, differed in cardinal orientation by at least $13^{\circ}$ and height by at least $0.5 \mathrm{~m}$, which suggests subtle niche partitioning by these species. Nevertheless, due to the patchiness of suitable substrate on host trees, dispersal and establishment limitations are surely more important than competition for resources (Bennett 1987). 
I believe that my study bridges a key gap in our understanding of within-tree distributions of epiphytes and mistletoes, and raises further questions on the drivers of air plant distributions. For example, what is the influence of non-vascular bryophytes on vascular epiphyte position within the canopy? At what latitudes do air plants exhibit a directional bias? How does radial position interact with other drivers of air plant within-tree distributions? By considering microclimate gradients that exist radially around the trunks of trees in other localities, further general patterns in the mechanisms behind air plant distributions may be identified. 
Chapter

6

Chapter 6-General discussion 
In the first biogeographic study of epiphyte-host interactions, I confirm that epiphytic plant assemblages are structured by stochastic mechanisms (Chapter 2). At the community level, however, I found evidence to suggest deterministic structuring in New Zealand epiphyte assemblages with respect to nestedness. As such, aside from the tendency for greater nestedness in New Zealand networks, most epiphyte species in New Zealand and southern Chile were distributed on their host trees at random. Being the first study to document epiphytic plant assemblage structure at such a large biogeographic scale, the results of this thesis are an important contributor to understanding global drivers of epiphyte distributions. For example, stochastic structuring suggests that disturbances, dispersal, and the availability of suitable host traits are important for epiphyte establishment success at the biogeographic scale. However, facilitation by other epiphytes may be important at the local scale.

Similar to Chapter 2, stochastic structuring was observed in plant assemblages inhabiting epiphytic birds' nest ferns on Lord Howe Island, Australia (Chapter 3). Here, plant assemblages were significantly affected by fern size, fern isolation from a major propagule source and resident plant species richness. Furthermore, animal-dispersed taxa, and taxa with no specialised dispersal strategies were absent in the most isolated ferns, which suggests that dispersal plays a key role in structuring these plant assemblages. Similar to epiphytic birds' nest ferns, host trees vary in size, isolation from propagule sources and epiphyte species richness. As such, the results of this study may be applied more broadly to epiphyte assemblages, and may help explain drivers of epiphyte assemblage structure.

Using the general principles of Darwin's geological theory of island ontogeny, I determined how epiphyte assemblages change throughout the lifespan of their host trees (Chapter 4). Theoretical frameworks have helped bridge the gap between our understanding of epiphyte ecology and terrestrial plants, however, this is the first study to use a theoretical framework to research epiphyte assemblage development. Here, I found interspecific (i.e. between tree species) variation in the diameter at which epiphytes first established on host trees. Additionally, I found interspecific variation in the rate at which epiphyte species richness increased with host tree diameter. The results of Chapter 4 illustrate the importance of theoretical frameworks from other study systems as guides for studying epiphyte distributions. 
Lastly, I bridge a key gap in our understanding of within-tree distributions of epiphytes and mistletoes by quantifying their radial distributions on tree trunks with respect to microclimate (Chapter 5). Additionally, I confirm that the photochemical and photosynthetic efficiency of epiphytes and mistletoes is highest in plants growing in conditions with high water and light availability, respectively. However, the photosynthetic parameters of mistletoe leaves suggest that they are also efficient at assimilating $\mathrm{CO}_{2}$ in lower light conditions, and are highly adapted to growing in a canopy environment. Previous studies that relate microclimate to epiphyte distributions have nearly always focused on the vertical column of forest canopies. However, the results of Chapter 5 illustrate the importance of other microclimatic drivers of epiphyte distributions that exist around the trunks of trees. Together, these results have increased our understanding of epiphyte assemblage structure and distributions within south-temperate forests, which can be built upon to further elucidate drivers of epiphyte assembly and distribution patterns.

\section{The role of chance in structuring epiphyte assemblages}

Understanding the influence of stochastic and deterministic processes in structuring ecological communities is a central goal of ecology. Under random community assembly, stochastic events and dispersal, along with a species' ability to withstand local environmental conditions are postulated to randomise species compositions (Connor and Simberloff 1979, Hubbell et al. 1999). However, under niche-based assembly, community composition between sites of similar environmental conditions is assumed to be predictable (Tuomisto et al. 2003; Dornelas et al 2006). The results described in this thesis make clear for the first time that epiphytic plant assemblages at the biogeographic scale are structured by stochastic mechanisms. For one, when considering all measures of network structure (i.e. nestedness, negative cooccurrences, and species specialisation), 27 out of 36 results were consistent with randomised expectations (Chapter 2). Furthermore, plant communities inhabiting epiphytic birds' nest ferns on Lord Howe Island showed no predictable patterns of community composition, and were strongly influenced by species dispersal strategies 
(Chapter 3). The occurrence of animal-dispersed taxa and taxa with no specific dispersal strategy decreased as fern isolation from a major propagule source increased. Winddispersed taxa, however, were still recorded in the most isolated ferns. This suggests that dispersal plays a key role in structuring these plant communities.

Despite this, a significant result of nestedness in New Zealand networks was found, which suggests that deterministic mechanisms structure epiphyte assemblages at the community level. Burns (2007) hypothesised that nestedness in epiphyte assemblages may be a result of the sequential colonisation of epiphyte species on developing host trees. Epiphytes with a nest-like growth form facilitate this process by accumulating water and leaf litter, which eventually break down to create a nutrientrich humus (Dawson and Sneddon 1969). In support of Burn's (2007) interpretation, the structure of forest stands that contained fewer nest epiphytes did not deviate from randomised expectations. For example, only one Astelia individual was recorded on Stewart Island, New Zealand, and the nest-like Fascicularia bicolor was only sparsely recorded in southern Chile. Nest epiphytes may facilitate the establishment of not only epiphytes, but an array of fauna, and subsequently may increase biodiversity within tree canopies (Henwood et al. 2014; Angelini and Silliman 2014).

Similar to the nest epiphytes of New Zealand, the epiphytic birds' nest fern, Asplenium goudeyi, captures organic detritus within the upright extensions of their fern fronds (Zhang et al. 2010). However, rather than providing a medium for propagules to germinate in within the canopy, Asplenium goudeyi provides habitat for terrestrial plant species on the vertical cliffs of Lord Howe Island, Australia (Chapter 3). Here, the frequency of individual plant species occurrences increased with resident plant species richness, which is consistent with the hypothesis that resident plants facilitate the establishment of later colonising species (Bertness and Hacker 1994, Valente et al. 2014). As such, it is not unreasonable to consider that nest epiphytes are keystone species, which increase habitat quality for later colonising species.

Negative species co-occurrences were not observed in epiphyte-host networks (Chapter 2) or plant assemblages inhabiting Asplenium goudeyi ferns (Chapter 3), which suggests that negative species interactions (e.g. competition) are not important determinants of epiphyte assemblage structure. In Chapter 3, variation in community composition may occur due to low rates of species persistence relative to high rates of 
colonisation (Zalewski and Ulrich 2006). For example, species persistence on cliff escarpments is generally low due to frequent disturbances and resource limitations (Cooper 1997). While disturbances are also frequent in tree canopies (Sillett and Bailey 2003), epiphyte colonisation is inherently slow, and depends on the availability of suitable microhabitats (Dickinson et al. 1993) and tree architecture (Hirata et al. 2008). As such, the variation in epiphyte species co-occurrences observed in Chapter 2 and Chapter 3 may be a result of slow rates of colonisation relative to disturbance regimes.

At the forest stand level, a number of factors may explain variation in epiphyte species occupancy among host trees. For one, local disturbances created by falling trees or branches may alter microclimate and recruitment (Hubbell et al. 1999). Additionally, interspecific differences in epiphyte dispersal and establishment abilities may randomise species co-occurrences. For terrestrial plant species (i.e. non arboreal), predictability of plant composition patterns from environmental conditions is positively correlated with a plants' ability to disperse over long distances (Ozinga et al. 2005). However, given that the majority of epiphytes are wind-dispersed (Gentry and Dodson 1987), and are capable of long-distance dispersal, perhaps factors other than dispersal limitations are randomising epiphyte occupancy among host trees. Young trees in the understory, for example, may lack suitable growing sites, bark characteristics and branching architecture for epiphyte establishment, however, older individuals of the same species may offer all of these (Zotz and Vollrath 2003). As such, variation in epiphyte species occupancy among host trees at the stand level may occur as a result of the patchy distribution of suitable growing sites.

\section{Epiphyte distributions in relation to microclimate and tree ontogeny}

Animals select habitat in relation to the availability of limiting resources. For example, avian taxa select habitat with sufficient food availability, breeding potential, and nesting sites (Hilden 1965). Similarly, prey species may select habitat in an attempt to reduce predation pressures (Abramsky et al. 1996, Heithaus and Dill 2002, Creel et al. 2005). 
Plants, however, are comparatively immobile, which restricts individuals to local microclimates. As a response to their immobility, selection pressures have enabled plants to optimally exploit resources within their distributional range (Bazzaz 1991, Gersani et al. 1998). Arboreal plants, which are specialised to spend their entire life cycle within trees, are distributed in relation to vertical gradients of light and water within forest canopies (Medina 1974, Griffiths 1989, Maxwell et al. 1995, Zotz and Hietz 2001, Graham and Andrade 2004, Sonnleitner et al. 2009). Studies observing the partitioning of tree canopies by vascular epiphytes in response to these vertical gradients span over 120 years (Schimper 1888, Johansson 1974, ter Steege and Cornelissen 1989, Hietz and Briones 1998, Zotz and Hietz 2001, Krömer et al. 2007, Mota de Oliveira et al. 2009, Sporn et al. 2010), and the importance of vertical microclimates as drivers of epiphyte distributions is well established. Despite this, few studies have considered other axes of resource availability, such as those that exist radially around the trunks of trees.

This dissertation illustrates the importance of microclimates that exist radially around the trunks of trees as potential drivers of epiphyte distributions (Chapter 5). Epiphytes oriented southeast, which overlapped with gradients of higher humidity, lower light intensity and temperature. Mistletoes, however, were oriented towards the sun, which suggests that mistletoes are adapted to growing in higher light environments relative to epiphytes. This is unsurprising considering that mistletoes are reliant on host tree water potential rather than microclimate humidity to meet their water requirements (Ehleringer et al. 1986). Nevertheless, mistletoe leaves growing in low light environments were still able to photosynthesise efficiently, which suggests a high plasticity of mistletoes to growing in a canopy environment. Epiphytes, however, did not show the same levels of plasticity and decreased in photochemical efficiency when experimentally induced to reductions in water availability, which agrees with previous observations that epiphyte occurrences are limited by water (Zotz et al. 2005).

Arboreal biota including epiphytes, avifauna, arthropods, reptiles, and mammals frequently increase in diversity as trees age and expand (Kelly et al. 1994, Rosso et al. 2000). One reason for this is that suitable substrate habitat becomes increasingly available as trees progress through ontogeny, thus increasing colonisation and establishment success (Sillett and Van Pelt 2007). Consistent with previous studies, I 
found a positive relationship between tree diameter and epiphyte species richness, however, below a certain size threshold, epiphyte species richness deviated from a predictable species-area relationship (Chapter 4). In addition to a deviation from a predictable species-area relationship below a threshold size, I found interspecific differences in the rate of epiphyte assemblage development. These results can be interpreted based on the general features of island ontogeny. For example, like small islands, small trees may be more vulnerable to stochastic events such as disturbances, which may prevent epiphyte assemblages reaching equilibrium (see MacArthur and Wilson 1967, p. 30). Similarly, like small islands, small trees may not have suitable habitats to facilitate epiphyte establishment (see Triantis et al. 2003). Furthermore, just as new habitats are formed progressively on larger islands (Whitehead and Jones 1969), habitat heterogeneity in the form of bark characteristics and branching architecture increase with tree size (Benzing 1990, Balfour and Bond 1993, Campbell and Newbery 1993, Lyons et al. 2000, Malizia 2003, Male and Roberts 2005), thus increasing species diversity (Wiens 1962).

Understanding epiphyte assemblage development is not only important for the plant community, but for the canopy dwelling arthropods and vertebrates that utilise epiphytes as habitat (Frank 1983; Davidson and Epstein 1989). Additionally, epiphytes contribute significantly to nutrient cycling (Nadkarni 1985) and total biomass of forested ecosystems (Nadkarni 1992), which may change throughout epiphyte assemblage development.

\section{Conclusions and Future directions}

Recent research on the structure of epiphyte assemblages has produced inconsistent and even conflicting results. In Chapter 2, I found a tendency for greater nestedness in New Zealand epiphyte assemblages, which I attributed to the presence of nest epiphytes. However, had I not used a conservative metric (NODF), and a conservative null model that constrains marginal sums, the degree of nestedness would likely be higher. Additionally, epiphyte assemblages in southern Chile would likely exhibit a 
significant result of nestedness. The discrepancy in metrics and null models used to determine the structure of epiphyte assemblages may be the reason behind conflicting results in the literature. For example, Burns (2007), Zhao et al. (2015), and Burns and Zotz (2010) calculated matrix "temperature" as a measure of nestedness. However, this method is both sensitive to matrix size and prone to type-I statistical errors, which may give false estimates of nestedness (Almeida-Neto and Ulrich 2011). Despite correcting for these errors using modified procedures, the matrix temperature metric is not as conservative as the NODF metric used in Chapter 2. The use of conservative metrics and null models should be implemented as a more coherent measure of epiphyte-host network structure in future studies.

The lack of predictable species composition patterns observed in Chapters 2 and 3 suggests that negative species interactions (e.g. competition) are not important in structuring epiphyte assemblages. Establishment limitations may be lessened by the presence of foundation species, specifically nest epiphytes. This occurs in the lowland tropical forests of Malaysia, where epiphytic birds' nest ferns provide habitat for up to 93\% of local canopy invertebrates (Ellwood et al. 2002). Similarly, in palm plantations, birds' nest ferns act as microcosms of biodiversity (Turner and Foster 2006). Henwood et al. (2014) also stressed the importance of nest epiphytes as habitat for faunal assemblages in New Zealand forests. However, while nest epiphytes are undoubtedly keystone species in forest canopies, no study has explicitly addressed this. By emphasising the importance of nest epiphytes in maintaining canopy biodiversity, they may receive greater consideration in ecosystem-management practises.

My findings in Chapter 4 illustrate that an island ontogeny framework may guide investigations on epiphyte assemblage development. However, although I suggest mechanisms that may drive variation in epiphyte assemblage development, further quantitative analyses are needed to confirm such mechanisms. For example, tree age correlates with a number of other traits including tree size, branch thickness, and bark water-holding capacity (Van Pelt and Nadkarni 2004, Nascimbene et al. 2009). However, whether these develop in unison, or whether epiphytes select for one specific trait over others needs further scrutiny. In addition, at what point in tree ontogeny do epiphyte assemblages become saturated? Similar to insular taxa do epiphyte species follow a 
period of decline once saturation has occurred? Only long-term investigations of epiphyte assemblages can answer these questions.

The results of Chapter 5 help bridge a key gap in our understanding of epiphyte and mistletoe distributions within a canopy environment. I showed that epiphyte and mistletoe distributions are highly directional, and are significantly influenced by microclimates that exist radially around the trunks of trees. Whether the same radial signalling occurs at the establishment phase would make an interesting comparison. Additionally, how these results fit in with other drivers of air plant distributions would complete our understanding of their within-tree distributions. 


\section{Appendices}




\section{Appendix 1}

Appendix 1A. Species, genus, authorities, and family names of vascular epiphytes and host trees recorded in New Zealand. Nomenclature follows Allan (1961), Moore and Edgar (1980), Brownsey and Smith-Dodsworth (2000), and Connor and Edgar (1987). Nomenclature for Prumnopitys follows de Laubenfels (1978), Fuscospora follows Heenan and Smissen (2013), Podocarpus laetus follows Molloy (2015), Astelia hastata follows Birch (2015), and Phlegmariurus varius follows Field and Bostock (2013).

\section{Epiphytes}

1. Asplenium flaccidum G.Forst. (Aspleniaceae)

2. Asplenium polyodon G.Forst. (Aspleniaceae)

3. Asplenium oblongifolium Colenso (Aspleniaceae)

4. Astelia hastata (Col.) Skottsb. (Asteliaceae)

5. Astelia solandri A.Cunn. (Asteliaceae)

6. Bulbophyllum pygmaeum (Sm.) Lindl. (Orchidaceae)

7. Cardiomanes reniforme (G.Forst.) C.Presl. (Hymenophyllaceae)

8. Dendrobium cunninghamii Lindl. (Orchidaceae)

9. Drymoanthus adversus (Hook.f.) Dockrill (Orchidaceae)

10. Earina autumnalis (G.Forst.) Hook.f. (Orchidaceae)

11. Earina mucronata Lindl. (Orchidaceae)

12. Griselinia lucida G.Forst. (Griseliniaceae)

13. Griselinia littoralis Raoul. (Griseliniaceae)

14. Hymenophyllum bivalve (G.Forst.) Sw. (Hymenophyllaceae)

15. Hymenophyllum demissum (G.Forst.) Sw. (Hymenophyllaceae)

16. Hymenophyllum dilatatum (G.Forst.) Sw. (Hymenophyllaceae)

17. Hymenophyllum flabellatum Labill. (Hymenophyllaceae)

18. Hymenophyllum multifidum (G.Forst.) Sw. (Hymenophyllaceae)

19. Luzuriaga parviflora (Hook.f.) Kunth (Luzuriagaceae)

20. Metrosideros robusta A.Cunn. (Myrtaceae)

21. Metrosideros umbellata Cav. (Myrtaceae) 
22. Notogrammitis billardierei (Willd.) Parris (Polypodiaceae)

23. Notogrammitis heterophylla (Labill.) Parris (Polypodiaceae)

24. Phlegmariurus varius (R.Br.) A.R. Field et Bostock (Lycopodiaceae)

25. Pittosporum cornifolium A.Cunn. (Pittosporaceae)

26. Pyrrosia eleagnifolia (Bory.) Hovenkamp. (Polypodiaceae)

27. Rumohra adiantiformis (G.Forst.) Ching. (Dryopteridaceae)

28. Tmesipteris elongata P.A. Dang. (Psilotaceae)

\section{Host trees}

1. Agathis australis (D.Don) Lindl. (Araucariaceae)

2. Alectryon excelsus Gaertn. subsp. excelsus (Sapindaceae)

3. Beilschmiedia tawa (A. Cunn.) Benth. et Hook.f. ex Kirk (Lauraceae)

4. Brachyglottis rotundifolia var. rotundifolia (J.R.Forst. et G.Forst.) B.Nord. var. rotundifolia (Asteraceae)

5. Carpodetus serratus J.R.Forst. et G.Forst. (Rousseaceae)

6. Coprosma arborea Kirk (Rubiaceae)

7. Coprosma foetidissima J.R.Forst. et G.Forst. (Rubiaceae)

8. Cordyline australis (Forst.f.) Endl. (Asparagaceae)

9. Corynocarpus laevigatus J.R.Forst. et G.Forst. (Corynocarpaceae)

10. Dacrycarpus dacrydioides (A.Rich.) de Laub. (Podocarpaceae)

11. Dacrydium cupressinum (Lamb.) (Podocarpaceae)

12. Dysoxylum spectabile (G.Forst.) Hook.f. (Meliaceae)

13. Elaeocarpus dentatus var. dentatus (J.R. Forst et G. Forst) Vahl var. dentatus (Elaeocarpaceae)

14. Fuscospora solandri (Hook.f.) Heenan et Smissen (Nothofagaceae)

15. Fuscospora truncata (Colenso) Heenan et Smissen (Nothofagaceae)

16. Griselinia littoralis Raoul. (Griseliniaceae)

17. Hedycarya arborea J.R.Forst. et G.Forst. (Monimiaceae)

18. Knightia excelsa R. Br. (Proteaceae)

19. Kunzea ericoides (A.Rich) Joy Thomps. (Myrtaceae)

20. Laurelia novae-zelandiae A.Cunn. (Atherospermataceae) 
21. Leptecophylla juniperina subsp. juniperina (J.R.Forst. et G.Forst.) C.M.Weiller subsp. juniperina (Ericaceae)

22. Litsea calicaris (A.Cunn.) Benth. et Hook.f. ex Kirk (Lauraceae)

23. Lophomyrtus bullata Burret (Myrtaceae)

24. Melicytus ramiflorus J.R.Forst. et G.Forst (Violaceae)

25. Metrosideros robusta A.Cunn. (Myrtaceae)

26. Metrosideros umbellata Cav. (Myrtaceae)

27. Myrsine australis (A.Rich.) Allan (Primulaceae)

28. Neomyrtus pedunculata (Hook.f.) Allan (Myrtaceae)

29. Nestegis cunninghamii (Hook.f.) L.A.S.Johnson (Oleaceae)

30. Olearia rani var. colorata (Colenso) Kirk (Asteraceae)

31. Pennantia corymbosa J.R.Forst. et G.Forst (Pennantiaceae)

32. Phyllocladus trichomanoides D.Don (Phyllocladaceae)

33. Pinus radiata D.Don (Pinaceae)

34. Pittosporum eugenioides A.Cunn. (Pittosporaceae)

35. Podocarpus laetus Hooibr. Ex Endl. (Podocarpaceae)

36. Podocarpus totara G.Benn. ex D.Don var. totara (Podocarpaceae)

37. Prumnopitys ferruginea (D.Don) Laubenf. (Podocarpaceae)

38. Prumnopitys taxifolia (DDon) de Laub. (Podocarpaceae)

39. Pseudopanax arboreus (L.f.) Allan (Araliaceae)

40. Pseudopanax crassifolius (Sol. Ex A.Cunn.) C.Koch (Araliaceae)

41. Rhopalostylis sapida H.Wendl. et Drude (Arecaceae)

42. Schefflera digitata J.R.Forst. et G.Forst (Araliaceae)

43. Weinmannia racemosa L.f. (Cunoniaceae)

Appendix 1B. Species, genus, authorities, and family names of vascular epiphytes and host trees recorded in Chile. Nomenclature follows Zuloaga et al. (2008). Nomenclature for Lophozonia follows Heenan and Smissen (2013).

\section{Epiphytes}

1. Asplenium dareoides Desv. (Aspleniaceae)

2. Asplenium trilobum Cav. (Aspleniaceae) 
3. Fascicularia bicolor (Ruiz \& Pav.) Mez ssp. bicolor (Bromeliaceae)

4. Grammitis magellanica Desv. (Polypodiaceae)

5. Hymenophyllum caudiculatum Mart. var. caudiculatum (Hymenophyllaceae)

6. Hymenoglossum cruentum (Cav.) C. Presl (Hymenophyllaceae)

7. Hymenophyllum dentatum Cav. (Hymenophyllaceae)

8. Hymenophyllum dicranotrichum (C.Presl) Hook. ex Sadeb. (Hymenophyllaceae)

9. Hymenophyllum krauseanum Phil. (Hymenophyllaceae)

10. Hymenophyllum pectinatum Cav. (Hymenophyllaceae)

11. Hymenophyllum peltatum (Poir.) Desv. (Hymenophyllaceae)

12. Hymenophyllum plicatum Kaulf. (Hymenophyllaceae)

13. Luzuriaga radicans Ruiz \& Pav. (Luzuriagaceae)

14. Luzuriaga polyphylla (Hook.) J.F.Macbr. (Luzuriagaceae)

15. Pleopeltis macrocarpa (Bory ex Willd.) Kaulf. (Polypodiaceae)

16. Raukaua laetevirens (Gay) Frodin (Araliaceae)

17. Synammia feuillei (Bertero) Copel. var. feuillei (Polypodiaceae)

18. Sarmienta scandens (J.D.Brandis ex Molina) Pers. (Gesneriaceae)

19. Tillandsia usneoides (L.) L. (Bromeliaceae)

\section{Host trees}

1. Aextoxicon punctatum Ruiz \& Pav. (Aextoxicaceae)

2. Caldcluvia paniculata (Cav.) D.Don (Cunoniaceae)

3. Citronella mucronata (Ruiz \& Pav.) D.Don (Cardiopteridaceae)

4. Cryptocarya alba (Molina) Looser (Lauraceae)

5. Dasyphyllum diacanthoides (Less.) Cabrera (Asteraceae)

6. Drimys winteri J.R. Forst. \& G.Forst. var. winteri (Winteraceae)

7. Embothrium coccineum J.R.Forst. \& G.Forst. (Proteaceae)

8. Eucryphia cordifolia Cav. (Eucryphiaceae)

9. Gevuina avellana Molina (Proteaceae)

10. Laurelia sempervirens (Ruiz \& Pav.) Tul. (Monimiaceae)

11. Laureliopsis phillippiana (Looser) Schodde (Monimiaceae)

12. Lithraea caustica (Molina) Hook. \& Arn. (Anacardiaceae)

13. Lophozonia alpina (Poepp. \& Endl.) Heenan \& Smissen (Nothofagaceae) 
14. Lophozonia obliqua (Mirb.) Heenan \& Smissen subsp. obliqua (Nothofagaceae)

15. Luma apiculata (DC.) Burret (Myrtaceae)

16. Myrceugenia planipes (Hook. \& Arn.) O.Berg (Myrtaceae)

17. Nothofagus dombeyi (Mirb.) Oerst. (Nothofagaceae)

18. Nothofagus nitida (Phil.) Krasser (Nothofagaceae)

19. Persea lingue Nees (Lauraceae)

20. Peumus boldus Molina (Monimiaceae)

21. Podocarpus nubigenus Lindl. (Podocarpaceae)

22. Saxegothaea conspicua Lindl. (Podocarpaceae)

23. Weinmannia trichosperma Cav. (Cunoniaceae) 


\section{References}

Agostinelli, C., and M. C. Agostinelli. 2009. Package 'CircStats'.

Allan, H. 1961. Flora of New Zealand Volume I: Indigenous Trachaeophyta, Psilopsida, Lycopsida, Filcopsida, Gymnospermae, Dicotyledones. Government Printer, Wellington.

Almeida-Neto, M., and W. Ulrich. 2011. A straightforward computational approach for measuring nestedness using quantitative matrices. Environmental Modelling and Software 26:173-178.

Almeida-Neto, M., P. Guimaraes, P. R. Guimarães, R. D. Loyola, and W. Ulrich. 2008. A consistent metric for nestedness analysis in ecological systems: reconciling concept and measurement. Oikos 117:1227-1239.

Abramsky, Z., E. Strauss, A. Subach, A. Riechman, and B. Kotler. 1996. The effect of barn owls (Tyto alba) on the activity and microhabitat selection of Gerbillus allenbyi and G. pyramidum. Oecologia 105:313-319.

Angelini, C., and B. R. Silliman. 2014. Secondary foundation species as drivers of trophic and functional diversity: evidence from a tree-epiphyte system. Ecology 95:185196.

Atmar, W., and B. D. Patterson. 1993. The measure of order and disorder in the distribution of species in fragmented habitat. Oecologia 96:373-382.

Baeza, C. M., C. Marticorena, and R. Rodriguez. 1999. Catálogo de la flora vascular del Monumento Natural Contulmo, Chile. Gayana Botánica 56: 125-135.

Badano, E. I., L. A. Cavieres, M. A. Molina-Montenegro, and C. Quiroz. 2005. Slope aspect influences plant association patterns in the Mediterranean matorral of central Chile. Journal of Arid Environments 62:93-108.

Balfour, D. A., and W. J. Bond. 1993. Factors limiting climber distribution and abundance in a southern African forest. Journal of Ecology 81:93-99.

Barton, K. 2013. MuMIn: Multi-model inference. R package version 1.9. 5.

Bascompte, J., P. Jordano, C. J. Melián, and J. M. Olesen. 2003. The nested assembly of plant-animal mutualistic networks. Proceedings of the National Academy of Sciences 100:9383-9387. 
Bazzaz, F. 1991. Habitat selection in plants. American Naturalist 137:S116-S130.

Belinchón, R., I. Martínez, M. A. Otálora, G. Aragón, J. Dimas, and A. Escudero. 2009. Fragment quality and matrix affect epiphytic performance in a Mediterranean forest landscape. American Journal of Botany 96:1974-1982.

Bellay, S., D. P. Lima, R. M. Takemoto, and J. L. Luque. 2011. A host-endoparasite network of Neotropical marine fish: are there organizational patterns? Parasitology 138:1945-1952.

Bennett, B. C. 1987. Spatial distribution of Catopsis and Guzmania (Bromeliaceae) in southern Florida. Bulletin of the Torrey Botanical Club 114:265-271.

Benzing, D. H. 1981. Bark surfaces and the origin and maintenance of diversity among angiosperm epiphytes: a hypothesis. Selbyana 5:248-255.

Benzing, D. H. 1990. Vascular epiphytes. General biology and related biota. Cambridge University Press, Cambridge.

Benzing, D. H. 1998. Vulnerabilities of tropical forests to climate change: the significance of resident epiphytes. Climate Change 39:519-540.

Bergey, E. A., C. A. Boettiger, and V. H. Resh. 1995. Effects of water velocity on the architecture and epiphytes of Cladophora glomerata (Chlorophyta). Journal of Phycology 31:264-271.

Bertness, M. D., and S. D. Hacker. 1994. Physical stress and positive associations among marsh plants. American Naturalist 144:363-372.

Birch, J. L. 2015. A revision of infrageneric classification in Astelia Banks \& Sol. Ex R. Br. (Asteliaceae). PhytoKeys 52:105.

Blick, R., and K. Burns. 2009. Network properties of arboreal plants: Are epiphytes, mistletoes and lianas structured similarly? Perspectives in Plant Ecology, Evolution and Systematics 11:41-52.

Blüthgen, N. 2010. Why network analysis is often disconnected from community ecology: a critique and an ecologist's guide. Basic and Applied Ecology 11:185195.

Blüthgen, N., J. Fründ, D. P. Vázquez, and F. Menzel. 2008. What do interaction network metrics tell us about specialization and biological traits. Ecology 89:3387-3399. 
Blüthgen, N., F. Menzel, T. Hovestadt, B. Fiala, and N. Blüthgen. 2007. Specialization, constraints, and conflicting interests in mutualistic networks. Current Biology 17:341-346.

Boccaletti, S., V. Latora, Y. Moreno, M. Chavez, and D.-U. Hwang. 2006. Complex networks: structure and dynamics. Physics reports 424:175-308.

Botto-Mahan, C., R. Medel, R. Ginocchio, and G. Montenegro. 2000. Factors affecting the circular distribution of the leafless mistletoe Tristerix aphyllus (Loranthaceae) on the cactus Echinopsis chilensis. Revista Chilena de Historia Natural 73:525-531.

Brownsey, P. J., and J. C. Smith-Dodsworth. 2000. New Zealand Fern and Allied Plants. Bateman Publishing, Auckland.

Bryan, C. 2011. Ecology of vascular epiphytes in urban forests with special reference to the shrub epiphyte Griselinia lucida. Unpublished MSc thesis, The University of Waikato, Hamilton.

Buckley, H. L. 2011. Isolation affects tree-scale epiphytic lichen community structure on New Zealand mountain beech trees. Journal of Vegetation Science 22:10621071.

Burgess, V. J., D. Kelly, A. W. Robertson, and J. J. Ladley. 2006. Positive effects of forest edges on plant reproduction: literature review and a case study of bee visitation to flowers of Peraxilla tetrapetala (Loranthaceae). New Zealand Journal of Ecology 30:179-190.

Burnham, K. P., and D. R. Anderson. 2002. Model selection and multimodel inference: a practical-theoretic approach. Springer, New York.

Burns, K. 2007. Network properties of an epiphyte metacommunity. Journal of Ecology 95:1142-1151.

Burns, K. 2008. Meta-community structure of vascular epiphytes in a temperate rainforest. Botany 86:1252-1259.

Burns, K., and G. Zotz. 2010. A hierarchical framework for investigating epiphyte assemblages: networks, meta-communities, and scale. Ecology 91:377-385.

Burns, K. C., and J. Dawson. 2005. Patterns in the diversity and distribution of epiphytes and vines in a New Zealand forest. Austral Ecology 30:891-899. 
Campbell, E. J. F., and D. M. Newbery. 1993. Ecological relationships between lianas and trees in lowland rainforest in Sabah, East Malaysia. Journal of Tropical Ecology 9:469-490.

Chesson, P. 2000. Mechanisms of maintenance of species diversity. Annual review of Ecology and Systematics 31:343-366.

Clements, F. E. 1916. Plant succession: an analysis of the development of vegetation. Carnegie Institution of Washington.

Connor, E. F., and D. Simberloff. 1979. The assembly of species communities: chance or competition? Ecology 60:1132-1140.

Connor, H. E., and E. Edgar. 1987. Name changes in the indigenous New Zealand flora, 1960-1986 and Nomina Nova IV, 1983-1986. New Zealand Journal of Botany 25:115-171.

Cooper, A. 1997. Plant species coexistence in cliff habitats. Journal of Biogeography 24:483-494.

Creel, S., J. Winnie Jr, B. Maxwell, K. Hamlin, and M. Creel. 2005. Elk alter habitat selection as an antipredator response to wolves. Ecology 86:3387-3397.

Darlington, P. J. 1957. Zoogeography and the Geographic Distribution of Animals. John Wiley and Sons, New York.

Darwin, C. 1859. The origin of species by means of natural selection. Penguin Classics, Harmondsworth.

Davidson, D., and W. Epstein. 1989. Epiphytic associations with ants. Pages 200-233 Vascular plants as epiphytes. Springer, Berlin.

Dawson, J. 1988. Forest vines to snow tussocks. Victoria University Press, Welington.

Dawson, J., and B. Sneddon. 1969. The New Zealand rain forest: a comparison with tropical rain forest. University of Hawaii Press, Hawaii.

Dawson, J. W., and R. Lucas. 2005. The Nature of Plants: Habitats, Challenges and Adaptations. Timber Press, Portland.

de Laubenfels, D. 1978. The genus Prumnopitys (Podocarpaceae). Blumea 24:189-190.

Denslow, J. S., J. C. Schultz, P. M. Vitousek, and B. R. Strain. 1990. Growth responses of tropical shrubs to treefall gap environments. Ecology 71:165-179.

Dettki, H., P. Klintberg, and P.A. Esseen. 2000. Are epiphytic lichens in young forests limited by local dispersal? Ecoscience 7:317-325. 
Diamond, J. M. 1975. The island dilemma: lessons of modern biogeographic studies for the design of natural reserves. Biological Conservation 7:129-146.

Díaz, I. A., K. E. Sieving, M. E. Pena-Foxon, J. Larraín, and J. J. Armesto. 2010. Epiphyte diversity and biomass loads of canopy emergent trees in Chilean temperate rain forests: A neglected functional component. Forest ecology and management 259:1490-1501.

Dickinson, K. J. M., A. F. Mark, and B. Dawkins. 1993. Ecology of Lianoid Epiphytic Communities in Coastal Podocarp Rain-Forest, Haast Ecological District, NewZealand. Journal of Biogeography 20:687-705.

Dixon, P., and M. Palmer. 2003. VEGAN, a package of R functions for community ecology. Journal of Vegetation Science 14:927-930.

Dobbertin, M., N. Hilker, M. Rebetez, N. E. Zimmermann, T. Wohlgemuth, and A. Rigling. 2005. The upward shift in altitude of pine mistletoe (Viscum album ssp. austriacum) in Switzerland-the result of climate warming? International Journal of Biometeorology 50:40-47.

Dormann, C. F., J. Fründ, N. Blüthgen, and B. Gruber. 2009. Indices, graphs and null models: analyzing bipartite ecological networks. The Open Ecology Journal 2:724.

Dornelas, M., S. R. Connolly, and T. P. Hughes. 2006. Coral reef diversity refutes the neutral theory of biodiversity. Nature 440:80-82.

Drake, J. A. 1990. Communities as assembled structures: do rules govern pattern? Trends in Ecology and Evolution 5:159-164.

Dunne, J. A., R. J. Williams, and N. D. Martinez. 2002. Network structure and biodiversity loss in food webs: robustness increases with connectance. Ecology Letters 5:558-567.

Ehleringer, J., E. Schulze, H. Ziegler, O. Lange, G. Farquhar, and I. Cowan. 1985. Xylemtapping mistletoes: water or nutrient parasites. Science 227:1479-1481.

Ehleringer, J. R., C. S. Cook, and L. L. Tieszen. 1986. Comparative water use and nitrogen relationships in a mistletoe and its host. Oecologia 68:279-284.

Ehrlen, J., and O. Eriksson. 2000. Dispersal limitation and patch occupancy in forest herbs. Ecology 81:1667-1674. 
Ellwood, M. D., D. T. Jones, and W. A. Foster. 2002. Canopy Ferns in Lowland Dipterocarp Forest Support a Prolific Abundance of Ants, Termites, and Other Invertebrates. Biotropica 34:575-583.

Enloe, H. A., R. C. Graham, and S. C. Sillett. 2006. Arboreal histosols in old-growth redwood forest canopies, Northern California. Soil Sciences Society of America Journal 70:408-418.

Fekedulegn, D., R. R. Hicks, and J. Colbert. 2003. Influence of topographic aspect, precipitation and drought on radial growth of four major tree species in an Appalachian watershed. Forest ecology and management 177:409-425.

Fernández-Juricic, E. 2000. Bird community composition patterns in urban parks of Madrid: the role of age, size and isolation. Ecological Research 15:373-383.

Field, A. R.,and P.D. Bostock. 2013. New and existing combinations in Palaeotropical Phlegmariurus (Lycopodiaceae) and lectotypification of the type species Phlegmariurus phlegmaria (L.) T.Sen \& U.Sen. PhytoKeys 20:33-51.

Flores-Palacios, A., and J. García-Franco. 2001. Sampling methods for vascular epiphytes: their effectiveness in recording species richness and frequency. Selbyana 22:181-191.

Flores-Palacios, A., and J. G. Garcia-Franco. 2006. The relationship between tree size and epiphyte species richness: testing four different hypotheses. Journal of Biogeography 33:323-330.

Frank, J. H. 1983. Bromeliad phytotelmata and their biota, especially mosquitos. In: Frank, J. H., and L. P. Lounibos., eds. Phytotelmata: terrestrial plants as hosts for aquatic insect communities. Plexus Publishing, New Jersey.

Frazer, G. W., C. Canham, and K. Lertzman. 1999. Gap Light Analyzer (GLA), Version 2.0: Imaging software to extract canopy structure and gap light transmission indices from true-colour fisheye photographs, users manual and program documentation. Simon Fraser University, Burnaby, British Columbia, and the Institute of Ecosystem Studies, Millbrook, New York.

Freiberg, M. 1996. Spatial distribution of vascular epiphytes on three emergent canopy trees in French Guiana. Biotropica 28:345-355.

Gause, G. F. 2003. The struggle for existence. Dover Publications Inc, New York. 
Gaxiola, A., L. E. Burrows, and D. A. Coomes. 2008. Tree fern trunks facilitate seedling regeneration in a productive lowland temperate rain forest. Oecologia 155:325335.

Gehlhausen, S. M., M. W. Schwartz, and C. K. Augspurger. 2000. Vegetation and microclimatic edge effects in two mixed-mesophytic forest fragments. Plant Ecology 147:21-35.

Gentry, A. H., and C. Dodson. 1987. Diversity and biogeography of neotropical vascular epiphytes. Annals of the Missouri Botanical Garden 74:205-233.

Gersani, M., Z. Abramsky, and O. Falik. 1998. Density-dependent habitat selection in plants. Evolutionary Ecology 12:223-234.

Gilpin, M. E. 1980. The role of stepping-stone islands. Theoretical population biology 17:247-253.

Gleason, H. A. 1917. The structure and development of the plant association. Bulletin of the Torrey Botanical Club 44:463-481.

Gotelli, N. J. 2000. Null model analysis of species co-occurrence patterns. Ecology 81:2606-2621.

Gotelli, N. J., and R. K. Colwell. 2001. Quantifying biodiversity: procedures and pitfalls in the measurement and comparison of species richness. Ecology Letters 4:379391.

Grace, J. B. 1999. The factors controlling species density in herbaceous plant communities: an assessment. Perspectives in plant ecology, evolution and systematics 2:1-28.

Graham, E. A., and J. L. Andrade. 2004. Drought tolerance associated with vertical stratification of two co-occurring epiphytic bromeliads in a tropical dry forest. American Journal of Botany 91:699-706.

Griffiths, H. 1989. Carbon dioxide concentrating mechanisms and the evolution of CAM in vascular epiphytes. Pages 42-86 Vascular plants as epiphytes. Springer, New York.

Griffiths, H., and J. A. C. Smith. 1983. Photosynthetic pathways in the Bromeliaceae of Trinidad: relations between life-forms, habitat preference and the occurrence of CAM. Oecologia 60:176-184. 
Grime, J. P. 2006. Plant strategies, vegetation processes, and ecosystem properties. John Wiley and Sons, New York.

Gustafsson, L., and I. Eriksson. 1995. Factors of importance for the epiphytic vegetation of aspen Populus tremula with special emphasis on bark chemistry and soil chemistry. Journal of applied ecology 32:412-424.

Heenan, P. B., and R. D. Smissen. 2013. Revised circumscription of Nothofagus and recognition of the segregate genera Fuscospora, Lophozonia, and Trisyngyne (Nothofagaceae). Phytotaxa 146:1-31

Heithaus, M. R., and L. M. Dill. 2002. Food availability and tiger shark predation risk influence bottlenose dolphin habitat use. Ecology 83:480-491.

Henwood, O. R., C. L. Kirby, and B. T. Cutting. 2014. An exploratory faunal survey of New Zealand temperate rainforest epiphytes. New Zealand Natural Sciences 39:1024.

Hepburn, I. 1943. A study of the vegetation of sea-cliffs in North Cornwall. Journal of Ecology 31:30-39.

Hietz-Seifert, U., P. Hietz, and S. Guevara. 1996. Epiphyte vegetation and diversity on remnant trees after forest clearance in southern Veracruz, Mexico. Biological Conservation 75:103-111.

Hietz, P. 2005. Conservation of vascular epiphyte diversity in Mexican coffee plantations. Conservation Biology 19:391-399.

Hietz, P., and O. Briones. 1998. Correlation between water relations and within-canopy distribution of epiphytic ferns in a Mexican cloud forest. Oecologia 114:305-316.

Hilden, O. 1965. Habitat selection in birds. Anales Zoological Fennici 2:53-75.

Hinsley, S., P. Bellamy, I. Newton, and T. Sparks. 1995. Habitat and landscape factors influencing the presence of individual breeding bird species in woodland fragments. Journal of Avian Biology 26:94-104.

Hirata, A., T. Kamijo, and S. Saito. 2008. Host trait preferences and distribution of vascular epiphytes in a warm-temperate forest. Plant Ecology 201:247-254.

Hölldobler, B., and E. O. Wilson. 1990. The ants. Harvard University Press, Cambridge.

Holyoak, M., M. A. Leibold, N. Mouquet, R. D. Holt, and M. Hoopes. 2005. A framework for large scale community ecology. Metacommunities: spatial dynamics and ecological communities. The University of Chicago Press, Chicago. 
Hubbell, S. P. 2001. The unified neutral theory of biodiversity and biogeography Princeton University Press, New Jersey.

Hubbell, S. P., R. B. Foster, S. T. O'Brien, K. Harms, R. Condit, B. Wechsler, S. J. Wright, and S. L. De Lao. 1999. Light-gap disturbances, recruitment limitation, and tree diversity in a neotropical forest. Science 283:554-557.

Hull, R. J., and O. A. Leonard. 1964. Physiological aspects of parasitism in mistletoes (Arceuthobium and Phoradendron). II. The photosynthetic capacity of mistletoe. Plant Physiology 39:1008-1017.

Hurtt, G. C., and S. W. Pacala. 1995. The consequences of recruitment limitation: reconciling chance, history and competitive differences between plants. Journal of Theoretical Biology 176:1-12.

Hutchinson, G. E. 1959. Homage to Santa Rosalia or why are there so many kinds of animals? American Naturalist 93:145-159.

Hylander, K. 2005. Aspect modifies the magnitude of edge effects on bryophyte growth in boreal forests. Journal of applied ecology 42:518-525.

Ibisch, P. L. 1996. Neotropische Epiphytendiversitat: das Beispiel Bolivien. Archiv naturwissenschaftlicher Dissertationen.

Jacquemyn, H., J. Butaye, and M. Hermy. 2001. Forest plant species richness in small, fragmented mixed deciduous forest patches: the role of area, time and dispersal limitation. Journal of Biogeography 28:801-812.

Jaramillo, M.A., R. Callejas, C. Davidson, J. F. Smith, A. C. Stevens, and E. J. Tepe. 2008. A phylogeny of the tropical genus Piper using ITS and the chloroplast intron psbjpetA. Systematic Botany 33:647-660.

Jarvis, S. 1974. Soil factors affecting the distribution of plant communities on the cliffs of Craig Breidden, Montgomeryshire. Journal of Ecology 62:721-733.

Johansson, D. 1974. Ecology of vascular epiphytes in West African rain forest. Acta phytogeographica Suecica Dissertation.

Johansson, V., T. Ranius, and T. Snäll. 2012. Epiphyte metapopulation dynamics are explained by species traits, connectivity, and patch dynamics. Ecology 93:235241.

Jorgensen, P. 1999. León-Yánez. Catalogue of the vascular plants of Ecuador. Monogr. Syst. Bot. Missouri Bot. Gard 75:1-1181. 
Jueriado, I., L. Karu, and J. Liira. 2012. Habitat conditions and host tree properties affect the occurrence, abundance and fertility of the endangered lichen Lobaria pulmonaria in wooded meadows of Estonia. The Lichenologist 44:263-275.

Jüriado, I., J. Liira, J. Paal, and A. Suija. 2009. Tree and stand level variables influencing diversity of lichens on temperate broad-leaved trees in boreo-nemoral floodplain forests. Biodiversity and Conservation 18:105-125.

Kadmon, R., and H. R. Pulliam. 1995. Effects of isolation, logging and dispersal on woody-species richness of islands. Vegetatio 116:63-68.

Karasawa, S., and N. Hijii. 2006. Determinants of litter accumulation and the abundance of litter-associated microarthropods in bird's nest ferns (Asplenium nidus complex) in the forest of Yambaru on Okinawa Island, southern Japan. Journal of Forest Research 11:313-318.

Kavanagh, P. H., and K. C. Burns. 2014. The repeated evolution of large seeds on islands. Proceedings of the Royal Society of London B: Biological Sciences 281:20140675. Keddy, P. A. 1992. Assembly and response rules: two goals for predictive community ecology. Journal of Vegetation Science 3:157-164.

Kelly, D., E. Tanner, E. N. Lughadha, and V. Kapos. 1994. Floristics and biogeography of a rain forest in the Venezuelan Andes. Journal of Biogeography 21:421-440.

Kelly, D. L., G. O'Donovan, J. Feeham, S. Murphy, S. O. Drangeid, and L. Marcano-Berti. 2004. The epiphyte communities of a montane rain forest in the Andes of Venezuela: patterns in the distribution of the flora. Journal of Tropical Ecology 20:643-666.

Kernan, C., and N. Fowler. 1995. Differential substrate use by epiphytes in CorcovadoNational Park, Costa-Rica - a source of guild structure. Journal of Ecology 83:6573.

Kreft, H., N. Köster, W. Küper, J. Nieder, and W. Barthlott. 2004. Diversity and biogeography of vascular epiphytes in Western Amazonia, Yasuní, Ecuador. Journal of Biogeography 31:1463-1476.

Krömer, T., M. Kessler, and S. R. Gradstein. 2007. Vertical stratification of vascular epiphytes in submontane and montane forest of the Bolivian Andes: the importance of the understory. Plant Ecology 189:261-278. 
Krömer, T., M. Kessler, S. R. Gradstein, and A. Acebey. 2005. Diversity patterns of vascular epiphytes along an elevational gradient in the Andes. Journal of Biogeography 32:1799-1809.

Kutiel, P. 1992. Slope aspect effect on soil and vegetation in a Mediterranean ecosystem. Israel Journal of Botany 41:243-250.

Laube, S., and G. Zotz. 2007. A metapopulation approach to the analysis of long - term changes in the epiphyte vegetation on the host tree Annona glabra. Journal of Vegetation Science 18:613-624.

Löbel, S., T. Snäll, and H. Rydin. 2006. Species richness patterns and metapopulation processes-evidence from epiphyte communities in boreo-nemoral forests. Ecography 29:169-182.

Loope, L. L., and T. W. Giambelluca. 1998. Vulnerability of island tropical montane cloud forests to climate change, with special reference to East Maui, Hawaii. Climatic Change 39:503-517.

López-Villalobos, A., A. Flores-Palacios, and R. Ortiz-Pulido. 2008. The relationship between bark peeling rate and the distribution and mortality of two epiphyte species. Plant Ecology 198:265-274.

Luebert, F, and P. Pliscoff. 2006. Sinopsis bioclimática y vegetacional de Chile. Editorial Universitaria, Santiago de Chile.

Lund, U., C. Agostinelli, and M. C. Agostinelli. 2013. Package 'circular'. Repository CRAN.

Lyons, B., N. M. Nadkarni, and M. P. North. 2000. Spatial distribution and succession of epiphytes on Tsuga heterophylla (western hemlock) in an old-growth Douglasfir forest. Canadian Journal of Botany 78:957-968.

MacArthur, R. H. 1972. Geographical ecology: patterns in the distribution of species. Princeton University Press, New Jersey.

MacArthur, R. H., and E. O. Wilson. 1967. The theory of island biogeography. Princeton University Press, New Jersey.

Male, T. D., and G. E. Roberts. 2005. Host associations of the strangler fig Ficus watkinsiana in a subtropical Queensland rain forest. Austral Ecology 30:229-236.

Malizia, A. 2003. Host tree preference of vascular epiphytes and climbers in a subtropical montane cloud forest of Northwest Argentina. Selbyana 24:196-205. 
Martinez, N. D., B. A. Hawkins, H. A. Dawah, and B. P. Feifarek. 1999. Effects of sampling effort on characterization of food-web structure. Ecology 80:1044-1055.

Maxwell, C., H. Griffiths, A. Borland, A. Young, M. Broadmeadow, and M. Fordham. 1995. Short-term photosynthetic responses of the $C_{3}$-CAM epiphyte Guzmania monostachia var. monostachia to tropical seasonal transitions under field conditions. Functional Plant Biology 22:771-781.

McAuliffe, J. R. 1984. Sahuaro-nurse tree associations in the Sonoran Desert: competitive effects of sahuaros. Oecologia 64:319-321.

McMullin, R. T., P. N. Duinker, D. H. Richardson, R. P. Cameron, D. C. Hamilton, and S. G. Newmaster. 2010. Relationships between the structural complexity and lichen community in coniferous forests of southwestern Nova Scotia. Forest ecology and management 260:744-749.

Medina, E. 1974. Dark $\mathrm{CO}_{2}$ fixation, habitat preference and evolution within the Bromeliaceae. Evolution 28:677-686.

Mehltreter, K., A. Flores-Palacios, and J. G. Garcia-Franco. 2005. Host preferences of low-trunk vascular epiphytes in a cloud forest of Veracruz, Mexico. Journal of Tropical Ecology 21:651-660.

Molloy, B. P. J. 1985. The continuing saga of native conifer nomenclature. DSIR Botany Division Newsletter 102:26-27.

Montgomery, B. R., D. Kelly, A. W. Robertson, and J. J. Ladley. 2003. Pollinator behaviour, not increased resources, boosts seed set on forest edges in a New Zealand Loranthaceous mistletoe. New Zealand Journal of Botany 41:277-286.

Moore, L. B., and E. Edgar. 1976. Flora of New Zealand Volume II: Indigenous Tracheophyta, Monocotyledones except Graminae. Government Printer, Wellington.

Moreira-Muñoz, A. 2011. Plant geography of Chile. Springer, Netherlands.

Mota de Oliveira, S., H. Ter Steege, J. H. Cornelissen, and S. Robbert Gradstein. 2009. Niche assembly of epiphytic bryophyte communities in the Guianas: a regional approach. Journal of Biogeography 36:2076-2084.

Mouillot, D. 2007. Niche-assembly vs. dispersal-assembly rules in coastal fish metacommunities: implications for management of biodiversity in brackish lagoons. Journal of applied ecology 44:760-767. 
Muggeo, V. M. R. 2003. Estimating regression models with unknown break-points. Statistics in Medicine 22:3055-3071.

Muñoz-Schick, M. 1980. Flora del parque nacional Puyehue. Editorial Universitaria, Santiago de Chile.

Nadkarni, N. M. 1985. Epiphyte biomass and nutrient capital of a neotropical elfin forest. Biotropica 16:249-256.

Nadkarni, N. M. 1992. The conservation of epiphytes and their habitats: summary of a discussion at the international symposium on the biology and conservation of epiphytes. Selbanyana 13:140-142.

Nascimbene, J., L. Marini, R. Motta, and P. L. Nimis. 2009. Influence of tree age, tree size and crown structure on lichen communities in mature Alpine spruce forests. Biodiversity and Conservation 18:1509-1522.

Nathan, R. 2006. Long-distance dispersal of plants. Science 313:786-788.

Nielsen, A., and J. Bascompte. 2007. Ecological networks, nestedness and sampling effort. Journal of Ecology 95:1134-1141.

Niklas, K. J. 1993. Plant allometry. University of Chicago Press, Chicago.

Norton, D., and P. De Lange. 1999. Host specificity in parasitic mistletoes (Loranthaceae) in New Zealand. Functional Ecology 13:552-559.

Olesen, J. M., L. I. Eskildsen, and S. Venkatasamy. 2002. Invasion of pollination networks on oceanic islands: importance of invader complexes and endemic super generalists. Diversity and Distributions 8:181-192.

Ozinga, W. A., R. M. Bekker, J. H. Schaminée, and J. M. Van Groenendael. 2004. Dispersal potential in plant communities depends on environmental conditions. Journal of Ecology 92:767-777.

Ozinga, W. A., J.H. Schaminée, R. M. Bekker, S. Bonn, P. Poschlod, O. Tackenberg, J. P. Bakker, and J. M. Groenendael. 2005. Predictability of plant species composition from environmental conditions is constrained be dispersal limitation. Oikos 108:555-561.

Parra, M. J., K. Acuna, L. J. Corcuera, and A. Saldaña. 2009. Vertical distribution of Hymenophyllaceae species among host tree microhabitats in a temperate rain forest in Southern Chile. Journal of Vegetation Science 20:588-595. 
Paulay, G. 1994. Biodiversity on oceanic islands: its origin and extinction. American Zoologist 34:134-144.

Piazzon, M., A. R. Larrinaga, and L. Santamaría. 2011. Are nested networks more robust to disturbance? A test using epiphyte-tree, comensalistic networks. PLoS One 6:e19637.

Pickard, J. 1984. Exotic plants on Lord Howe Island: Distribution in space and time, 18531981. Journal of Biogeography 11:181-208.

Proctor, M. C., and Z. Tuba. 2002. Poikilohydry and homoihydry: antithesis or spectrum of possibilities? New Phytologist 156:327-349.

Proctor, M. C. F. 2012. Light and desiccation responses of some Hymenophyllaceae (filmy ferns) from Trinidad, Venezuela and New Zealand: poikilohydry in a lightlimited but low evaporation ecological niche. Annals of Botany 109:1019-1026.

Pupulin, F., E. Bianchi, M. Germani, D. Pedruzzi, and A. Wagner. 1995. Orchid diversity and distribution on a tree at Reserva Forestal de San Ramón, Costa Rica. Brenesia 43:47-54.

Reich, P., I. Wright, J. Cavender-Bares, J. Craine, J. Oleksyn, M. Westoby, and M. Walters. 2003. The evolution of plant functional variation: traits, spectra, and strategies. International Journal of Plant Sciences 164:S143-S164.

Reyes-García, C., H. Griffiths, E. Rincón, P. Huante. 2008. Niche differentiation in tank and atmospheric epiphytic bromeliads of a seasonally dry forest. Biotropica 40:168-175.

Ricklefs, R. E., and I. J. Lovette. 1999. The roles of island area per se and habitat diversity in the species-area relationships of four Lesser Antillean faunal groups. Journal of Animal Ecology 68:1142-1160.

Rosso, A. L., B. McCune, and T. R. Rambo. 2000. Ecology and conservation of a rare, oldgrowth-associated canopy lichen in a silvicultural landscape. The Bryologist 103:117-127.

Ruchty, A., A. L. Rosso, and B. McCune. 2001. Changes in epiphyte communities as the shrub, Acer circinatum, develops and ages. The Bryologist 104:274-281.

Saldaña, A, and C. H. Lusk. 2003. Influencia de las especies del dosel en la disponibilidad de recursos y regeneración avanzada en un bosque templado lluvioso del sur de Chile. Revista chilena de historia natural 76: 639-650. 
Sáyago, R., M. Lopezaraiza-Mikel, M. Quesada, M. Y. Álvarez-Añorve, A. CascanteMarín, and J. M. Bastida. 2013. Evaluating factors that predict the structure of a commensalistic epiphyte-phorophyte network. Proceedings of the Royal Society of London B: Biological Sciences 280:20122821.

Schimper, A. F. W. 1888. Die epiphytische vegetation Amerikas. G. Fischer.

Sfenthourakis, S., and K. A. Triantis. 2009. Habitat diversity, ecological requirements of species and the Small Island Effect. Diversity and Distributions 15:131-140.

Shaw, D., and S. Weiss. 2000. Canopy light and the distribution of hemlock dwarf mistletoe (Arceuthobium tsugense (Rosendahl) GN Jones subsp. tsugense) aerial shoots in an old-growth Douglas-fir/western hemlock forest. Northwest Science 74:306-315.

Sillett, S. C., and M. G. Bailey. 2003. Effects of tree crown structure on biomass of the epiphytic fern Polypodium scouleri (Polypodiaceae) in redwood forests. American Journal of Botany 90:255-261.

Sillett, S. C., and M. N. Goslin. 1999. Distribution of epiphytic macrolichens in relation to remnant trees in a multiple-age Douglas-fir forest. Canadian Journal of Forest Research 29:1204-1215.

Sillett, S. C., and R. Van Pelt. 2007. Trunk reiteration promotes epiphytes and water storage in an old-growth redwood forest. Ecological Monographs 77:335-359.

Silvertown, J. 2004. Plant coexistence and the niche. Trends in Ecology and Evolution 19:605-611.

Silvertown, J., K. McConway, D. Gowing, M. Dodd, M. F. Fay, J. A. Joseph, and K. Dolphin. 2006. Absence of phylogenetic signal in the niche structure of meadow plant communities. Proceedings of the Royal Society B: Biological Sciences 273:39-44.

Simberloff, D. 1978. Using island biogeographic distributions to determine if colonization is stochastic. American Naturalist 112:713-726.

Snäll, T., P. Ribeiro Jr, and H. Rydin. 2003. Spatial occurrence and colonisations in patchtracking metapopulations: local conditions versus dispersal. Oikos 103:566-578.

Sonnleitner, M., S. Dullinger, W. Wanek, and H. Zechmeister. 2009. Microclimatic patterns correlate with the distribution of epiphyllous bryophytes in a tropical lowland rain forest in Costa Rica. Journal of Tropical Ecology 25:321-330. 
Sporn, S. G., M. M. Bos, M. Kessler, and S. R. Gradstein. 2010. Vertical distribution of epiphytic bryophytes in an Indonesian rainforest. Biodiversity and Conservation 19:745-760.

Stephenson, A. 1981. Flower and fruit abortion: proximate causes and ultimate functions. Annual review of Ecology and Systematics 12:253-279.

Stone, L., and A. Roberts. 1990. The checkerboard score and species distributions. Oecologia 85:74-79.

Strong Jr, D. R. 1977. Epiphyte loads, tree falls, and perennial forest disruption: a mechanism for maintaining higher tree species richness in the tropics without animals. Journal of Biogeography 4:215-218.

Stubben, C., and B. Milligan. 2007. Estimating and analyzing demographic models using the popbio package in R. Journal of Statistical Software 22:1-23.

Taylor, A., and K. Burns. 2015. Epiphyte community development throughout tree ontogeny: an island ontogeny framework. Journal of Vegetation Science 26: 902910.

Taylor, A., and K. Burns. 2015. Plant composition patterns inside an endemic birds' nest fern (Asplenium goudeyi) on Lord Howe Island: effects of fern size, fern isolation and plant dispersal abilities. Journal of Tropical Ecology, 31: 413-421.

Taylor, A., Saldaña, A., Zotz, G., Kirby, C. and Díaz, I. (2016). Composition patterns and network structure of epiphyte-host interactions in Chilean and New Zealand temperate forests. New Zealand Journal of Botany, doi: $10.1080 / 0028825 \times .2016 .1147471$.

Taylor, A., and K. Burns. 2016. Radial distributions of air plants: a comparison between epiphytes and mistletoes. Ecology (in press).

ter Steege, H., and J. H. C. Cornelissen. 1989. Distribution and ecology of vascular epiphytes in lowland rainforest of Guyana. Biotropica 21:331-339.

Tewari, M., N. Upreti, P. Pandey, and S. P. Singh. 1985. Epiphytic Succession on Tree Trunks in a Mixed Oak-Cedar Forest, Kumaun Himalaya. Vegetatio 63:105-112.

Thomas, S. C. 1996. Asymptotic height as a predictor of growth and allometric characteristics in Malaysian rain forest trees. American Journal of Botany 83:556-566. 
Tilman, D. 1994. Competition and biodiversity in spatially structured habitats. Ecology 75:2-16.

Tremblay, R. L., and J. V. Castro. 2009. Circular distribution of an epiphytic herb on trees in a subtropical rain forest. Tropical Ecology 50:211-217.

Triantis, K., M. Mylonas, K. Lika, and K. Vardinoyannis. 2003. A model for the speciesarea-habitat relationship. Journal of Biogeography 30:19-27.

Tuomisto, H., K. Ruokolainen, and M. Yli-Halla. 2003. Dispersal, environment, and floristic variation of western Amazonian forests. Science 299:241-244.

Turner, E., and W. A. Foster. 2006. Assessing the influence of bird's nest ferns (Asplenium spp.) on the local microclimate across a range of habitat disturbances in Sabah, Malaysia. Selbyana 27:195-200.

Ulrich, W., and N. J. Gotelli. 2007. Null model analysis of species nestedness patterns. Ecology 88:1824-1831.

Valente, L. M., R. S. Etienne, and A. B. Phillimore. 2014. The effects of island ontogeny on species diversity and phylogeny. Proceedings of the Royal Society B: Biological Sciences 281:20133227.

Van Dorp, D., and P. Opdam. 1987. Effects of patch size, isolation and regional abundance on forest bird communities. Landscape Ecology 1:59-73.

Van Pelt, R., and N. M. Nadkarni. 2004. Development of canopy structure in Pseudotsuga menziesii forests in the southern Washington Cascades. Forest Science 50:326-341.

Vázquez, D. P., N. Blüthgen, L. Cagnolo, and N. P. Chacoff. 2009. Uniting pattern and process in plant-animal mutualistic networks: a review. Annals of Botany 103:1445-1457.

Vázquez, D. P., and D. Simberloff. 2003. Changes in interaction biodiversity induced by an introduced ungulate. Ecology Letters 6:1077-1083.

Wagner, K., W. Bogusch, and G. Zotz. 2013. The role of the regeneration niche for the vertical stratification of vascular epiphytes. Journal of Tropical Ecology 29:277290.

Wagner, K., G. Mendieta-Leiva, and G. Zotz. 2015. Host specificity in vascular epiphytes: a review of methodology, empirical evidence and potential mechanisms. AoB plants 7:plu092. 
Wardle, D. A., G. W. Yeates, G. M. Barker, P. J. Bellingham, K. I. Bonner, and W. M. Williamson. 2003. Island biology and ecosystem functioning in epiphytic soil communities. Science 301:1717-1720.

Werner, F. A., and S. R. Gradstein. 2008. Seedling establishment of vascular epiphytes on isolated and enclosed forest trees in an Andean landscape, Ecuador. Biodiversity and Conservation 17:3195-3207.

Werth, S., H. H. Wagner, F. Gugerli, R. Holderegger, D. Csencsics, J. M. Kalwij, and C. Scheidegger. 2006. Quantifying dispersal and establishment limitation in a population of an epiphytic lichen. Ecology 87:2037-2046.

Whitehead, D. R., and C. E. Jones. 1969. Small islands and the equilibrium theory of insular biogeography. Evolution 23:171-179.

Whittaker, R. J., K. A. Triantis, and R. J. Ladle. 2008. A general dynamic theory of oceanic island biogeography. Journal of Biogeography 35:977-994.

Wiens, H. J. 1962. Atoll environment and ecology. Yale University Press, New Haven and London.

Williams, C. B. 1964. Patterns in the balance of nature and related problems of quantitative ecology. Academic Press, New York.

Winkler, M., K. Hülber, and P. Hietz. 2007. Population dynamics of epiphytic bromeliads: life strategies and the role of host branches. Basic and Applied Ecology 8:183196.

Wolf, J. H. 1994. Factors controlling the distribution of vascular and non-vascular epiphytes in the northern Andes. Vegetatio 112:15-28.

Wyse, S. V., and B. R. Burns. 2011. Do host bark traits influence trunk epiphyte communities? New Zealand Journal of Ecology 35:296-301.

Yeaton, R. I., and D. E. Gladstone. 1982. The pattern of colonization of epiphytes on Calabash Trees (Crescentia alata HBK.) in Guanacaste Province, Costa Rica. Biotropica 14:137-140.

Yuan, J. G., W. Fang, L. Fan, Y. Chen, D. Q. Wang, and Z. Y. Yang. 2006. Soil formation and vegetation establishment on the cliff face of abandoned quarries in the early stages of natural colonization. Restoration Ecology 14:349-356. 
Zalewski, M., and W. Ulrich. 2006. Dispersal as a key element of community structure: the case of ground beetles on lake islands. Diversity and Distributions 12:767775.

Zartman, C. E. 2003. Habitat fragmentation impacts on epiphyllous bryophyte communities in central Amazonia. Ecology 84:948-954.

Zhang, L., S. Nurvianto, and R. Harrison. 2010. Factors affecting the distribution and abundance of Asplenium nidus L. in a tropical lowland rain forest in Peninsular Malaysia. Biotropica 42:464-469.

Zhao, M., N. Geekiyanage, J. Xu, M. M. Khin, D. R. Nurdiana, E. Paudel, and R. D. Harrison. 2015. Structure of the Epiphyte Community in a Tropical Montane Forest in SW China. PLos One 10:e0122210.

Zobel, M. 1997. The relative of species pools in determining plant species richness: an alternative explanation of species coexistence? Trends in Ecology and Evolution 12:266-269.

Zotz, G. 2005. Vascular epiphytes in the temperate zones-a review. Plant Ecology 176:173-183.

Zotz, G., P. Bermejo, and H. Dietz. 1999. The epiphyte vegetation of Annona glabra on barro colorado island, Panama. Journal of Biogeography 26:761-776.

Zotz, G., and P. Hietz. 2001. The physiological ecology of vascular epiphytes: current knowledge, open questions. Journal of experimental botany 52:2067-2078.

Zotz, G., P. Hietz, and G. Schmidt. 2001a. Small plants, large plants: the importance of plant size for the physiological ecology of vascular epiphytes. Journal of experimental botany 52:2051-2056.

Zotz, G., V. Thomas, and W. Hartung. 2001b. Ecophysiological consequences of differences in plant size: abscisic acid relationships in the epiphytic orchid Dimerandra emarginata. Oecologia 129:179-185.

Zotz, G., and B. Vollrath. 2003. The epiphyte vegetation of the palm Socratea exorrhiza: Correlations with tree size, tree age and bryophyte cover. Journal of Tropical Ecology 19:81-90.

Zuloaga, F., O. Morrone, and M. Belgrano (eds) 2008. Catálogo de las plantas vasculares del cono sur (Argentina, southern Brazil, Chile, Paraguay y Uruguay). 
Monographs in Systematic Botany from the Missouri Botanical Garden 107, 3 volumes. 